University of Louisville ThinkIR: The University of Louisville's Institutional Repository

Electronic Theses and Dissertations

$8-2013$

\title{
The involvement of beta-catenin in the inflammatory response leading to autoimmune diabetes development.
}

Arin Lee Zirnheld

University of Louisville

Follow this and additional works at: https://ir.library.louisville.edu/etd

Part of the Medical Immunology Commons, and the Medical Microbiology Commons

\section{Recommended Citation}

Zirnheld, Arin Lee, "The involvement of beta-catenin in the inflammatory response leading to autoimmune diabetes development." (2013). Electronic Theses and Dissertations. Paper 2266.

https://doi.org/10.18297/etd/2266

This Doctoral Dissertation is brought to you for free and open access by ThinkIR: The University of Louisville's Institutional Repository. It has been accepted for inclusion in Electronic Theses and Dissertations by an authorized administrator of ThinkIR: The University of Louisville's Institutional Repository. This title appears here courtesy of the author, who has retained all other copyrights. For more information, please contact thinkir@louisville.edu. 
THE INVOLVEMENT OF $\beta$-CATENIN IN THE INFLAMMATORY RESPONSE LEADING TO AUTOIMMUNE DIABETES DEVELOPMENT

By Arin Lee Zirnheld

A Dissertation submitted to the faculty of the School of Medicine of the University of Louisville in Partial Fulfillment of the Requirements for the Degree of

Doctor of Philosophy

Department of Microbiology and Immunology

University of Louisville

Louisville, KY

August, 2013 

THE INVOLVEMENT OF $\beta$-CATENIN IN THE INFLAMMATORY RESPONSE

LEADING TO AUTOIMMUNE DIABETES DEVELOPMENT

\author{
By Arin Lee Zirnheld \\ MS University of Louisville, 2011 \\ MAT University of Louisville, 2008 \\ BS University of Louisville, 2006
}

A Dissertation Approved on

July 25, 2013

By the following committee:

Pascale Alard

Michele Kosiewicz

Dennis Warner

Thomas Mitchell

Jala Venkatakrishna 


\section{ACKNOWLEDGEMENTS}

I would like to thank my mentor, Dr. Pascale Alard, for all of her help and support throughout this project. I would also like to thank my other committee members, Dr. Michele Kosiewicz, Dr. Dennis Warner, Dr. Jala Venkatakrishna, and Dr. Thomas Mitchell for all of their guidance. Finally, I would like to thank my parents for their constant love and encouragement. 


\section{ABSTRACT \\ THE INVOLVEMENT OF $\beta$-CATENIN IN THE INFLAMMATORY RESPONSE LEADING TO AUTOIMMUNE DIABETES DEVELOPMENT}

\section{Arin Zirnheld}

\section{July 25, 2013}

We identified and characterized a novel defect in $\beta$-catenin expression in bone marrow derived dendritic cells (BMDC) from NOD mice, a model for human Type I diabetes. This protein is expressed at high levels throughout the lifespan of the mouse and correlates with increased pro-inflammatory cytokine production by the BMDC and IFN $\gamma$ induction by $\mathrm{T}$ cells cocultured with the BMDC. These defects, including a similar pattern of pro-inflammatory cytokine production, are also observed in human monocytederived DC from diabetic patients. After exploring several potential mechanisms involved in the accumulation of $\beta$-catenin in NOD BMDC, we found that $\beta$-catenin is phosphorylated at higher levels in NOD BMDC at two residues associated with increased stabilization of this protein. Upon inhibition of the two kinases responsible for these phosphorylations, Akt and PKA, $\beta$-catenin expression is reduced. Therefore, $\beta$-catenin accumulates in NOD BMDC through an Akt and PKA-mediated mechanism. We also explored mechanisms by which $\beta$-catenin influences pro-inflammatory cytokine production and found that inhibition of $\beta$-catenin leads to decreased activation of the transcription factor $\mathrm{NF \kappa B}$, suggesting that pro-inflammatory cytokine production is increased in NOD BMDC through an NFkB-dependent mechanism. Finally, we 
performed several in vivo experiments aimed at inhibiting $\beta$-catenin activity or reducing $\beta$-catenin expression to reduce disease incidence and/or increase survival. Treatment of NOD mice with quercetin, a $\beta$-catenin inhibitor, led to reduced disease incidence and a decreased inflammatory environment. Transfer of $\beta$-catenin siRNA-treated BMDC into NOD mice also reduced disease incidence. These studies reveal that $\beta$-catenin plays a role in the inflammation leading to diabetes development. 


\section{TABLE OF CONTENTS}

PAGE

ACKNOWLEDGEMENTS.................................................ii

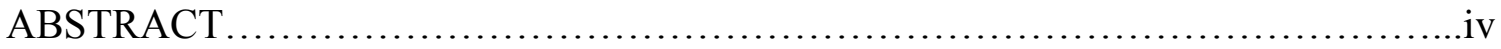

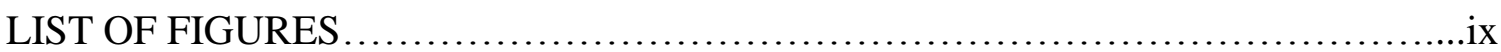

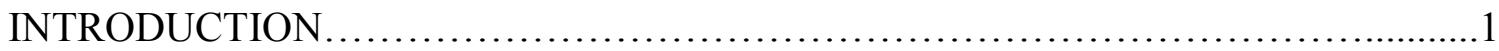

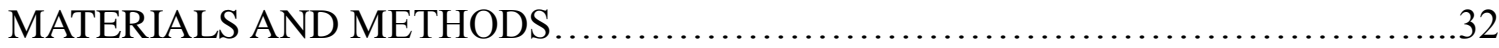

RESULTS.............................................................. 40

GOAL 1: CHARACTERIZING $\beta$-CATENIN EXRESSION AND ITS ROLE IN PRO-

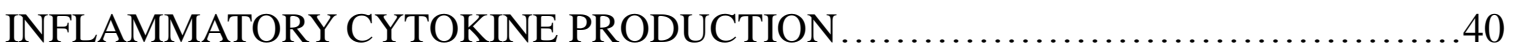

1. In which cellular compartments is $\beta$-catenin overexpressed in NOD BMDC at different

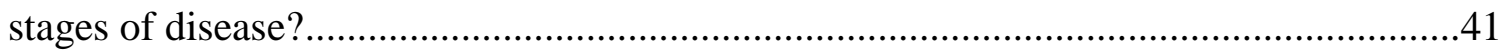

2. Is $\beta$-catenin overexpressed in primary dendritic cells from NOD mice?...................42

3. Is $\beta$-catenin overexpressed differentially in NOD and B6 congenic strains expressing protective or disease-inducing loci from B10 or NOD mice, respectively?.....

4. Is there a correlation between $\beta$-catenin levels in DC and pro-inflammatory cytokine

production in mice?

5. Is there a correlation between $\beta$-catenin levels in DC and pro-inflammatory cytokine

production in humans?

GOAL 2: PREVENTING AND/OR TREATING TYPE I DIABETES BY REDUCING THE INFLAMMATORY ENVIRONMENT IN VIVO .............................55

1. Can direct delivery of $\beta$-catenin inhibitors reduce inflammation and inhibit diabetes 
development and mortality in vivo?....

2. Can $\beta$-catenin siRNA treated-BMDC transfer reduce disease and incidence and mortality in vivo?

GOAL 3: EXPLORING THE MECHANISMS BY WHICH $\beta$-CATENIN ACCUMULATES AND INFLUENCES PRO-INFLAMMATORY CYTOKINE

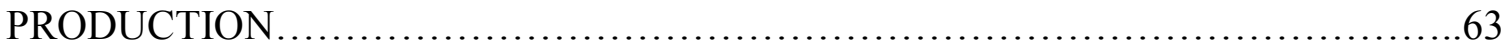

1. Why does $\beta$-catenin accumulate at excess levels in NOD BMDC?.........................63

1.1 Does an elevated level of $\beta$-catenin transcription play a role in b-catenin accumulation of $\beta$-catenin in NOD BMDC?

1.2 Does defective sequestration of $\beta$-catenin by E-cadherin play a role in accumulation of $\beta$-catenin in NOD BMDC?

1.3 Does defective proteasomal degradation or ubiquitination play a role in accumulation of $\beta$-catenin in NOD BMDC?

1.4 Does defective phosphorylation and stabilization of $\beta$-catenin play a role in accumulation of $\beta$-catenin in NOD BMDC?

2. Why does $\beta$-catenin accumulate in the nucleus of NOD BMDC but not B6.g7

BMDC? .70

2.1 Does defective sumoylation play a role in nuclear accumulation of $\beta$-catenin in NOD BMDC? .70

2.2 Does defective expression of Pyk2 or defective phosphorylation of $\beta$-catenin by Pyk2 play a role in nuclear accumulation of $\beta$-catenin in NOD BMDC? .71

3. What are the mechanisms by which $\beta$-catenin induces pro-inflammatory cytokine production?. 
3.1 Does $\beta$-catenin activate the MAPK pathway to induce pro-inflammatory cytokine production?.

3.2 Does $\beta$-catenin interact with the NFאB pathway to induce pro-inflammatory cytokine

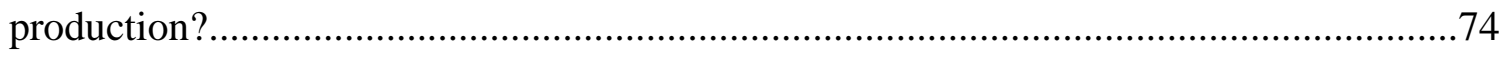

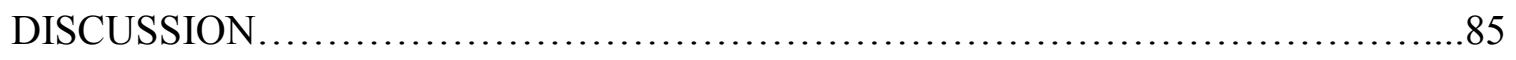

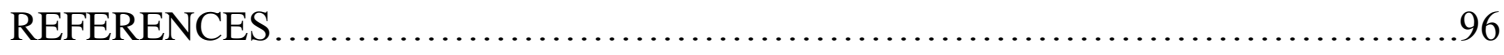

CURRICULUM VITAE ..................................................... 112 


\section{LIST OF FIGURES}

FIGURE

PAGE

1. NOD BMDC express higher levels of $\beta$-catenin than B6.g7 BMDC in the cytoplasm and nucleus and whole cell

2. Primary DC from NOD organs do not overexpress $\beta$-catenin....................50

3. Idd3/5 mice, but not Idd4 mice overexpress $\beta$-catenin........................51

4. Inhibiting the activity of or knocking down expression of $\beta$-catenin in NOD BMDC leads to reduced IL-12 production and IFN $\gamma$ induction of T cells....................52

5. Increasing the activity or expression of $\beta$-catenin in B6.g7 BMDC leads to increased

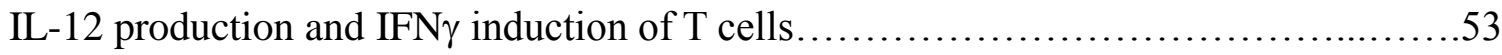

6. Human monocyte-derived DC express higher levels of $\beta$-catenin than moDC from non-diabetic donors, and inhibiting the activity of $\beta$-catenin in human monocyte-derived DC leads to reduced pro-inflammatory cytokine production.......................54 7. Oral gavage in vivo delivery of quercetin does not delay disease incidence or increase survival in NOD mice.

8. Intraperitoneal injection of quercetin may delay disease incidence and increase survival by reducing the pathogenic inflammatory environment that contributes to Type I

diabetes.

9. Lifetime intraperitoneal treatment with quercetin does not increase survival or reduce disease incidence as compared to 18 -week treatment. 
10. Adoptive transfer of $\beta$-catenin siRNA-treated DC reduces disease incidence and slightly increases survival................................................62

11. Lack of difference in $\beta$-catenin mRNA levels, in the interaction between $\beta$-catenin and E-cadherin, and in the degradation rate and ubiquitintion of $\beta$-catenin between B6.g7 and NOD BMDC .76

12. $\beta$-catenin accumulates in NOD BMDC through stabilizing phosphorylations through an Akt and PKA-dependent mechanism .79

13. There is no difference in PKA or Akt expression in NOD and B6.g7 BMDC. .81

14. There are no differences in MAPK pathway activation in B6.g7 and NOD BMDC...83 15. The $\beta$-catenin inhibitors quercetin and ICG-001 reduce NFאB activation in NOD BMDC

16. $\beta$-catenin as a master modulator of pro-inflammatory versus anti-inflammatory responses....................................................................... 87

17. A scenario leading to $\beta$-catenin accumulation and pro-inflammatory cytokine production in NOD BMDC. 


\section{INTRODUCTION}

\section{General Description of Type I diabetes}

There are two main types of diabetes: Type I and Type II. Although the symptoms are similar in these two diseases, they have very different etiologies. While Type II diabetes results from a lack of insulin production or a reduction in sensitivity to insulin, Type I diabetes results from an autoimmune process in which the insulin-producing beta cells of the pancreas are destroyed by a T-cell driven inflammatory process. The World Health Organization estimates that about 10 percent of the 350 million people in the world with diabetes have Type I diabetes; most have Type II, which is associated with obesity and lack of exercise.

Type I diabetes is an autoimmune disease as demonstrated by insulitis, which is the presence of infiltrating cells in the Islets of Langerhans, antibodies against islet cells, and T cells that recognize beta cell antigens. Moreover, the disease frequently occurs with other autoimmune diseases, including celiac disease, Addison's disease, and autoimmune thyroid disease [1].

The symptoms of Type I diabetes include thirst, frequent urination, and increased hunger in childhood or young adulthood [2]. There are several complications caused by the disease including kidney damage, eye damage and blindness, heart disease and stroke [2].

Cardiovascular disease is of particular concern for Type I diabetes (TID) patients, 
as they are highly susceptible to coronary heart disease. IL-12, the hallmark pathogenic cytokine in Type I diabetes development, may play a central role in these high cardiovascular disease rates. It has been reported that cells in atherosclerotic arteries produce higher levels of IL-12 than in healthy arteries. Furthermore, IL-12-induced IFN $\gamma$ production is also known to exacerbate atherosclerosis, while blockade of IL-12

decreases atherosclerosis in mice [3]. Additionally, Type I diabetes patients have a variety of elevated inflammatory biomarkers including CRP, nitrotyrosine, monocyte superoxide, a variety of inflammatory cytokines, VCAM, and pERK [4].

\section{Disease Induction and Progression}

It is unknown what initial signal triggers diabetes development, but suggested triggers include pathogens, commensals and aberrant beta cell death [5]. Regardless of the nature of the initiating trigger, development of disease is preceded by cellular infiltration of the pancreatic islets by $\mathrm{T}$ cells and macrophages. This infiltration can then progress to destruction of the beta cells. Although the mechanisms for this destruction have not been entirely delineated, possibilities include CD8+ T cell cytotoxicity, macrophage-produced ROS, cytokine-induced apoptosis, and FAS-FAS ligand signaling. B cells, NK cells, and NKT cells may also play a role in disease development and progression [6].

Despite the variety of cells involved in infiltration, it is known that $\mathrm{CD} 4^{+}$and $\mathrm{CD} 8^{+} \mathrm{T}$ cells and B cells are necessary for disease. B cell-deficient NOD mice do not develop disease or insulitis [7]. Disease is also delayed or reversed in NOD mice that underwent antibody-mediated B cell deletion [8]. However, serum from diabetic mice 
does not transfer disease suggesting that B cells may influence disease development through their role as antigen-presenting cells rather than as autoantibody-producing cells [5].

$\mathrm{CD}^{+} \mathrm{T}$ cells also play a pivotal role in disease development. The presence of autoreactive $\mathrm{CD} 8^{+}$cells correlates with beta cell destruction, recurrent autoimmunity after islet transplant, and graft failure in humans [9]. $\mathrm{CD}^{+}$cells can kill beta cells upon interaction with the Class I molecules expressed on the beta cells [2]. Interestingly, NOD mice that have been modified to not produce Class I on beta cells do develop insulitis but not hyperglycemia nor subsequent disease [10].

$\mathrm{CD}^{+}{ }^{+} \mathrm{T}$ cells play a key role as well. Transfer of $\mathrm{CD}^{+}{ }^{+} \mathrm{T}$ cells into NOD SCID mice can initiate diabetes, although development of diabetes took twice as long following transfer of $\mathrm{CD}^{+} \mathrm{T}$ cells from pre-diabetic mice compared to $\mathrm{CD} 4^{+} \mathrm{T}$ cells from diabetic mice [11]. Another study found that $\mathrm{CD}^{+} \mathrm{T}$ cells are only able to initiate disease when $\mathrm{CD}^{+} \mathrm{T}$ cells were present [12]. $\mathrm{CD}^{+} \mathrm{T}$ cells also provide help to $\mathrm{B}$ cells and $\mathrm{CD} 8^{+}$cells and secrete cytokines that create the pathogenic proinflammatory environment that contributes to disease [2]. Overall, it appears that $\mathrm{CD}^{+}$and $\mathrm{CD}^{+} \mathrm{T}$ cells work together to initiate disease.

Our understanding of disease progression is changing. In the classic model proposed by George Eisenbarth, a person with a genetic susceptibility encounters an environmental trigger that leads to progressive beta cell destruction. Only after the majority of the beta cells (90-95\%) are destroyed do the symptoms of diabetes appear. However, a more modern model has been proposed (See Figure below) [2]. In this more complex model, a variety of genetic susceptibility genes and environmental triggers 
interact with each other. Loss of immune regulation is also included in this model.

Additionally, the disease is no longer seen as a directly linear process in every patient.

Instead, many patients will experience a relapsing-remitting disease in which beta cell

mass and function fluctuates. Indeed, as many as $60 \%$ of patients experience a

honeymoon period in which temporary remission occurs after diagnosis [2].

In the NOD mouse model of disease, disease progression mirrors what occurs in human diabetic patients. In these mice, disease progression follows a predictable sequence of events: at 3-4 weeks of age, NOD mice exhibit peri-insulitis in which mononuclear infiltrates surround the islets but are not yet invasive; by 10 weeks of age, $\mathrm{CD}^{+}$and $\mathrm{CD} 8^{+}$cells along with NK cells, B cells, DC, and macrophages have infiltrated the islets resulting in insulitis $[5,13]$.

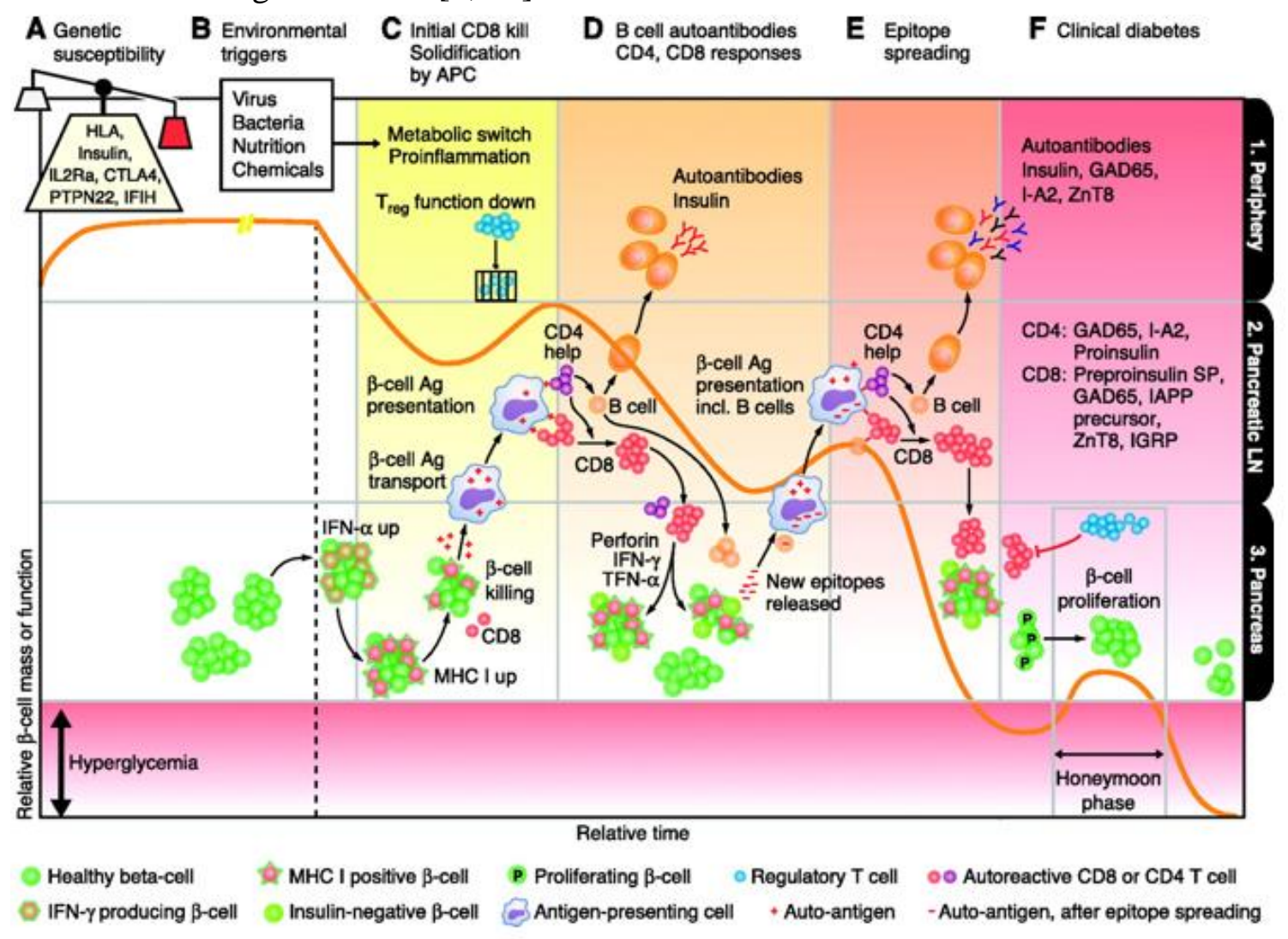

Model for initiation and progression of Type I diabetes [8] 


\section{Prevention, Prediction, and Treatment of Type I diabetes}

Type I diabetes is a devastating chronic disease that requires continuous care, and has enormous financial and social impacts, e.g., increased divorce rates in families with children with the disease. Current treatments for Type I diabetes are limited to insulin injections or pumps [2]. Despite the impact of technological progress on diagnostics and treatments, the modern life style has made it more difficult for diabetic patients to control blood glucose levels. However, T1D can be predicted with some accuracy which leads to the possibility of preventative treatments. One study found that in individuals with risk factors for T1D, including having a relative with T1D and having autoantibodies against islet cells (ICA), glucose tolerance tests can predict the onset of disease with a 0.66 accuracy [14]. Another study found that $89 \%$ of children with two or more different islet autoantibodies progressed to T1D [15]. Additionally, children with persistently high levels of insulin autoantibody (IAA) had a 100\% chance of progression to T1D. Other autoantibodies, such as those against GAD65 or IA2 (islet antigen 2)/ICA512 (islet cell autoantigen 512), did not show the same correlation with disease progression [15]. Finally, genetically high-risk children, those with the DR3/4-DQ8 HLA genotype, who were found to have multiple autoantibodies at an early age were much more likely to develop diabetes than those with non-high risk HLA genotypes, only one autoantibody, or presence of autoantibodies at a later age [16].

Promisingly, various therapies have successfully prevented or cured diabetes in NOD mice. Some of the various successful therapies in mice include anti-CD3 antibody treatment, which has resulted in remission in a variety of studies [17-19]. However, several studies also showed no effect of this treatment when therapy started at different 
time points [19-22]. Additionally, TNF- $\alpha$ administration has resulted in disease protection in various studies, although at least one study found an exacerbating effect [23]. These conflicting findings are likely due to differences in timing and length of administration [23]. It does not appear that the success of preventative treatments depends on early administration as evidenced by the success of several treatments that began at more than 4 weeks of age, including some anti-CD3 antibody studies, CTLA- 4 antibody treatment, and TNF $\alpha$ administration [23]. Additionally oral feeding of insulin and GAD65 reduced diabetes incidence in NOD mice by inhibiting islet infiltration and IFN $\gamma$ production [24].

Several therapies first demonstrated to be effective in NOD mice have been tried in human clinical trials. These include anti-CD3 in recently diagnosed diabetic patients which resulted in reduced requirements for insulin and oral insulin [25-27]. Although the treatment was administered for a short time, its protective effects lasted for at least 4 years. Younger patients, between the ages of 17 and 27 years old and those patients in the early stages of beta cell destruction responded better to the therapy than older patients and those in later stages of disease [28]. Studies treating high risk pre-diabetic individuals with oral insulin, plasmid-encoded proinsulin, or subcutaneous GAD65 have also been performed. Oral insulin treatment in individuals with anti-insulin autoantibodies reduced incidence, but this effect disappeared once treatment ended [29]. Pro-insulin plasmid treatment resulted in preservation of high C-peptide levels and reduced $\mathrm{CD} 8^{+} \mathrm{T}$ cell infiltration [30]. Subcutaneous GAD65 had no effect on diabetes incidence or levels of Cpeptide [31].

Interestingly, several studies have shown that Vitamin D (1 $\alpha, 25$-dihydroxyvitamin 
D) can modulate the immune responses in NOD mice. High doses of Vitamin D administration to NOD mice reduced the incidence of diabetes to $8 \%$ [32]. 1,25Dihydroxyvitamin D3 has been shown to inhibit IL-12 production by activated dendritic cells and macrophages by downregulating NFkB activation [33]. Vitamin D has been used in human clinical trials as well. However, in one study, a dose of 0.25 ug of Vitamin D had no effect on beta-cell function in recently diagnosed T1D patients [34]. In another study, pregnant women whose children were at risk for T1D were given Vitamin D supplements. Supplementation was not associated with decreased risk for T1D for their children later in life [35].

Additionally, there have been a variety of studies using cell-based therapies such as T regulatory cells (Tregs). Treg transfer into NOD mice can reverse diabetes after onset $[36,37]$. Similarly, in humans, administration of Tregs to recent-onset diabetic children led to increased C-peptide levels [38]. Various treatments aimed at restoring beta cell function have been tried, all with varying degrees of success. It is likely that combination therapies will be necessary to fully prevent or cure T1D [2]. Despite several promising therapies, Type I diabetes treatment continues to consist of insulin therapy. Therefore, the search for effective therapies must continue.

\section{The Non-Obese Diabetic (NOD) Mouse}

The NOD strain was established by selectively breeding a female mouse that had spontaneously developed polyuria, glycosuria, and weight loss. Female NOD mice typically have a diabetes incidence of 70-80\% and onset of disease at 10 weeks, while males have an incidence of about $20 \%$ and onset at 20 weeks, although there is variability 
among colonies [39]. Some of this variability may be due to differences in gut microbiota composition. For example, the presence of segmented filamentous bacteria (SFB) has been found to correlate with protection from diabetes in NOD females as compared to female mice lacking SFB from the same facility [40]. The symptoms of disease in NOD mice include polyuria, glycosuria, hyperglycemia, insulin deficiency, ketonuria, and rapid weight loss. Mice typically die within 1-2 months of onset of disease [39].

Disease pathogenesis in NOD mice is similar to humans; they exhibit the presence of similar pancreatic autoantigens including glutamic acid decarboxylase (GAD), insulin, and ZnT8 (a zinc transporter) [41]. Autoreactive $\mathrm{CD} 4^{+}$and $\mathrm{CD}^{+} \mathrm{T}$ cells infiltrate the pancreas in both the mouse model and human patients. NOD mice are susceptible to other autoimmune diseases, similar to some T1D patients [13]. Additionally, NOD mice have a nonaspartic acid substitution at position 57 of the beta chain of their unique MHC molecule. A similar substitution is seen in human susceptibility loci in the DQ beta chain [13].

\section{Autoimmunity, Tolerance, and Tregs in Type I diabetes}

In healthy immune system development, most $\mathrm{T}$ cells that recognize beta cell selfantigens are deleted [42]. However, self-reactive T cells against beta cells are found in T1D patients as well as healthy individuals. Therefore, other mechanisms control the self-reactivity of these T cells: ignorance, anergy, deletion, and regulation [43].

Suppressor cells, characterized as $\mathrm{CD}^{+} \mathrm{T}$ cells and later described as regulatory $\mathrm{T}$ cells, have been found to be capable of protecting NOD mice, a powerful mouse model for 
T1D, from diabetes [41]. Foxp3 Tregs are the main focus of regulatory cell research, but other cells, such as NKT cells, can regulate autoimmunity in T1D. For example, various studies found that activation of NKT cells with alpha-galactosylceramide led to a shift towards a Th-2 phenotype in treated mice and led to protection of islets transplanted into diabetic mice $[44,45]$.

Various pieces of evidence indicate defects in Tregs are important in development of disease in NOD mice. For example, B7-1 knockout mice and CD28 knockout mice have greatly reduced percentages of $\mathrm{CD} 4^{+} \mathrm{CD} 25^{+}$Tregs and develop T1D very quickly [46]. However, disease progression can be slowed in NOD/SCID mice that have been induced to have diabetes with administration of CD28 deficient splenocytes by adoptively transferring CD25 $5^{+}$Tregs [46]. Additionally, progression of diabetes has been associated with both decreased percentages of Tregs in the pancreatic lymph nodes of NOD mice versus control mice [47] as well as decreased suppressive activity of Tregs $[48,49]$. On the other hand, another study showed no difference in frequencies of Tregs [50]. However, Treg function and ability to proliferate may decline with age [49]. Additionally, decreased suppressive activity of Tregs and decreased sensitivity to regulation of pathogenic $\mathrm{T}$ cells may contribute to disease $[48,51]$.

Despite these studies that clearly indicate a protective role for Tregs in T1D in NOD mice, studies on Tregs in humans have given contradictory and difficult to interpret results [43]. For example, one study found reduced numbers of Tregs in PBMCs of diabetic patients [52], while others have found no differences [53-55]. Additionally, one study found no difference in the suppressive capacity of Tregs from diabetic patients [54], but several studies did find qualitative differences in $\mathrm{T}$ cell populations from diabetic 
patients including reduced suppressive capacity $[53,55]$ and increased pro-inflammatory cytokine production [55].

\section{Genetic Factors in T1D}

A variety of genetic and environmental factors have been proposed as contributing to the development of Type I diabetes [6]. There are a few single locus genetic conditions that can result in T1D in humans. These include IPEX and autoimmune polyendocrine syndrome Type I. In IPEX, multiorgan autoimmunity, including that of the pancreas, occurs as a result of a mutation in the gene for Foxp3 and subsequent dysfunction of regulatory T cells [56]. This disease is modeled in the scurfy mouse [57]. Autoimmune polyendocrine syndrome results in autoimmune diabetes $20 \%$ of the time as a consequence of a mutation in AIRE, a protein important for expression of self-antigens in the thymus leading to self-tolerance [58].

More often, however, T1D is the result of a complex interplay between multiple genetic loci. In humans, the MHCII molecules HLA-DQ2 and HLA-DQ8 are the greatest risk factors for disease development [6] with the MHC locus contributing $40 \%$ of the susceptibility to T1D [41]. There is increased risk for DR3/4 as well, although the risk has been reported to be small [59]. Class I haplotypes, including HLA-A genotype A1and A2 have also been associated with T1D development. These genes, when combined with high-risk Class II haplotypes, correlate with high incidence and earlier appearance of islet autoantibodies [60]. These MHC susceptibility genes were identified very early on and are found within the chromosomal region referred to as IDDM 1 (Insulin-Dependent Diabetes Mellitus) [2]. There are also several identified HLA 
haplotypes that confer disease protection in humans: DRB1*1501-DQA1*0102DQB1*0602, DRB1*1401-DQA1*0101-DQB1*0503, and DRB1*0701-DQA1*0201DQB1*0303 [61]. The MHC genes play a large role in disease susceptibility in NOD mice as well: the cells of these mice have a unique MHC II molecule called $\mathrm{H} 2^{\mathrm{g} 7}$ [13]. However, NOD mice with the MHC molecule from diabetic-resistant B6 mice and B6 mice with this MHC molecule inserted do not develop diabetes, indicating that $\mathrm{H}_{2}^{\mathrm{g} 7}$ is not sufficient for disease development.

Many other non-HLA genes have been associated with T1D development in humans indicating that the disease has a complex genetic component [62]. Other associated genes include the 5' flanking region of the insulin gene, the PTPN22 gene, the CTLA4 gene [41], the IL2RA gene, and the IFIH1 gene [2]. The insulin gene is found within the chromosomal region referred to as IDDM2 found on chromosome 11 [2]. It was reported that a polymorphic region of the insulin gene was associated with T1D in Caucasians [63]. The PTPN22 gene encodes the protein lymphoid protein tyrosine phosphatase, which dephosphorylates Lck and Zap70, Vav, CD3e, and valosin containing protein, which is an important process in the negative regulation of TCR signaling [64]. Mutations in this gene may lead to aberrant T cell signaling and subsequent autoimmunity. CTLA4, an important negative regulator of lymphocyte proliferation [65], is found within the IDDM 12 region and can play a role in T1D and other autoimmune diseases as well $[66,67]$. It has been shown that knocking out CTLA-4 in mice leads to infiltration of lymphocytes in various organs, including the pancreas [65]. There are also variations in the alpha chain of the IL-2 receptor, which is involved in Treg differentiation, associated with T1D development [8, 68, 69]. Additionally, the gene for 
IL-2 is located on chromosome 4 in an area identified as containing susceptibility genes [70]. Finally, several studies have indicated a link between T1D and the IFIH1 gene, which encodes a cytoplasmic sensor protein that recognizes picorna viruses such as coxsackie virus, which may play a role as a triggering factor in diabetes development [2]. Higher levels of IFIH1 are found in the PBMCs of individuals with the susceptible polymorphisms of this gene [71]. Additionally, several polymorphisms of this gene have been found to be protective for T1D [72].

The NOD mouse model has provided several insights into the genetic basis of T1D. In this model, several chromosome segments have been associated with disease development. These genetic loci, called $I d d$, include various genes associated with Type I diabetes. Interestingly, Idd5 in NOD mice has been shown to contain the gene for CTLA4 [73]. Although the IL-2 receptor has not been associated with disease, the IL-2 gene itself is found within the chromosomal region Idd3 in NOD mice [74]. Despite the fact that mutations in PTPN22 have been shown to be an important genetic risk factor for autoimmunity in humans, knock down of PTPN22 expression in NOD mice led to protection from disease [75].

\section{Environmental Factors in T1D}

Although T1D certainly has a genetic component, environmental factors also play an important role in disease development and incidence. This is evidenced by twin studies in which monozygotic twin concordance rates are low at around 50\% indicating a strong environmental component [76]. Additionally, Type I diabetes incidence has been increasing in recent years. For example, in Finland incidence has increased from 
20/10 /year in 1972 to 65/10 /year currently [41]. In Auckland, New Zealand, incidence increased from 7.6 per year in 1990-1991 to 8.9 a year in 2008-2009 [77]. These large increases in incidence cannot be explained by genetic factors alone, and therefore there must be some environmental trigger. Based on epidemiology data and data generated in the NOD mouse model of Type I diabetes, the proposed environmental factors include viruses $[78,79]$, bacterial pathogens, and increased hygiene standards.

Epidemiological data points to a role for viral infection. In a meta-analysis of 33 studies, it was found that enterovirus infection correlates strongly with T1D development. There was almost 10 times greater occurrence of enterovirus infection in children with T1D as compared to control children [80]. Maternal infection with coxsackie virus during pregnancy was also found to correlate with T1D development in the children [8183]. Beta cells can be directly infected by coxsackie virus, and infection by this virus correlated with loss of beta cell function [84][[85]. Interestingly, a molecule found in the cocksackie virus is very similar to GAD, one of the identified autoantigens in T1D, suggesting that molecular mimicry may play a role in T1D [86]. However, another study reported that infection of NOD mice with coxsackie virus before disease onset may actually be protective suggesting that timing is key in the protective versus causative effect of the virus [87].

One study reported an increase in HLA Class I molecule and IFN $\alpha$ expression in the islets of T1D children, suggesting a role for viruses in the disease [88]. Other viruses have been implicated in T1D as well: cytomegalovirus [89], parvovirus [90], encephalomyocarditis virus [91], and rotavirus [92]. However, in patients, it is difficult to determine if viruses are a causative disease agent or if increased susceptibility to viral 
infections is a consequence of the disease. Additionally, in humans it has been shown that various factors relating to cleanliness and decreased antigenic stimulation are associated with TID. The hygiene hypothesis postulates that increases in various hygienic factors, including the absence of an older sibling [47], lack of exposure to viral infections [93] and lack of helminth infections [94], lead to increased susceptibility to Type I diabetes as well as other autoimmune diseases. Although this contradicts the data showing a link between particular viruses and Type I diabetes, it is possible that certain infections trigger disease, while others are protective. Additionally, it has been shown that there are differences in the intestinal microbiota between autoantibody-positive children and autoantibody-negative children. Autoantibody-positive children had particularly low levels of lactate and butyrate-producing bacteria, suggesting that the composition of the entire microbiota, not one particular organism, may influence disease [95]. A second study showed that the ratios of various groups of bacteria in diabetic children were significantly different than in healthy children [96]. Other non-pathogenic factors have been associated with the development of T1D in humans. These include ingestion of cow's milk $[97,98]$ and gliadin and Glb1, both proteins found in wheat [99, 100].

Various data generated with animal models of T1D also support an environmental effect in Type I diabetes. NOD mice raised in pathogen-free environments have higher rates of diabetes development than NOD mice raised in less clean environments [41]. Additionally, various pathogens can protect NOD mice from disease, including viruses such as Coxsackie B and lymphocytic choriomeningitis virus [93, 101], and parasites such as Schistosoma mansoni or only the eggs [102], and Trichinella spiralis or 
Heligmosomoides polygyrus [103]. Finally, bacteria in the gut play an important role in the development of diabetes. NOD mice raised under specific-pathogen free conditions and lacking Myd88 have altered microbiota composition and do not develop diabetes. However, germ-free mice lacking MyD88 do develop diabetes, although this can be attenuated by transferring the microbiota of specific germ-free NOD MyD88 knockouts indicating a role for te microbiota in disease development [104].

\section{Defects in APC in T1D}

A variety of defects in antigen presenting cells (APC) have been associated with T1D development in both human patients and NOD mice. In one study, dendritic cells from type I diabetic patients exhibited decreased maturation, reduced ability to cluster, and reduced ability to stimulate autologous and allogeneic T cell responses [105]. In another study, the yield of DC cultured from monocytes was lower in relatives of T1D patients as compared to control cells. A lower proportion of DC from T1D relatives expressed CD1a, B7-1, and B7-2 when compared to control cells, and the expression of these molecules was lower in relatives' cells. Overall, cells from relatives of Type I diabetes patients had defects similar to those found in Type I diabetic patients [106]. In a study performed on twins discordant for Type I diabetes, B cells from the diabetic twin displayed increased turnover of MHC Class II at the cell surface, inadequate glycosylation of MHC II, and reduced display of antigens resulting from decreased expression of li p35, which brings MHC Class II to the cell surface [107].

Studies using NOD APC have also reported a variety of defects. NOD BMDC showed low expression of MHC Class I and Class II and low levels of B7.1 and B7.2 and 
CD40 as compared to BMDC from non-diabetic B6 mice. NOD BMDC cultures also yielded fewer mature cells than B6 cultures. There was also a higher ratio of DC: responder T cells needed to induce proliferation with NOD BMDC (1:10) than with B6 BMDC (1:100). Additionally, NOD BMDC produced lower levels of IL-12 than B6 cells upon LPS stimulation [108].

Several other studies have found defects in NOD APC. Proliferation of T cells in response to antigen (hen egg lysozyme) was lower in NOD cells than in NOR cells (diabetes-resistant) due to a defect in APC activation in NOD mice. NOR macrophages produced more intracellular GSH (a reducing agent that breaks disulfide bonds in antigen molecules) resulting in more antigen processing than in NOD mice [109]. Another study found that NOD bone marrow cells proliferated and matured at lower levels in the presence of CSF-1 as compared to cells from non-diabetic mice. MHC-I expression was also lower in NOD macrophages compared to control cells [110].

\section{Involvement of IL-12 and IFN $\gamma$ in infection}

IL-12 has a very important role in clearing infection resulting from bacteria, intracellular protozoa, and fungi by helping to generate a proinflammatory Th1 response. IL-12 induces this proinflammatory environment by stimulating T cells and NK cells to produce GM-CSF, TNF, and IFN $\gamma$. In a healthy immune system, IFN $\gamma$ activates

phagocytes, such as macrophages, to destroy pathogens. Cells that produce IL-12 include DCs, macrophages, monocytes, and neutrophils. IFN $\gamma$ can also be produced by NKT cells, $\mathrm{CD} 8^{+} \mathrm{T}$ cells, gamma delta T cells, macrophages, DC, and B cells [111].

IL-12 is a heterodimer composed of two chains: p35 and p40 [112]. IL-12 is 
produced in response to recognition of pathogens through TLRs. Stimulation of TLR7 with R848 and TLR9 with CpG DNA results in robust production of IL-12 from BMDC. Stimulation of TLR4 with LPS and TLR 3 with Poly(I:C) results in IL-12 production, but at lower levels than in response to TLR7 or TLR9 stimulation [113]. TLR11 and TLR12 have also been found to be involved in IL-12 production in response to T. gondii infection. TLR12 was found to be important in the recognition of this pathogen by plasmacytoid DC, whereas both TLR11 and 12 were necessary for recognition by DC and macrophages. Signaling through TLR12 in pDC induced IL-12 and IFN $\alpha$ production which in turn induced IFN $\gamma$ production by NK cells [114]. Additionally, it has been shown that use of IFN $\gamma$ and CD40 stimulation can increase TLR-stimulated IL-12 production [115].

Once IL-12 is produced, it binds the IL-12 receptor, found mainly on activated T cells and NK cells, but on other cell types as well. This receptor has two chains: IL12R $\beta 1$ and IL-12R $\beta 2$. Signaling through the receptor activates the Jak-STAT signaling pathway, which results in STAT4-induced production of IFN $\gamma$ [111].

\section{Inflammatory cytokines and induction of pathogenic cells in T1D}

Several lines of evidence implicate inflammatory cytokines, especially IL-12 and IFN $\gamma$ as mediators of T1D development. Genetic studies have found an association between the IL-12 gene and T1D. One study found that certain alleles for the IL-12B gene, which encodes the p40 subunit of IL-12, have been associated with T1D risk. While various IL-12B polymorphisms don't necessarily correlate with susceptibility in all people, an allele encoding higher IL-12 production does correlate with increased risk for 
disease in a subset of T1D patients [116]. Another study identified IDDM18, a genetic locus near the IL-12p40 gene as contributing to T1D resulting from a polymorphism in the 3' untranslated region of the gene. Individuals with the susceptible allele have increased IL-12 production [117].

Studies in NOD mice also provide support for an important role for IL-12 and IFN $\gamma$ in disease development. IL-12 administration to NOD mice accelerates disease and is associated with infiltration of T cells into the pancreatic islets and loss of islets. More importantly, these $\mathrm{T}$ cells produce high levels of IFN $\gamma$ upon stimulation [118]. In addition, NOD mice deficient in IL-12p40 have reduced incidence of disease as compared to control NOD mice and show almost complete lack of cellular infiltration in the pancreas. Even after LPS stimulation, NOD mice deficient in IL-12 have 5\% the IFN $\gamma$ serum levels of their IL-12 replete counterparts [112].

A variety of APC, including macrophages from NOD mice have been found to produce aberrant levels of IL-12. Upon stimulation, macrophages from prediabetic NOD mice produce high levels of IL-12 when compared to diabetes resistant strains of mice [119]. One study found this may result from defective tyrosine phosphorylation of the cRel protein, a member of the NFKB family. Rel proteins bind to sites in the IL-12p40 promoter, influencing IL-12 production [120, 121]. IL-12 mRNA was also elevated in NOD mouse macrophages [120]. In another study, a site within the p40 promoter was found to bind Rel proteins upon stimulation with several molecules derived from IL-12inducing pathogens including LPS and LTA in macrophages [122]. Bone marrow derived and splenic-derived DC from NOD mice were also found to be more sensitive to particular stimuli such as IL-12, anti-CD40 Ab, TNF $\alpha$, and LPS and secrete more IL-12 
than DC from diabetes-resistant mice. [121]. In another study, transfecting BMDC from NOD mice with siRNA against $\mathrm{NF} \kappa \mathrm{B}$ resulted in reduced $\mathrm{NF} \kappa \mathrm{B}$ binding to the DNA and the suppression of IL-12 production upon LPS stimulation. Administering cells treated with this siRNA to NOD mice at 6-7 weeks of age resulted in protection from diabetes. At 30 weeks of age, treated mice had markedly reduced islet infiltration as compared to control-treated mice [50]. Injecting NOD mice with IL-12 also accelerates disease [118]. Contradictorily, intermittent intraperitoneal dosing of IL-12 can reduce diabetes in NOD mice [123]. These results likely stem from differences in dosage and timing.

\section{$\beta$-catenin and the Wnt signaling pathway}

The first Wnt protein, a group of secreted signaling glycoproteins, was identified in Drosophila and named Wingless [124]. Wingless signaling induces nuclear translocation of an intracellular protein named Armadillo or $\beta$-catenin in vertebrates [124]. The Wnt pathway is involved in development, tissue specification, and cellular migration [125]. Mutations in this pathway are associated with cancer, especially colon and breast cancer, due to this pathway's role in cell survival and growth [125-127]. Wnt proteins bind to frizzled receptors. Various proteins bind to Wnt proteins and block their interactions with their receptors [128]. There are canonical Wnt pathways that result in activation of $\beta$-catenin signaling and non-canonical Wnt pathways that do not activate $\beta$ catenin signaling. There are a variety of Wnt proteins, receptors, and coreceptors which allow for a large diversity of responses [125].

$\beta$-catenin, an important intracellular protein involved in the Wnt signaling pathway, has 12 ARM domains, each of which is comprised of a specific 42 amino acid 
motif. These ARM repeats form a long positively charged groove that allows $\beta$-catenin to bind to other proteins and complexes including the cadherin complex at the cell membrane, the degradation complex in the cytoplasm, and transcription factors in the nucleus [8]. In resting cells, $\beta$-catenin complexes with E-cadherin at the cell membrane and plays a role in maintaining cell junctions. Excess $\beta$-catenin not bound to E-cadherin forms complexes with several other proteins in the cytoplasm to form a multiprotein destruction complex. These other proteins include axin, APC, and GSK3 $\beta$. In the absence of Wnt signaling, $\beta$-catenin is phosphorylated by casein kinase I at Ser45 and subsequently phosphorylated by GSK3 $\beta$ on the serine/threonine residues 41, 33, and 37 [129]. $\beta$ TCRp then ubiquitinates $\beta$-catenin, targeting it for proteasomal degradation [130]. In contrast, upon Wnt signaling, Dishevelled recruits GBP/Frat-1 which displaces GSK3 $\beta$ and allows $\beta$-catenin to escape degradation [131]. Upon stabilization, $\beta$-catenin accumulates in the cytoplasm and can then translocate to the nucleus where it binds to TCF/LEF transcription factors and influence transcriptional activity in the cell [132].

$\beta$-catenin and Wnt signaling have been associated with metabolic regulation and Type II diabetes development. Components of the Wnt pathway have been found to be involved in beta cell proliferation, cholesterol metabolism, insulin secretion, and production of GLP-1 (glucagon-like peptide-1). Additionally, TCF4, a transcription factor that binds to $\beta$-catenin, has been identified as a susceptibility gene for Type II diabetes [133]. Interestingly, the human LRP5 gene, which codes for one of the Frizzled coreceptors LRP5, is associated, although not strongly, with Type I diabetes. This gene is found within IDDM 4, a chromosome region associated with Type I diabetes and is involved in insulin-secretion [107]. 


\section{Modulation of $\beta$-catenin at the cell membrane}

$\beta$-catenin plays an important role in cell adhesions due to its ability to complex with E-cadherin at the cell membrane. Binding of $\beta$-catenin to E-cadherin protects Ecadherin from degradation [79]. Additionally, the interaction between these two proteins helps regulate $\beta$-catenin signaling in the cell: one study found that overexpressing cadherins resulted in sequestration of the cytosolic pool of $\beta$-catenin leading to reduced $\beta$-catenin signaling [134]. Another study found that E-cadherin competed with LEF-1, one of $\beta$-catenin's transcriptional factor binding partners, for binding to $\beta$-catenin. In Ecadherin -/- stem cells, $\beta$-catenin accumulated and interacted with LEF-1 at higher levels. However, transfecting these cells with E-cadherin resulted in the restoration of $\beta$-catenin to the cell membrane [135]. These studies suggest that E-cadherin recruits $\beta$-catenin to the cell membrane and keeps it from accumulating in the nucleus where it can induce transcription.

This important protein interaction is regulated through the action of several kinases that can phosphorylate either $\beta$-catenin or E-cadherin at various residues. These phosphorylations can result in increased or decreased strength of the interaction between the two proteins. For example, phosphorylation of E-cadherin on Ser834, 836, and 842 by CK2 and GSK3 $\beta$ enhances the affinity of E-cadherin for binding to $\beta$-catenin [8]. However, phosphorylation of E-cadherin at Ser846 by CK1 destabilizes the E-cadherin/ $\beta$ catenin complex [136]. Phosphorylation of E-cadherin at Tyr831 and 860 by src kinase also inhibits the interaction between $\beta$-catenin and E-cadherin [137].

Similarly, phosphorylation of $\beta$-catenin on Tyr654 by Src kinase can reduce this interaction $[8,138]$. In contrast, phosphorylation of $\beta$-catenin by PKD1 at residues 
Thr112 and 120 increases $\beta$-catenin's interaction with E-cadherin. One one hand, mutating these two residues resulted in increased nuclear translocation of $\beta$-catenin and alteration of $\beta$-catenin transcriptional activity. On the other hand, overexpression of PKD1 resulted in decreased $\beta$-catenin transcriptional activity and cell proliferation [113].

It has also been shown that the interactions between other catenins and cadherins can be modulated by phosphorylation. Phosphorylation of $\beta$-catenin at Tyr142 by the tyrosine kinases Fen or Fyn leads to disruption of the interaction between $\beta$-catenin and $\alpha$-catenin, another protein important in forming cell-cell contacts [139]. This phosphorylation also increases binding with BCL9-2, a protein associated with nuclear transport of $\beta$-catenin [140]. Additionally, Abl kinase can phosphorylate $\beta$-catenin on Tyr489, leading to decreased interaction with $\mathrm{N}$-cadherin (a cadherin found in neurons), and increased nuclear translocation of $\beta$-catenin [141].

\section{$\beta$-catenin modulation in the cytoplasm and nucleus}

In addition to the $\beta$-catenin found at the cell membrane, a second pool of $\beta$ catenin is found in the cytoplasm and can be modulated via degradation or stabilization. $\beta$-catenin can form a destruction complex with several other proteins including axin, APC, CK1, and GSK3 $\beta$. Within this complex, axin acts as a coordinator of phosphorylation events while APC promotes the movement of $\beta$-catenin through the axin complex [8]. CK1 phosphorylates $\beta$-catenin at Ser45 $[120,129]$ and primes the $\beta$-catenin molecule for phosphorylation by GSK3 $\beta$ on Ser33 and 37 and Thr41 [142]. Once $\beta$ catenin is phosphorylated by GSK3 $\beta$, it is recognized by beta-TrCP, an Fbox protein 
involved in ubiquitination [130]. Ubiquitinated $\beta$-catenin is degraded by the proteasome as evidenced by one study which found that treatment of cells with proteasome inhibitors, including ALLN and lactacystin, resulted in accumulation of higher-molecular weight $\beta$ catenin in the cytoplasm. These higher-molecular weight molecules indicated the presence of ubiquitinated $\beta$-catenin. Inhibition of the proteasome resulted in longer stability of $\beta$-catenin in these cells. Additionally, a site on $\beta$-catenin composed of residues $33-45$, is required for ubiquitination. This site is the GSK3 $\beta$ consensus sequence [143]. It has also been found that PKC can phosphorylate $\beta$-catenin on Ser33 and 37 leading to its degradation [144].

In contrast, phosphorylation of other residues leads to $\beta$-catenin's stabilization. Activation of the PI3K pathway has been found to increase $\beta$-catenin stability and nuclear translocation. Upon signaling by a variety of factors including growth factors and insulin, PI3K becomes activated to produce 3-phosphoinositides which bind to the $\mathrm{PH}$ domain of Akt, also known as PKB. Akt is then recruited to the cell membrane where it can be phosphorylated [145] at Thr308 by PDK1 or Ser473 by PDK2 [146-148], leading to its activation. Akt can then phosphorylate other proteins, including GSK3 $\alpha$ on Serine 21 and GSK3 $\beta$ on Serine 9 [149] or $\beta$-catenin on Serine 552 [150]. These phosphorylations result in decreased activity of GSK3 [149] as well as direct stabilization of $\beta$-catenin, respectively [150].

One study found that Akt phosphorylates $\beta$-catenin on Ser552 which causes $\beta$ catenin to dissociate from the E-cadherin complex and allows it to accumulate in the cytoplasm and nucleus [150]. Additionally, mutation of PTEN (which in its non-mutated form inhibits PI3K activity) results in activation of Akt and leads to higher levels of $\beta$ - 
catenin phosphorylated at Ser552 and increased nuclear localization and transcriptional activity in intestinal stem cells [8]. It has also been found that prostaglandin E2 activates PI3K signaling which results in Akt activation. Prostaglandin E2 treatment induced the dissociation of GSK3 $\beta$ from the destruction complex, which resulted in decreased phosporylation of $\beta$-catenin by GSK3 $\beta$ and subsequent degradation. Upon PGE-2 stimulation, $\beta$-catenin can therefore accumulate in the cytoplasm, translocate to the nucleus, and induce transcription through an Akt-dependent mechanism [151]. Another study found that LPS stimulation of human alveolar macrophages resulted in activation of PI3K. Upon PI3K activation, Akt was phosphorylated at Ser473 and GSK3 was phosphorylated at Ser21 and 9. This stimulation resulted in increased nuclear accumulation of $\beta$-catenin and transcriptional activity [152].

PKA activity has also been implicated in the regulation of $\beta$-catenin stability and signaling. PKA is activated, not upon phosphorylation, but upon cAMP binding which results in the release of the catalytic subunits of PKA from the regulatory subunits. Although PKA is not activated by phosphorylation of particular residues, it has been found that PDK1 can phosphorylate the catalytic subunit at Thr197 resulting in optimal catalytic activity $[153,154]$. PKA has also been shown to phosphorylate GSK3 $\alpha$ at Ser 21 and GSK3 $\beta$ at Ser9 which results in inactivation of these enzymes [155]. More importantly, PKA has been found to phosphorylate $\beta$-catenin at Ser552 and Ser675. These phosphorylations resulted in increased transcriptional activity by $\beta$-catenin [156]. Mutation of the Ser675 site reduced $\beta$-catenin signaling induced by PKA activation, and phosphorylation of Ser675 increased the interaction between $\beta$-catenin and CBP, a transcriptional coactivator, suggesting that PKA can activate directly $\beta$-catenin via 
phosphorylation at this residue.

Another study found similar results for the role of Ser675 phosphorylation. In a mouse model in which the gene for $\beta$-catenin was modified so that it had a reduced affinity for E-cadherin, there was increased phosphorylation at Ser675 by PKA. Increased phosphorylation at Ser675 correlated with increased nuclear translocation and transcriptional activity of $\beta$-catenin. These data suggest that phosphorylation at Ser675 leads to subsequent increased nuclear translocation and activity [157]. In addition to increasing $\beta$-catenin's transcriptional activity, it has been shown that PKA activity is also associated with increased nuclear and cytoplasmic accumulation of $\beta$-catenin. PKA phosphorylation of $\beta$-catenin at Serine 675 was found to inhibit ubiquitination and degradation of $\beta$-catenin without interfering with its ability to bind to the degradation complex [158]. Additionally, when $\mathrm{APC}^{\mathrm{Min} /+}$ mice were treated with a PKA antagonist, Rp-8-Br-cAMPs, intestinal $\beta$-catenin expression, nuclear translocation, and expression of target genes were reduced. The same antagonist blocked $\mathrm{PGE}_{2}$ induced phosphorylation of $\beta$-catenin at Ser 552 and Ser 675 by PKA in a colon cancer cell line [159]. These data suggest that PKA plays a key role in stabilization and activity of $\beta$-catenin. The modulation of $\beta$-catenin by PKA, PKB and GSK3 is summarized in the figure below. 


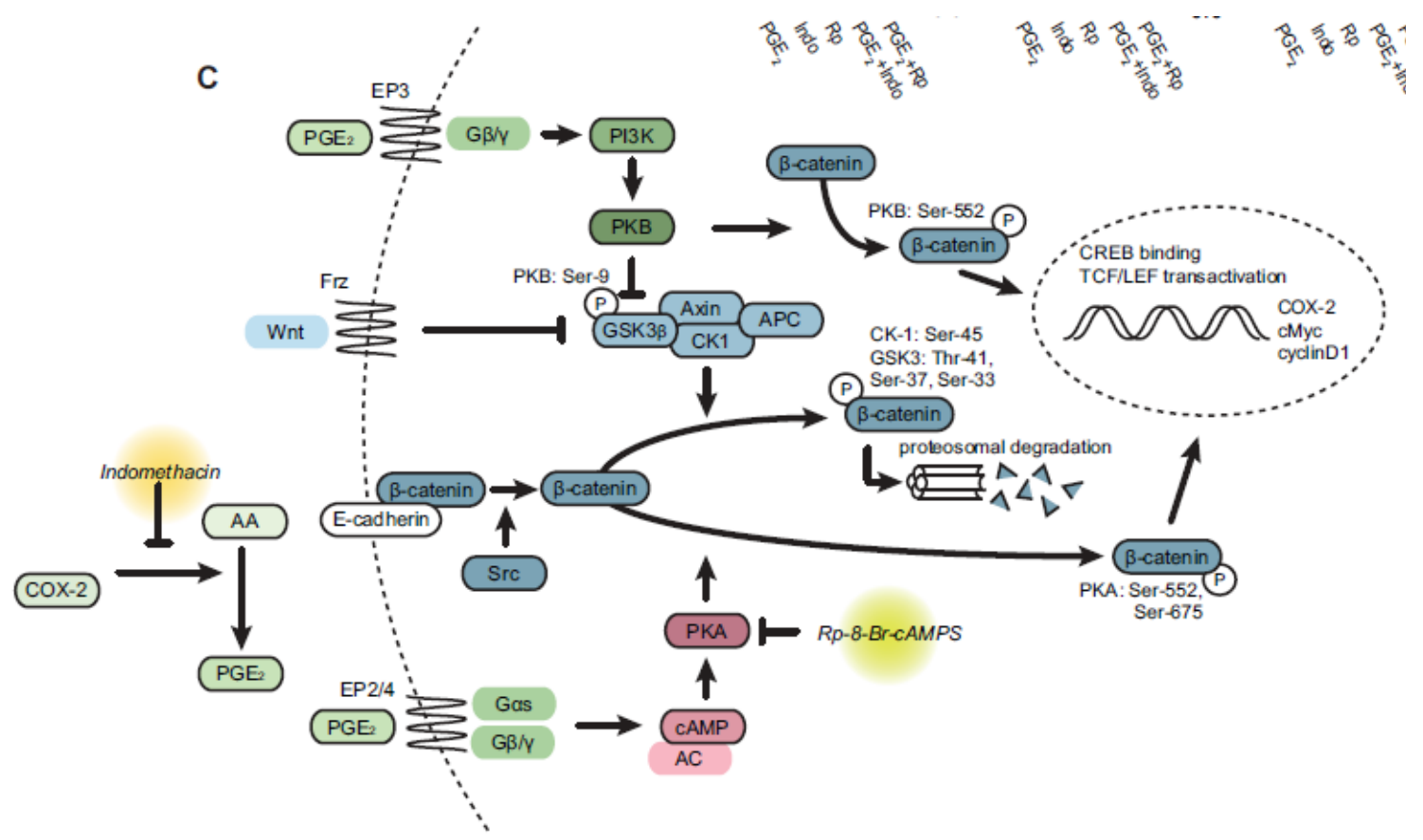

\section{Modulation of $\beta$-catenin expression [159]}

Finally, JNK has been reported to affect $\beta$-catenin stability. Wnt signaling activation of Rac1 leads to activation of JNK which phosphorylates $\beta$-catenin at residues Ser191 and Ser605. These phosphorylations stabilized $\beta$-catenin in the cytoplasm and result in increased nuclear translocation [160].

Overall, these data indicate that the stabilization or degradation of $\beta$-catenin is regulated through a complex array of mechanisms, signaling pathways, and stimuli.

\section{$\beta$-catenin nuclear translocation and transcriptional activity}

The mechanism by which $\beta$-catenin translocates to the nucleus is not well known. It has been shown that $\beta$-catenin has no nuclear location signal (NLS) that would help it travel from the cytoplasm to the nucleus. However, the protein has been found to bind to the nuclear envelope directly. Additionally, translocation of $\beta$-catenin is energy- 
dependent, suggesting that it can be imported into the nucleus independent of a signal sequence or other proteins [134].

Despite its suspected ability to translocate independently of a signal sequence, several studies have reported the involvement of other proteins in $\beta$-catenin localization from cytoplasm to nucleus or nucleus to cytoplasm. In one study, TCF4 and BCL9/Pygopus were found to recruit $\beta$-catenin to the nucleus, while APC and axin were responsible for enrichment of $\beta$-catenin in the cytoplasm. However, all of these factors function to retain $\beta$-catenin either in the cytoplasm or nucleus instead of acting as active transporters [161]. Overall, nuclear accumulation of $\beta$-catenin may be the result of excess protein simply moving from the cytoplasm to the nucleus instead of a regulated transport mechanism.

Sumoylation of $\beta$-catenin is another potential mechanism regulating nuclear translocation since $\beta$-catenin contains candidate sumoylation sites. However, no studies have been performed to examine $\beta$-catenin sumoylation. There are three mammalian SUMOs: SUMO-1, SUMO-2, SUMO-3. On the other hand, one study has found that TCF4, which binds to $\beta$-catenin and induces transcription along with $\beta$-catenin, is sumoylated. Moreover, treatment with PIAS $\gamma$, a SUMO E3 enzyme, increased $\beta$-catenin transcriptional activity. In contrast, Axam, a desumoylation enzyme, inhibited $\beta$-catenindependent TCF4 activation [107]. This study shows that sumoylation is an important post-translational modification in the $\beta$-catenin signaling pathway and can affect transcriptional activity.

Just as $\beta$-catenin can travel from cytoplasm to nucleus, it can also travel in the reverse direction. Axin not only acts as a member of the degradation complex, but also 
acts as a nuclear export shuttle for $\beta$-catenin from the nucleus to the cytoplasm as evidence by fluorescence microscopy experiments in which Axin and $\beta$-catenin translocated and colocalized to the cytoplasm [162]. Ranbp3, a protein found to interact with $\beta$-catenin, was also identified as a potential nuclear exporter of $\beta$-catenin.

Overexpression of Ranbp3 led to increased accumulation of active $\beta$-catenin in the cytoplasm versus nucleus and reduced $\beta$-catenin transcriptional activity. Furthermore, depletion of RanBP3 resulted in nuclear accumulation of $\beta$-catenin [163].

Once $\beta$-catenin has reached the nucleus, it binds with other transcription factors and coactivators to influence gene transcription. $\beta$-catenin binds to members of the TCF and LEF families of transcription factors. Additionally, $\beta$-catenin binds to the transcriptional coactivators $\mathrm{CBP}$ (creb-binding protein) $[164,165]$ and $\mathrm{p} 300$, two related acetyltransferases [165]. Phosphorylation of TCF and LEF factors enhances their binding affinity to $\beta$-catenin, and therefore affects $\beta$-catenin transcriptional activity [8]. $\beta$-catenin signaling influences the transcription of a huge variety of genes. For example, Ecadherin is transcribed at lower levels upon $\beta$-catenin signaling [166, 167]. Many other genes are upregulated in response to $\beta$-catenin transcriptional activity: CTLA-4, [168], cMyc [153], cyclin D1 [169, 170], Tcf-1 [171], Lef-1 [172, 173], and Axin2 [174-176].

Several inhibitors of $\beta$-catenin transcriptional activity have been discovered. These inhibitors target the ability of $\beta$-catenin to bind to transcription factors and coactivators. One molecule, ICG-001, inhibits $\beta$-catenin/TCF transcriptional activity by disrupting the interaction between $\beta$-catenin and CBP, but not with $\mathrm{p} 300$. It was found that ICG-001 can inhibit colon tumor growth [177] and reduce the transcription of gene 
targets of $\beta$-catenin/TCF including cyclin D1 and c-myc [178]. A second molecule, quercetin, was found to inhibit $\beta$-catenin transcriptional activity when a constitutively active $\beta$-catenin mutant was transfected into cell lines. Quercetin inhibited the TCF complex from binding to its DNA binding-site and inhibited $\beta$-catenin-TCF association as well as reduced $\beta$-catenin nuclear translocation [179]. Another study found that quercetin treatment resulted in reduced $\beta$-catenin transcriptional activity and reduced colon cancer cell viability [180].

\section{$\beta$-catenin and inflammation}

There are conflicting reports regarding the role of $\beta$-catenin in promoting or inhibiting inflammation. On one hand, $\beta$-catenin has been found to be necessary for the production of anti-inflammatory molecules in lamina propria dendritic cells. Lamina propria DCs from knockout mice had increased levels of mRNA encoding inflammatory cytokines such as IL-23a and IL-6 and lower levels of anti-inflammatory IL-10. Additionally, $\beta$-catenin conditional knockout mice had lower frequencies of regulatory $\mathrm{T}$ cells and higher frequencies of Th1 and Th17 cells in the lamina propria [181].

A few studies have shown that $\beta$-catenin is involved in regulating inflammation induced by Salmonella in epithelial cells. In one study, expression of constitutively active $\beta$-catenin decreased NFאB's ability to bind DNA. Activation of $\beta$-catenin signaling also inhibited IL-8 production induced by Salmonella [178]. In another study, $\mathrm{LiCl}$ treatment, which inhibits GSK3$\beta$ activity and leads to $\beta$-catenin accumulation, resulted in reduction of Salmonella-induced IL-8 production. Moreover, cells expressing 
constitutively active $\beta$-catenin had reduced NFkB activity upon Salmonella infection [182].

On the other hand, there are several reports that link $\beta$-catenin expression with increased inflammatory cytokine production in various cell types. In one study, treatment of mycobacterial products (PPD)-reactive PBMC with neutralizing antibodies against Wnt5a and its receptor, FZD5, resulted in reduced IL-12 production in response to PPD and reduced IFN $\gamma$ production by T cells [183]. Since Wnt5a plays a role in $\beta$-catenin signaling, these data indicate a role for $\beta$-catenin in Th1 cytokine regulation. In another study, $\beta$-catenin was found to regulate IFN $\beta$ production by interacting with LRRFIP1, a cytosolic nucleic acid sensor. In macrophages, this sensor promoted $\beta$-catenin activation by phosphorylating $\beta$-catenin at the residue Ser552 upon infection with VSV, resulting in increased IFN $\beta$ production through the interaction of $\beta$-catenin with IRF3 and subsequent binding to $\mathrm{p} 300$, leading to increased transcription of IFN $\beta$ [184]. Yet another study reported that there is an increased expression of $\beta$-catenin in microglia under neuroinflammatory conditions, such as that found in Alzheimer's. Wnt3A stimulation of microglia results in the expression of proinflammatory genes and the production of IL-6, IL-12, and TNF $\alpha$ [185]. Interestingly, simultaneous activation with LPS led to downregulation of the inflammatory response [186], suggesting that $\beta$-catenin can either upregulate or downregulate inflammation. Similarly, the activation of $\beta$-catenin in APC/- mice resulted in the induction of a pro- and anti-inflammatory environment in the liver. $\beta$-catenin was found to directly induce expression of several genes including Cc124, Cxc12, Cxcl10, Cxc111, IL15, IL18, and Ikk $\beta$, and was associated with NFאB activation. However, $\beta$-catenin also upregulated chemokine-like chemotactic factor 
leukocyte cell-derived chemotaxin 2 (LECT2) gene, which was found to control the intensity of the inflammation as well as the degree of tumor aggressiveness [187].

Overall, $\beta$-catenin's role as an anti-inflammatory or pro-inflammatory agent appears to be dependent on multiple parameters, including cell type, stimulus, and experimental system being used. It can therefore be assumed that $\beta$-catenin is able to modulate inflammation in either direction depending on the context/environment. However, it is unknown what role $\beta$-catenin plays in the inflammatory cytokine production that leads to Type I diabetes, which is the focus of this study. 


\section{MATERIALS AND METHODS}

Mice

C57BL/6Jg7, NOD/LtJ, and BDC2.5 NOD mice were purchased from the Jackson Laboratory. All mice were maintained according to Institutional Animal Care and Use Committee (IACUC) guidelines.

\section{Generation of bone marrow-derived DC and human monocyte-derived DC}

Bone marrow-derived dendritic cells (BMDC) were generated by culturing BM cells for 12 days with $5 \mathrm{ng} / \mathrm{mL}$ granulocyte-monocyte colony stimulating factor (GMCSF; PeproTech) in complete media containing RPMI (Mediatech) supplemented with $1 \%$ 1M Hepes buffer (MP Biomedicals), 1\% $100 \mathrm{mM}$ sodium pyruvate, $1 \% 200 \mathrm{mM} \mathrm{L}-$ glutamine, $1 \%$ 10,000 IU/mL penicillin and 10,000 ug/mL streptomycin, $1 \%$ nonessential amino acids (Mediatech), 0.1\% $50 \mathrm{mM}$ ß2-mercaptoethanol (Sigma-Aldrich), and $10 \%$ fetal calf serum (FCS) (Hyclone). Monocytes were isolated from PBMC from healthy and type 1 diabetic individuals (Research Blood Components) using CD14 microbeads and magnetic columns (Miltenyi) and were cultured for 8 days in the presence of GM-CSF and IL-4 (PeproTech) in complete medium as described above.

\section{Western Blot}

Whole cell lysates were prepared using the lysis buffer and PBS+inhibitors 
recipes from the Universal Magnetic Co-IP Kit (ActiveMotif) for whole cell lysates. Lysates were stored at $-80^{\circ} \mathrm{C}$. Lysates were prepared for electrophoresis with NuPage LDS Sample Buffer (Life Technologies) and NuPage Sample Reducing Agent (Life Technologies). NuPage MES or MOPS SDS Running Buffer (Life Technologies) was prepared with NuPage Antioxidant (Life Technologies). Samples were electrophoresed using the NuPAGE system using 4-12\% Bis-Tris gels. Protein was transferred onto PVDF membrane using NuPage Transfer Buffer (Life Technologies) with 10\% methanol for 1.5-2 hours at 35V. Membranes were blocked in 5\% non-fat dry milk in Tris-buffered saline with Tween (TBST) prior to primary antibody incubation. Membranes were incubated with primary antibody at a concentration of 1:1000 in 5\% non-fat dry milk or 5\% BSA in TBST overnight. Membranes were then incubated in anti-mouse or antirabbit HRP-linked secondary antibody (Cell Signaling) diluted in 5\% non-fat dry milk for 1 hour before exposure. All washes were performed with TBST. Chemiluminescent detection was performed using SuperSignal West Dura Chemiluminescent Substrate (Thermo) or SuperSignal West Pico Chemiluminescent Substrate (Thermo). Membranes were exposed using a Kodak Image Station 40000MM (Eastman Kodak) or an ImageQuant LAS 4000 (GE Healthcare).

\section{Confocal Microscopy}

Cells were fixed with 4\% paraformaldehyde in PBS for 1 hour at room temperature, followed by permeabilization with $0.1 \%$ TritonX-100. Cells were then labeled with anti- $\beta$-catenin primary antibody and AlexaFluor488 anti-rabbit secondary antibody followed by DRAQ5 nuclear label (Alexis Biochemicals). Cells were 
visualized using an Olympus FV1000 confocal microscope.

\section{Intracellular Labeling}

Cells were incubated in Fc block, fixed in $4 \%$ paraformaldehyde at $37^{\circ} \mathrm{C}$, permeabilized in $90 \%$ methanol, and labeled with anti- $\beta$-catenin antibodies followed by AlexaFluor488 anti-rabbit secondary antibodies. Cells were then acquired and analyzed using a FACScalibur (Becton Dickinson).

\section{Antibodies}

Antibodies used for Western blot, including antibodies against $\beta$-catenin, Ecadherin, $\beta$-actin, ubiquitin, phospho-Akt-308, phospho-Akt-473, pan Akt, phosphoPKA-197, total PKAc, phospho-GSK3 $\beta$-S9, total GSK3 $\beta$, phospho- $\beta$-catenin-S552, phospho- $\beta$-catenin-S675, phospho-ERK1/2, total ERK1/2, phospho-p38, and total p-38 were all purchased from Cell Signaling. The anti- $\beta$-catenin antibodies used for confocal and flow cytometry were also purchased from Cell Signaling. The AlexaFluor488 antirabbit antibody was purchased from Life Technologies.

\section{Isolation of primary DC from organs}

Spleens and Peyer's patches were harvested, cut into small pieces, and then incubated in collagenase VIII (Sigma) in Hank's Buffered Saline Solution (HBSS) for 1 hour at $37^{\circ} \mathrm{C}$. Tissue was then homogenized by syringe, filtered, and red blood cells in the spleen were lysed using Tris ammonium chloride. Mesenteric lymph nodes were harvested, pushed through a mesh filter with the end of a syringe plunger, and collected. 
Dendritic cells were then purified by labeling with CD11c magnetic beads and then passed through a magnetic column. Cells were then surface-labeled with CD11c-APC antibodies (Becton Dickinson) and labeled intracellulary for $\beta$-catenin.

\section{Transfection (siRNA and plasmids)}

Mouse BMDC were transfected with $5 \mu \mathrm{g}$ N-TARGET PLUS siRNA catenin beta $1.88 \mathrm{kDa}$ (cadherin associated protein) (DHARMACON RNA Technologies) and human cells were transfected with $2 \mu \mathrm{g}$ of this siRNA. For plasmid studies, $200 \mathrm{ng}$ of pcDNA3S33Y $\beta$-catenin (Addgene plasmid 19286) was used. Control cells were transfected with siGLO RISC-Free siRNA or pcDNA3 wildtype $\beta$-catenin plasmids (Addgene plasmid 16828). Cells were transfected using the AMAXA nucleofector system. Experiments were performed on cells 72-96 hours following transfection with siRNA or 48-96 hours following plasmid transfection.

\section{$\beta$-catenin Inhibitor Treatments}

150,000 BMDC or human DC were pre-treated with $75 \mu \mathrm{M}$ quercetin (Acros) or 12.5 $\mu \mathrm{M}$ ICG-001 (Dr. Michael Kahn) for 8 or 12 hours or $50 \mu \mathrm{M}$ Wnt3 agonist for 30 minutes (Calbiochem) followed by stimulation with $1 \mu \mathrm{g} / \mathrm{mL}$ LPS for 24 hours. Supernatants were collected after the 24-hour LPS treatment and cells were washed three times before coculture as described below.

\section{Coculture experiments}

BMDC or human DC treated as described in the "Transfection" and " $\beta$-catenin 
Inhibitor Treatments" sections were cocultured with mouse or human T cells. Mouse T cells were prepared from spleen or lymph nodes from BDC2.5 NOD mice. Both types of cells were magnetically labeled with anti-CD4 magnetic beads and then passed through a CD4 T cell column (R\&D). T cells were added to the cell culture along with $100 \mathrm{ng} / \mathrm{mL}$ pancreatic peptide for the mouse experiments or $0.5 \mathrm{ug} / \mathrm{mL}$ human anti-CD3 antibody for the human experiments. Supernatants were collected 48 hours later.

\section{ELISA}

Supernatants were collected and stored at $-20^{\circ} \mathrm{C}$. Kits for IL-12 and IFN $\gamma$ were purchased from Biolegend and used according to the manufacturer's instructions.

\section{Delivery of $\beta$-catenin inhibitors in vivo}

For oral gavage delivery, a $25 \mathrm{mg} / \mathrm{kg}$ dose was give to each mouse three times a week. For each mouse, $0.5 \mathrm{mg}$ quercetin dihydrate (LKT labs) was dissolved in $10 \mathrm{uL}$ ethanol, filter sterilized and diluted 1:10 in sterile corn oil. For the vehicle, sterile ethanol was added to sterile corn oil at a 1:10 dilution. $100 \mathrm{uL}$ of these solutions were given to each mouse.

For intraperitoneal delivery, a $5 \mathrm{mg} / \mathrm{kg}$ dose was given to each mouse twice a week. For each mouse, $5 \mathrm{mg}$ quercetin was diluted in $10 \mathrm{uL} \mathrm{DMSO}$, filter sterilized, and then diluted 1:1000 in water. For the vehicle, DMSO was diluted in water at a ratio of 1:1000. $200 \mathrm{uL}$ of these solutions were injected into each mouse. 


\section{Adoptive transfer of transfected DC}

For the adoptive transfer experiments, 0.5 million BMDC/well were transfected with $1 \mu \mathrm{g}$ of $\beta$-catenin or control siRNA using the Amaxa system. One million treated or control BMDC were then transferred intravenously to female 3 week-old NOD mice. To determine diabetes incidence, urine glucose was tested beginning at 10 weeks of age. Upon a positive test for urine glucose, blood glucose was taken and recorded. Mice were considered to have diabetes after two consecutive blood glucose readings $>300 \mathrm{mg} / \mathrm{dL}$.

\section{Urine and Blood Glucose Testing of NOD mice}

Mice were tested once a week beginning at 10 weeks of age. Urine glucose was first tested using Diastix (Bayer). Once the Diastix indicated that glucose was present in the urine, blood glucose testing began. Blood glucose testing was performed on blood from the tail using a human blood glucose monitor system from Walgreens. Blood glucose was recorded and mice were considered to have diabetes after two consecutive readings of $>600 \mathrm{mg} / \mathrm{dL}$.

\section{Real time RT-PCR}

RNA was isolated from BMDC using an RNeasy Mini Kit (Qiagen). cDNA was then prepared using the Quantitect Reverse Transcription Kit (Qiagen) and Quantitect SYBR Green Kit (Qiagen). PCR was performed using a real time PCR machine (Applied Biosystems). 


\section{Coimmunoprecipitation}

Coimmunoprecipitation experiments were performed using the Universal Magnetic Co-IP Kit (ActiveMotif) for whole cell lysates. Pulldown antibodies recognizing $\beta$-catenin and E-cadherin were purchased from Cell Signaling.

\section{Proteasomal Degradation Experiments}

BMDC were pre-treated with a $50 \mu \mathrm{M}$ dose of MG-132 (Tocris) for 12 hours. The cells were washed and a $2 \mathrm{ug} / \mathrm{mL}$ dose of cycloheximide or DMSO vehicle was added for 1, 2, 6, or 10 hours. Cells were washed and lysates prepared using the lysis buffer from the Universal CoIP kit from ActiveMotif.

\section{Akt/PKA Pathway Inhibitor and Activator Treatments}

BMDC were treated with a $40 \mu \mathrm{M}$ dose of the PKA inhibitor H89 (EMD Millipore or LC Labs) or a $25 \mu \mathrm{M}$ dose of the PI3K inhibitor LY294002 (Tocris) for 4 hours. Cells were then washed and lysed using the lysis buffer from the Universal CoIP kit from ActiveMotif.

\section{NFKB Activation Assay}

Cells were treated with a $75 \mu \mathrm{M}$ dose of quercetin (Acros) or a $12.5 \mu \mathrm{M}$ dose of ICG-001 (provided by Michael Kahn). Nuclear lysates were prepared using the Nuclear Extract Kit (Active Motif). Nuclear lysates were then analyzed using the TransAm NFkB Family Assay Kit (Active Motif). 


\section{Statistical Analysis}

All data were analyzed using the student's t test. Statistical significance was achieved when $\mathrm{p}<0.05$. 


\section{RESULTS}

\section{GOAL 1: CHARACTERIZING $\beta$-CATENIN EXRESSION AND ITS ROLE IN PRO-INFLAMMATORY CYTOKINE PRODUCTION}

Our lab has previously observed a novel defect in $\beta$-catenin expression in BMDC from adult NOD mice as compared to BMDC from diabetic-resistant adult B6.g7 mice. Therefore, we aimed to 1) characterize the expression of $\beta$-catenin in BMDC from both NOD mice and human diabetic patients, in various NOD congenic strains, and in primary DC from different organs and to 2) explore the correlation between $\beta$-catenin expression and pro-inflammatory cytokine production. To accomplish these goals, we examined $\beta$-catenin expression at various time points in disease progression, looking at whole cell, nuclear, and cytoplasmic fractions by Western blot, FACS analysis, and confocal microscopy. We also examined $\beta$-catenin expression in Idd4 and Idd $3 / 5$ mice through Western blot and in primary DC through FACS analysis. We used anti- $\beta$-catenin siRNA treatment and $\beta$-catenin inhibitors to inhibit expression and activity of $\beta$-catenin and measured resulting pro-inflammatory cytokine production and IFN $\gamma$ induction in $\mathrm{T}$ cells. Finally, we used $\beta$-catenin plasmids and Wnt agonist treatment to induce $\beta$-catenin expression and activity in BMDC from non-diabetic mice and measured cytokine production. 


\section{In which cellular compartments is $\beta$-catenin overexpressed in NOD BMDC at different stages of disease?}

Our lab has previously observed a defect in $\beta$-catenin expression in BMDC from adult NOD mice as compared to BMDC from diabetic-resistant adult B6.g7 mice. Diabetes follows a predictable pattern of progression in NOD mice. At 3 weeks of age, periinsulitis, in which infiltrating cells surround the islets, is observed. By 6 weeks of age, insulitis begins to develop. Beginning around 10 weeks of age, mice test positive for high blood glucose, which reflects the destruction of their $\beta$-islet cells, and are considered to be diabetic. In order to examine the expression of $\beta$-catenin at different time points during disease progression, we performed Western blot, FACS analysis, and confocal microscopy using bone marrow-derived DC (BMDC) from 3 weeks, 6 weeks, and 10+ weeks old mice.

Upon performing Western blot, we found that NOD BMDC express higher levels of $\beta$-catenin than B6.g7 BMDC at all disease stages examined (Figure 1A-F). We confirmed our findings through FACS analysis and found a larger shift in $\beta$-catenin positive cells in the NOD BMDC compared to B6.g7 BMDC when compared to unlabeled cells at all ages examined (Figure 1G-I).

To determine whether $\beta$-catenin translocates to the nucleus where it can influence gene transcription, we examined $\beta$-catenin levels in the nuclei of NOD and B6.g7 BMDC. We found that NOD BMDC express higher levels of $\beta$-catenin in the nucleus at all disease stages (Figure $1 \mathrm{~J}-\mathrm{O}$ ), suggesting that high levels of $\beta$-catenin may influence the transcription of pathogenic proteins, such as IL-12, in type I diabetes.

Next, we performed confocal microscopy in order to examine the localization of 
$\beta$-catenin in the cytoplasm and nucleus of NOD and B6.g7 BMDC. We found statistically significant higher levels of $\beta$-catenin in both the nucleus and cytoplasm of NOD BMDC at both 3 and 6 weeks of age (Figure 1 P-U). Overall these data indicate that $\beta$-catenin is overexpressed in both the cytoplasm and nucleus of NOD BMDC during the peri-insulitis, insulitis, and full-blown disease stages of diabetes development. This suggests that $\beta$-catenin is overexpressed even before disease onset and may be useful as a prognostic marker. Additionally, the presence of higher levels of $\beta$-catenin in the nuclei of NOD BMDC indicates a possible role for this protein in transcription of other important disease-associated genes.

\section{Is $\beta$-catenin overexpressed in primary dendritic cells from NOD mice?}

Although we have found higher expression of $\beta$-catenin in NOD BMDC, these cells are cultured from bone marrow for a considerable length of time before use and therefore are not necessarily representative of dendritic cells in vivo. To address this issue, we examined $\beta$-catenin levels in DC from the spleen, mesenteric lymph node, and Peyer's patches from both NOD and B6.g7 mice using flow cytometry. DC from each organ were isolated using magnetic columns to separate the CD11c positive cells. Cells were then labeled with CD11c-APC surface antibodies followed by intracellular labeling with anti- $\beta$-catenin antibody and AlexaFluor488 antibody, and $\beta$-catenin expression was examined through FACS analysis. We found that DC from each organ expressed $\beta$ catenin, although at very low level, but there was very little difference in expression between NOD and B6.g7 cells for any of the three organs examined (Figure 2 A-C).

It is possible that we could not see any difference because the expression of $\beta$ - 
catenin in DC from the chosen sites is very low. Other organs that are known for containing $\beta$-catenin-expressing DC such as lamina propria [181] should be tested in the future and may allow us to distinguish the level of $\beta$-catenin expression between NOD and B6g7 DC.

\section{Is $\beta$-catenin overexpressed differentially in NOD and B6 congenic strains expressing protective or disease-inducing loci from B10 or NOD mice, respectively?}

Various sections of the NOD genome have been identified as conferring susceptibility to diabetes. In our lab, we maintain B6Idd4 and NODIdd3/5 congenic strains. Idd4 is a region identified on chromosome 11 which contains the candidate diabetic-inducing genes platelet activating factor acetylhydrolase Ib1, nitric oxide synthase-2, and CC chemokine genes [188]. The Idd4 mouse is a B6 mouse containing the inserted Idd4 locus from NOD mouse but is resistant to diabetes development. Idd3 is found on chromosome 3 and contains the candidate gene for IL-2 [74], while Idd5 is found on chromosome 1 and contains the candidate genes CTLA-4 and ICOS [189]. The Idd3/5 mouse is an NOD mouse with the Idd3 and Idd5 regions from a B10 mouse inserted into its genome which renders it diabetes-resistant. Although $\beta$-catenin is found

on the mouse chromosome $9, \beta$-catenin may interact with other genes within these loci to influence diabetes development. Therefore, we determined $\beta$-catenin expression in these two strains of mice by Western blot (Figure3A-B). We found that BMDC from Idd3/5 overexpress $\beta$-catenin at levels similar to the NOD mouse, whereas BMDC from Idd4 mice have low levels as seen in the B6.g7 BMDC. Therefore, the overexpression of $\beta$ catenin is not linked to these three loci. As shown previously for other molecules 
associated with disease development, e.g., Iag7, a defect in $\beta$-catenin expression is not sufficient to initiate diabetes in diabetes-resistant Idd $3 / 5$ mice. Instead $\beta$-catenin may be one of several genes that contribute to diabetes risk.

\section{Is there a correlation between $\beta$-catenin levels in $\mathrm{DC}$ and pro-inflammatory cytokine production in mice?}

Inflammatory cytokines, especially IL-12 and IFN $\gamma$, have been shown to play important roles in diabetes pathogenesis [112]. Additionally, several recent studies have linked $\beta$-catenin with inflammatory cytokine production [183-185, 187]. In light of these studies, we investigated a role for $\beta$-catenin overexpression in the pathogenic production of IL-12 and IFN $\gamma$ in NOD mice.

First, we explored the abilities of two $\beta$-catenin inhibitors, quercetin and ICG001, to reduce pro-inflammatory cytokine production. Quercetin reduces the ability of the $\beta$-catenin/TCF complex to bind to its target DNA sequence and also reduces $\beta$-catenin nuclear translocation [179]. ICG-001, on the other hand, reduces the ability of $\beta$-catenin to bind to CBP [177]. Upon pre-treatment with either inhibitor, followed by LPS stimulation of the NOD BMDC, we found that both inhibitors significantly reduced IL-12 production by the BMDC (Figure 4A and C). Next we cocultured the treated BMDC with $\mathrm{T}$ cells from $\mathrm{BDC} 2.5$ mice. These mice contain $\mathrm{T}$ cells with a specific $\mathrm{T}$ cell receptor that recognizes a pancreatic peptide [190]. Upon culture with antigen presenting cells (the BMDC) and pancreatic peptide, these T cells differentiate into IFN $\gamma$-producing cells. We found that treatment of the BMDC with either inhibitor also reduced IFN $\gamma$ production by these $T$ cells (Figure 4B and D). 
Next, we knocked down $\beta$-catenin expression by transfecting cells with anti- $\beta$ catenin siRNA and effectively reduced expression of $\beta$-catenin (Figure 4E). Following siRNA treatment, cells were stimulated with or without $1 \mu \mathrm{g} / \mathrm{mL}$ LPS and the supernatants tested for IL-12. Knockdown of $\beta$-catenin significantly lowered IL-12 production (Figure 4F). We finally incubated the treated cells with $\mathrm{T}$ cells from BDC2.5 mice. We found that BDC2.5 T cells incubated with anti- $\beta$-catenin siRNA-treated BMDC produced significantly less IFN $\gamma$ than T cells incubated with control siRNAtreated BMDC (Figure 4G). These results suggest that $\beta$-catenin overexpression in NOD BMDC does in fact play a role in the pathogenic production of inflammatory cytokines that contribute to disease in these mice.

In a second set of experiments, we examined the ability of inducing overexpression of $\beta$-catenin in B6.g7 BMDC to increase pro-inflammatory cytokine production. First, we treated the BMDC from B6.g7 mice with a Wnt agonist, which effectively increased the levels of nuclear $\beta$-catenin as compared to the vehicle control treatment (Figure 5A). We found that this treatment also resulted in increased IL-12 production by the B6.g7 BMDC (Figure 5B) as well as increased IFN $\gamma$ production by the BDC2.5 T cells cocultured with the treated BMDC (Figure 5C).

Additionally, we transfected B6.g7 BMDC with either a $\beta$-catenin plasmid encoding a degradation-resistant form of $\beta$-catenin or with a control plasmid. Transfection with the $\beta$-catenin plasmid effectively increased the level of nuclear $\beta$ catenin in these cells (Figure 5D). Using the same experimental system described above, we found that treatment with this plasmid resulted in increased IL-12 production by the B6.g7 BMDC (Figure 5E) as well as increased IFN $\gamma$ production by the BDC2.5 T cells 
cocultured with these treated BMDC (Figure 5F). These data suggest that overexpressing $\beta$-catenin leads to increased IL-12 production. Overall, it appears that $\beta$-catenin clearly has a role in the regulation of pro-inflammatory cytokine production which may contribute to Type I diabetes pathogenesis in NOD mice.

\section{Is there a correlation between $\beta$-catenin levels in DC and pro-inflammatory cytokine production in humans?}

Because we had found a correlation between overexpression of $\beta$-catenin in NOD BMDC and their ability to induce potential pathogenic cells, we wondered whether a similar trend would also observed in cells from type 1 diabetic patients. First, we established that mo-DC from T1D patients also express high levels of $\beta$-catenin as compared to cells from healthy controls through Western blot (Figure 6A). We confirmed these results by FACS (Figure 6B) and confocal microscopy (Figure 6C). We then examined the effect of knocking down $\beta$-catenin expression and inhibiting $\beta$-catenin activity in these cells. First, we stimulated mo-DC from healthy and T1D donors with LPS for 24 hours and measured levels of IL-12 production. Mo-DC from T1D patients produced significantly higher levels of IL-12 as compared to cells from healthy donors (Figure 6D). Next, we treated mo-DC with quercetin, the $\beta$-catenin inhibitor, and measured IL-12 production. As in mice, this treatment led to a reduction in IL-12 production (Figure 6E). Finally, we examined the effect of knocking down $\beta$-catenin expression with siRNA on pro-inflammatory cytokine expression. Similar to the results found using mouse BMDC, we found that knocking down expression of $\beta$-catenin led to reduced IL-12 production by the moDC upon LPS stimulation for 24 hours (Figure 6F). 
Following LPS treatment, we added human T cells to the DC for 48 hours and measured IFN $\gamma$ production. We found that knockdown of $\beta$-catenin in mo-DC also reduces IFN $\gamma$ production by the T cells (Figure 6G). These data therefore confirm in human cells the observations made using NOD BMDC. 

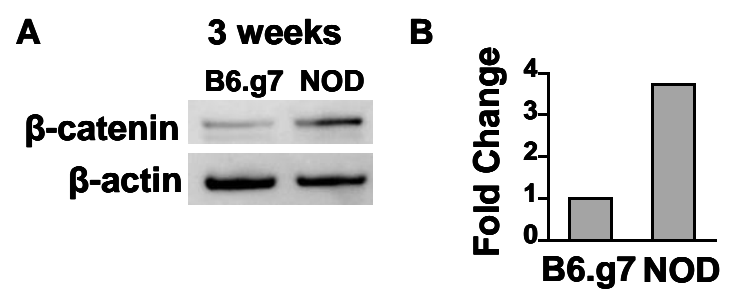

6 weeks
B6.g7 NOD
$\beta$-catenin
B-actin --
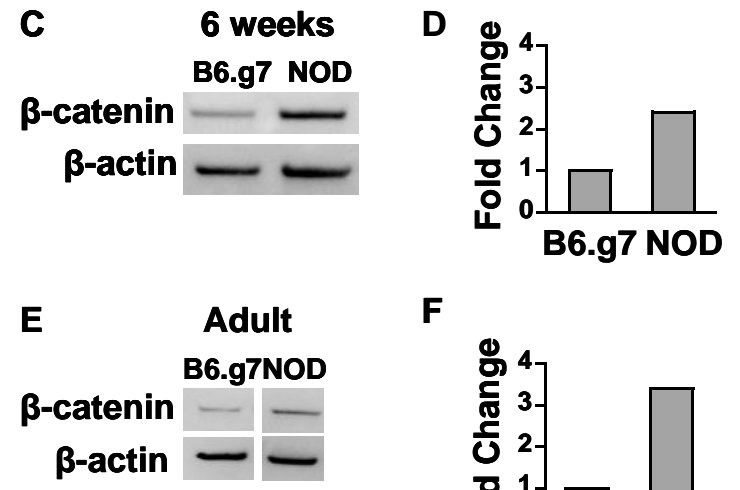

F
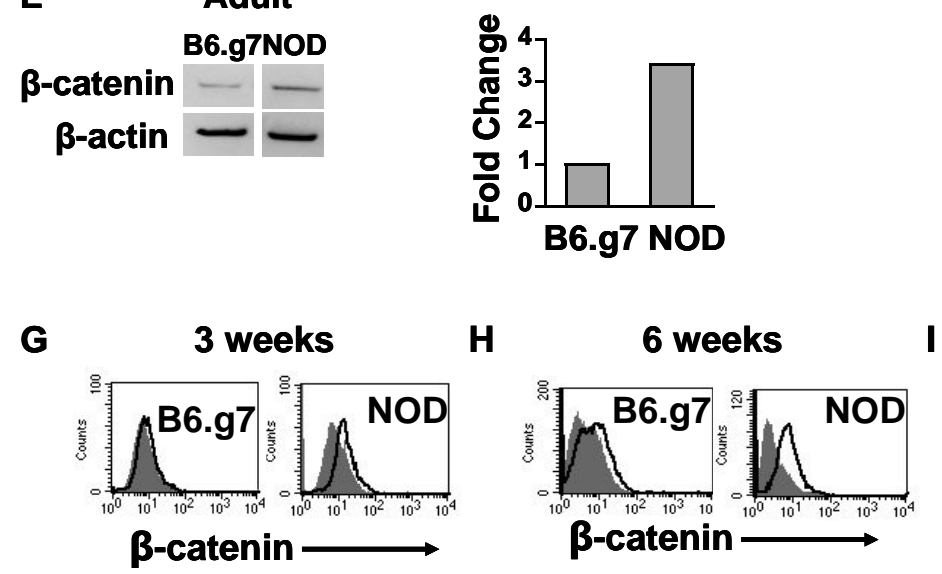

Adult

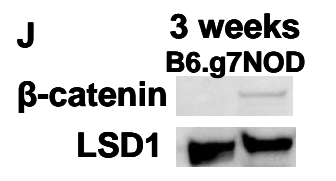

$L \quad 6$ week $M$

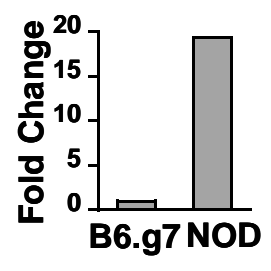

$\beta$-catenin LSD1
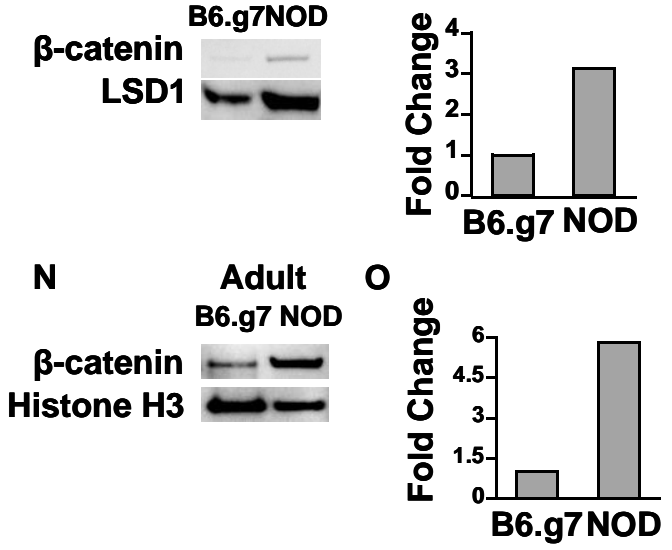

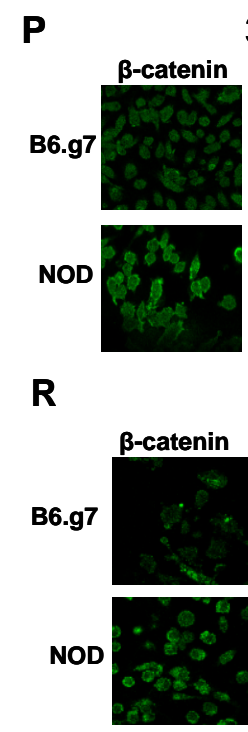

$\mathbf{T}$

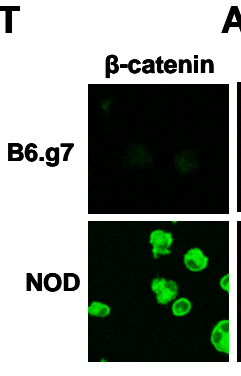

3 weeks

Nucleus

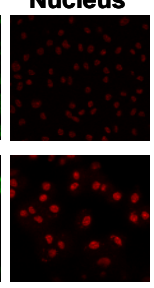

6 weeks

Nucleus

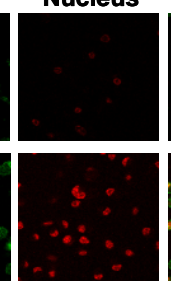

Adult

Nucleus

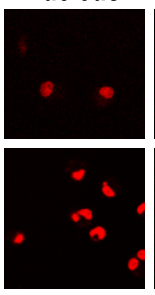

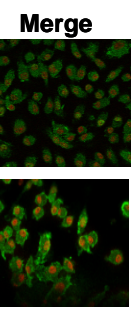

Merge

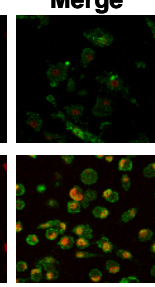

Merge

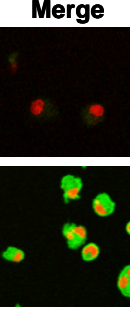

$\mathbf{Q}$

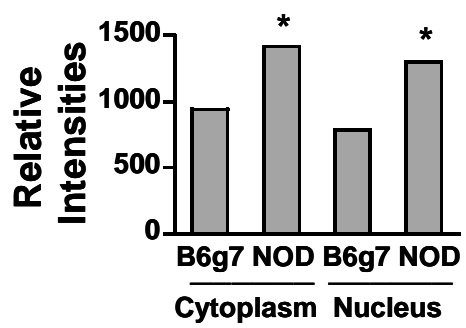

S

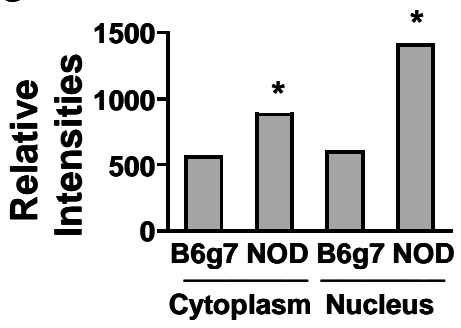

$\mathbf{U}$

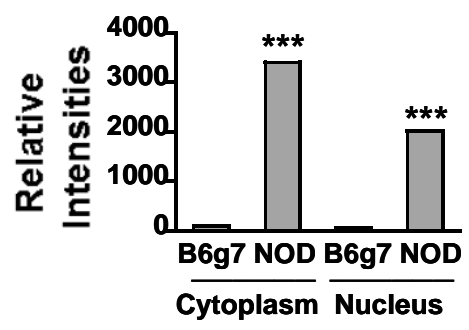

Figure 1. NOD BMDC express higher levels of $\beta$-catenin than B6.g7 BMDC in the cytoplasm and nucleus and whole cell. Whole cell lysates were prepared from BMDC from 3-week old (A), 6-week old (C), or adult (E) NOD or B6.g7 mice and Western blot performed using anti- $\beta$-catenin and anti- $\beta$-actin antibodies. The band intensities were quantified and expressed as fold change for 3-week old mice (B), 6-week old mice (D), and adult mice (F). BMDC from 3-week old mice (G), 6-week old mice $(\mathrm{H})$, and adult mice (I) were labeled with anti- $\beta$-catenin primary antibody and AlexaFluor488 secondary antibody and analyzed by FACS. Nuclear lysates were prepared from 3-week old (J), 6week old (L), or adult (N) NOD or B6.g7 BMDC and Western blot performed using anti$\beta$-catenin and anti-LSD1 or anti-histone antibodies. The band intensities were quantified and expressed as fold change for 3-week old (K), 6-week old mice (M), and adult mice $(\mathrm{O})$. BMDC from 3-week old (P), 6-week old (R), or adult $(\mathrm{T})$ were labeled with anti- $\beta$ catenin primary antibodies and AlexaFluor488 secondary antibody and DRAQ5 nuclear label and visualized by confocal microscopy. Relative intensities of $\beta$-catenin are shown for the nucleus and cytoplasm of BMDC from adult mice (Q), 6-week old mice (S), and 3 -week old mice $(\mathrm{U}) . *$ indicates $\mathrm{p}<0.05$; $* * *$ indicates $\mathrm{p}<0.0001$. Data are representative of two or more independent experiments. 
Mesenteric

Peyer's Patches

Spleen

B6.97

A
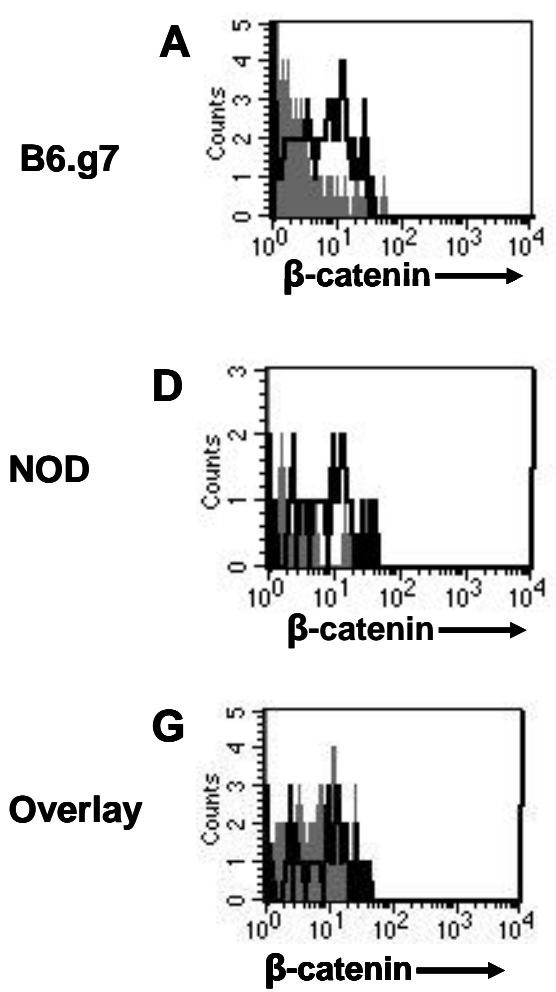
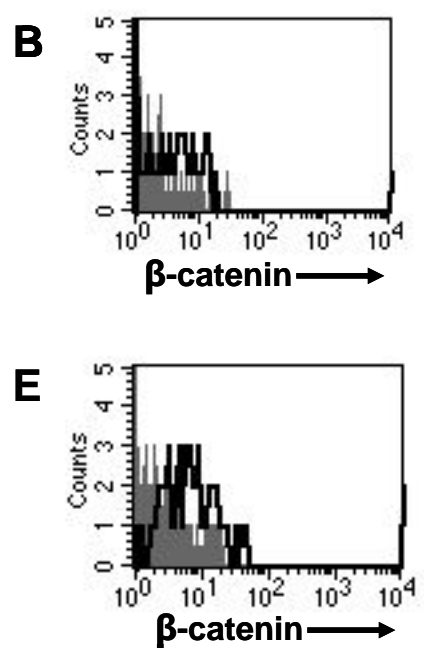

H

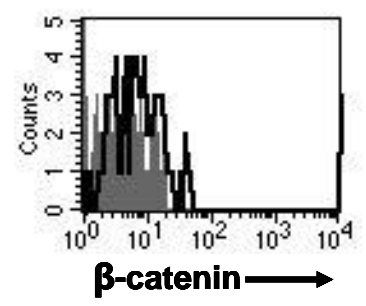

C

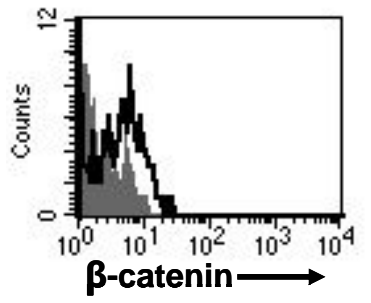

$\mathbf{F}$

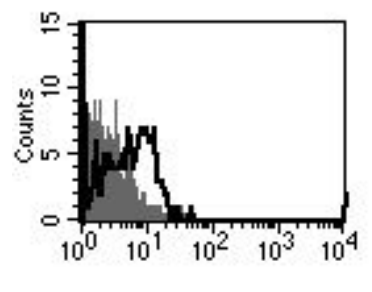

I

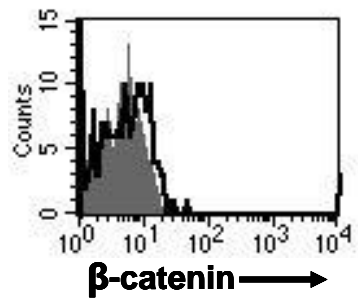

Figure 2: Expression of $\beta$-catenin by primary DC from NOD and B6.g7 lymphoid organs. DC were isolated from various organs, treated with Fc block, surface labeled using anti-CD11c-APC conjugated antibodies and labeled intracellularly using anti- $\beta$ catenin primary antibodies or IgG isotype control antibodies and AlexaFluor 488 secondary antibodies. Cells were analyzed through FACS. The histograms show the $\beta$ catenin-labeled cells in black and the isotype control-labeled cells in gray for each organ in B6.g7 (A-C) and NOD (D-F). The overlay of - $\beta$-catenin labeled NOD cells in black over $-\beta$-catenin labeled B6.g7 cells in gray is shown for the MLN (G), Peyer's patches $(\mathrm{H})$, and spleen (I). 


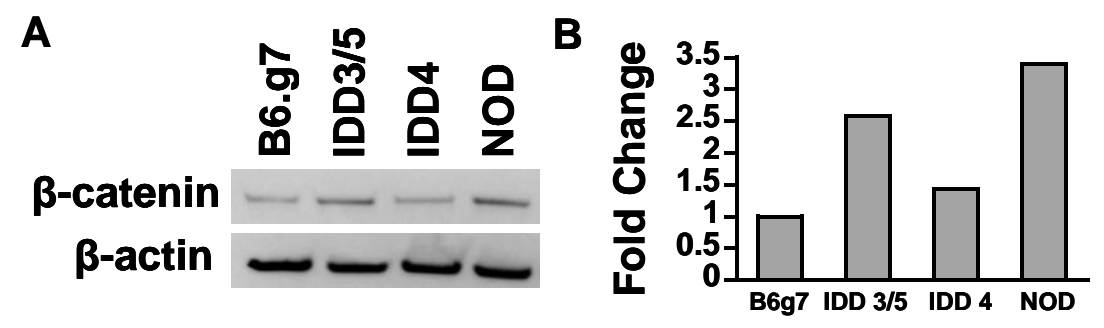

Figure 3. Idd3/5 mice, but not Idd4 mice overexpress $\beta$-catenin. BMDC from B6.g7, Idd $3 / 5$, Idd 4 , and NOD mice were lysed, and Western blot was performed using anti- $\beta$ catenin and anti- $\beta$-actin antibodies (A). The fold change for $\beta$-catenin expression is shown (B). Data are representative of two independent experiments. 


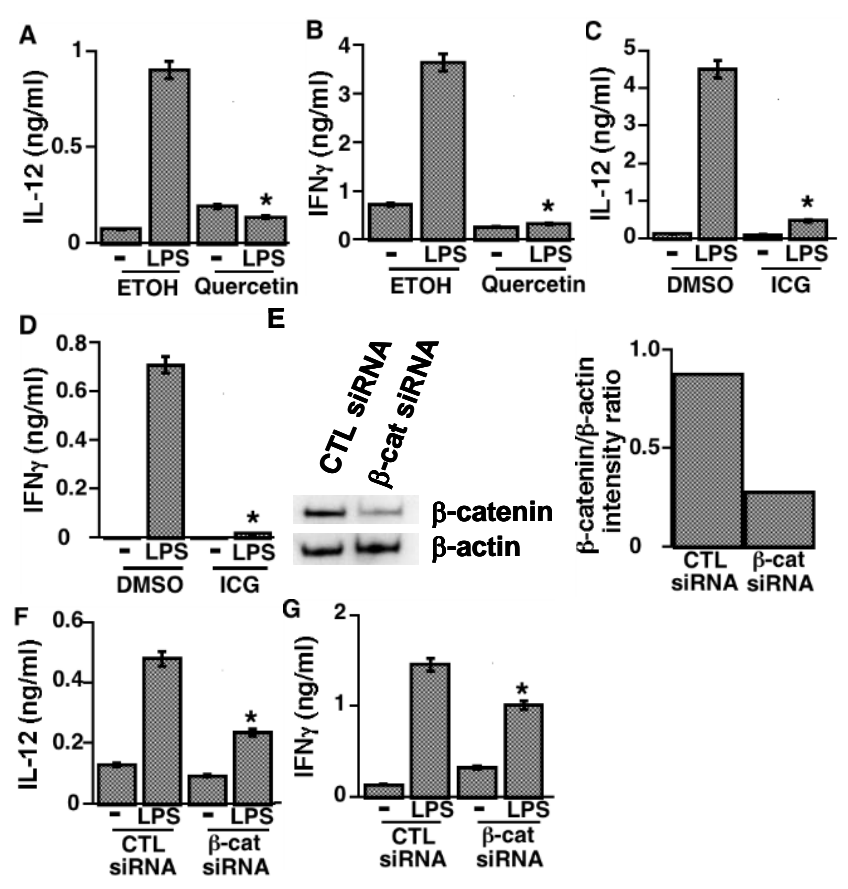

Figure 4. Inhibiting the activity of or knocking down expression of $\beta$-catenin in NOD BMDC leads to reduced IL-12 production and IFN $\gamma$ induction of T cells. NOD BMDC were pretreated with $75 \mu \mathrm{M}$ quercetin or vehicle (A-B) or $12.5 \mu \mathrm{M}$ ICG-001 or vehicle (C-D) for 12 hours, washed, and stimulated with $1 \mu \mathrm{g} / \mathrm{mL}$ LPS for 24 hours. The supernatants were collected and the presence of IL-12 was detected by ELISA (A, C). Quercetin-treated BMDC (B) or ICG-001-treated BMDC (D) were then washed and cocultured with $1 \times 10^{5} \mathrm{~T}$ cells from BDC2.5 mice for 48 hours along with $100 \mathrm{ng} / \mathrm{mL}$ of pancreatic peptide. Supernatants were collected and tested for the presence of IFN $\gamma$ by ELISA (B, D). NOD BMDC were transfected with 5 ng of $\beta$-catenin siRNA or control siRNA and 96 hours later lysed. Western blot was performed with anti- $\beta$-catenin and $\beta$ actin antibodies and the bands quantified by densitometry analysis (E). Transfected cells were treated with or without $1 \mu \mathrm{g} / \mathrm{mL}$ of LPS for 24 hours. Supernatants were collected and tested for the presence of IL-12 through ELISA (F). Transfected and LPS-treated cells were cultured with BDC2.5 T cells and $100 \mathrm{ng} / \mathrm{mL}$ pancreatic peptide for 48 hours. Supernatants were collected and tested for the presence of IFN $\gamma$ through ELISA (G). *indicates $\mathrm{p}<0.005$. 

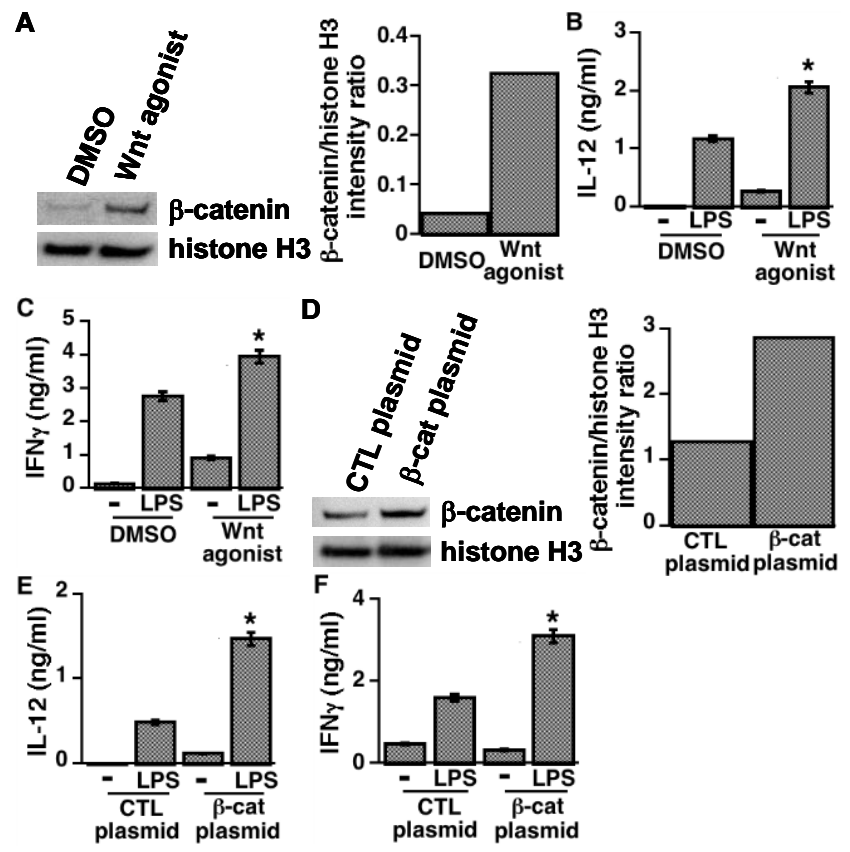

Figure 5: Increasing the activity or expression of $\beta$-catenin in B6.g7 BMDC leads to increased IL-12 production and IFN $\gamma$ induction of T cells. B6.g7 BMDC were treated with $50 \mu \mathrm{M}$ Wnt agonist. Nuclear lysis was performed followed by Western blot using anti- $\beta$-catenin and anti-histone antibodies. The band intensities were quantified and expressed as relative intensities (A). Following treatment, cells were washed and treated with $1 \mu \mathrm{g} / \mathrm{mL}$ LPS for 24 hours. Supernatants were collected and tested for the presence of IL-12 by ELISA (B). BMDC were then washed and cocultured with $1 \times 10^{5} \mathrm{~T}$ cells from BDC2.5 mice for 48 hours along with $100 \mathrm{ng} / \mathrm{mL}$ of pancreatic peptide.

Supernatants were collected and tested for the presence of IFN $\gamma$ by ELISA (C).

B6.g7 BMDC were transfected with $\beta$-catenin or control plasmid, lysed, and subjected to Western blot using anti- $\beta$-catenin and anti- $\beta$-actin antibodies. The band intensities were quantified and expressed as relative intensities (D). Following transfection, cells were treated with $1 \mu \mathrm{g} / \mathrm{mL}$ LPS for 24 hours. Supernatants were collected and tested for the presence of IL-12 by ELISA (E). BMDC were then washed and cocultured with $1 \times 10^{5} \mathrm{~T}$ cells from BDC2.5 mice for 48 hours along with $100 \mathrm{ng} / \mathrm{mL}$ of pancreatic peptide. Supernatants were collected and tested for the presence of IFN $\gamma$ by ELISA (F).* indicates $\mathrm{p}<0.005$. 
A

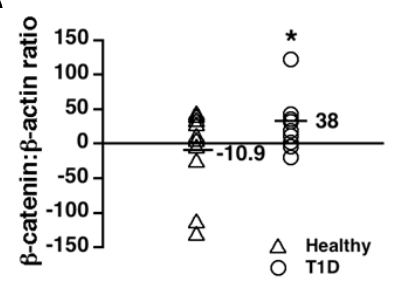

D

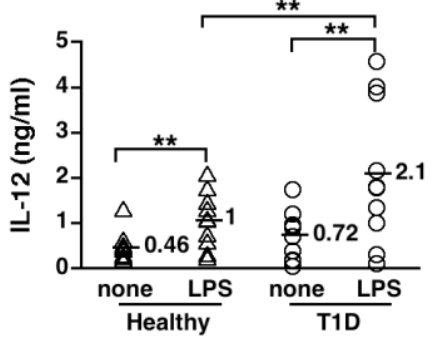

B

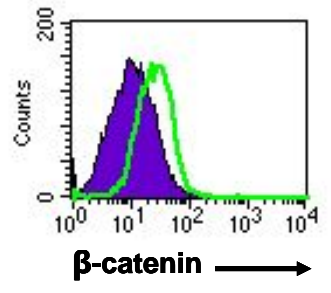

E

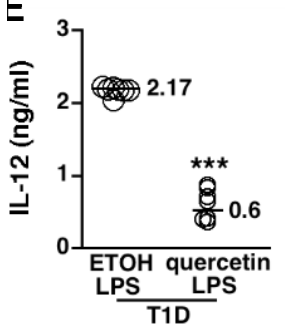

$\mathbf{F}$

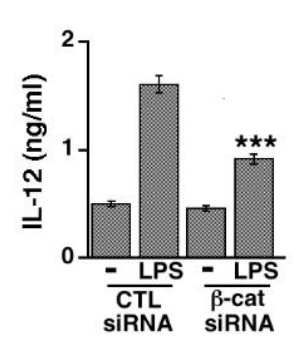

G

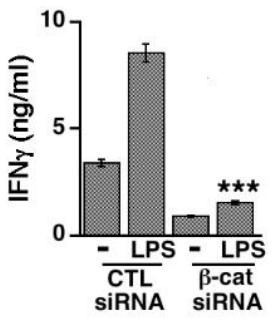

Figure 6: Human monocyte-derived DC express higher levels of $\beta$-catenin than moDC from non-diabetic donors, and inhibiting the activity of $\beta$-catenin in human monocyte-derived DC leads to reduced pro-inflammatory cytokine production. Western blot was performed on whole cell lysates from DC from 10 different patients and healthy donors using anti- $\beta$-catenin and anti- $\beta$-actin antibodies. The densities of the bands were quantified and expressed as a ratio for each sample (A). moDC from diabetic human patients were labeled with isotype control or anti- $\beta$-catenin antibody followed by secondary antibodies and analyzed by FACS (B) or labeled with nuclear dye and analyzed by confocal microscopy (C). moDC from healthy donors and diabetic patients were stimulated with or without LPS for 24 hours and the supernatants collected and tested for the presence of IL-12 by ELISA (D). moDC from diabetic patients were pretreated with quercetin for 12 hours followed by LPS treatment for 24 hours. Supernatants were collected and tested for the presence of IL-12 by ELISA (E). moDC from diabetic patients were treated with anti- $\beta$-catenin or control siRNA, followed by stimulation with or without LPS for 24 hours. Supernatants were collected and tested for the presence of IL-12 by ELISA (F). siRNA-treated cells were then cocultured with human T cells for 48 hours. Supernatants were collected and tested for the presence of IFN $\gamma$ by ELISA $(G)$. * indicates $\mathrm{p}=0.05 ; * *$ indicates $\mathrm{p}<0.0387 ; * * *$ indicates $\mathrm{p}<0.005$. 


\section{GOAL 2: PREVENTING AND/OR TREATING TYPE I DIABETES BY REDUCING THE INFLAMMATORY ENVIRONMENT IN VIVO}

Because pathogenic cytokine production by NOD BMDC can be reduced with $\beta$ catenin inhibitors or siRNA, as outlined in Goal 1, we sought to determine the ability of 1) the $\beta$-catenin inhibitor, quercetin, to reduce disease incidence, prolong survival, and reduce inflammation in NOD mice and 2) $\beta$-catenin siRNA-treated BMDC transfer to reduce disease incidence and prolong survival. Therefore, we performed a series of in vivo experiments in which quercetin was delivered for various amounts of time and through different routes.

\section{Can direct delivery of $\beta$-catenin inhibitors reduce inflammation and inhibit diabetes development and mortality in vivo?}

In light of our in vitro data showing that $\beta$-catenin is overexpressed in NOD BMDC, we sought to examine the effect of inhibiting $\beta$-catenin on disease incidence, survival, and pro-inflammatory cytokine production in vivo. First, we examined the effect of a $\beta$-catenin inhibitor, quercetin, on disease incidence and survival in NOD mice. Although quercetin inhibits several molecules, it has been found to inhibit $\beta$-catenin nuclear translocation as well as $\beta$-catenin transcriptional activity $[179,180]$. Therefore, we delivered quercetin or vehicle both orally and intraperitoneally to NOD mice. In the first of two experiments, a $25 \mathrm{mg} / \mathrm{kg}$ dose of quercetin or vehicle was delivered three times a week orally beginning at 3 weeks of age (Figure 7A and B). 
Treatment continued until sacrifice, which occurred after two high blood glucose readings ( $>300 \mathrm{mg} / \mathrm{dL}$ ). In the second experiment, mice were allowed to die naturally (Figure 7C and D). For both experiments, it appears that incidence may be slightly increased and survival slightly decreased with quercetin treatment as compared to vehicle treatment in each experiment, suggesting that oral delivery of quercetin is ineffective at preventing disease.

Because it appears that oral quercetin treatment had little effect on disease incidence or survival in NOD mice, next we designed an experiment in which a $5 \mathrm{mg} / \mathrm{kg}$ dose of quercetin or vehicle was injected intraperitoneally two times a week for 18 weeks based on a previous study showing that this dosage was effective at reducing proliferation in a breast cancer model when used in combination with other polyphenols [191]. Mice were allowed to die naturally. In the first of two experiments, treatment significantly delayed disease incidence and slightly increased survival (Figure 8A and B). Additionally, it appeared that incidence in the quercetin-treated group increased sharply upon discontinuation of the treatment at 21 weeks of age. However, in the second experiment, quercetin treatment had no effect on incidence or survival (Figure 8C and D). We also performed another experiment in which quercetin treatment continued for the life of each mouse (Figure 9A and B). However, lifetime treatment was not more effective than 18 week treatment in reducing incidence or increasing survival rates. There is a possibility that the discrepancy between the data from the different experiments is due to the potential inactivation of quercetin between the first intraperitoneal experiment and the two other experiments which were started 5 months later. To ease the solubilization of quercetin, some quantity was kept at $30^{\circ} \mathrm{C}$ possibly for the entire period between the 
experiments. However, storage at this temperature is not recommended for more than afew weeks. We are currently performing experiments in which fresh quercetin is used to prepare the treatments over the course of the experiment.

We also examined if intraperitoneal injection of quercetin into NOD mice had an impact on the in vivo production of IFN $\gamma$. Therefore, we treated a separate group of NOD mice with quercetin intraperitoneally twice a week starting at 3 weeks of age and harvested the spleens of mice at 14 weeks of age, after approximately 10 weeks of treatment. Two quercetin-treated and two vehicle-treated mice were used, one of which had tested positive for high blood glucose and one of which was healthy in each group. Spleen cells were stimulated with anti-CD3 or left untreated and supernatants collected and analyzed for IFN $\gamma$ production through ELISA. After both 72 and 96 hours of stimulation, the spleen cells from the quercetin-treated mice produced much less IFN $\gamma$ than spleen cells from vehicle-treated mice regardless of disease state (Figure 8E and F). This suggests that quercetin treatment does reduce the pathogenic inflammatory environment that contributes to Type I diabetes development in NOD mice. However, systemic reduction of IFN $\gamma$ may not be a good indication of disease status, suggesting that pancreatic lymph nodes and pancreas may be better organs to test. Other disease mechanisms are most likely still at play.

\section{Can $\beta$-catenin siRNA treated-BMDC transfer reduce disease incidence and mortality in vivo?}

We have found that downregulating $\beta$-catenin expression with siRNA treatment is effective in reducing IL-12 production in BMDC and subsequent IFN $\gamma$ induction by $\mathrm{T}$ 
cells co-cultured with the siRNA-treated BMDC in vitro. Therefore, we hypothesized that adoptive transfer of DC treated with anti- $\beta$-catenin siRNA would be effective in reducing disease incidence and/or increasing survival by reducing the pro-inflammatory environment that contributes to Type I diabetes.

We found that a single transfer of BMDC in which $\beta$-catenin expression had been knocked down resulted in delayed disease incidence and increased survival as compared to transfer of control siRNA-treated BMDC (Figure 10A and B). This suggests that even though the BMDC do not persist in the mouse, this reduction in $\beta$-catenin may be enough to reduce the inflammatory environment contributing to Type I diabetes and impact disease and/or induce long-term tolerance. 
Experiment 1

A

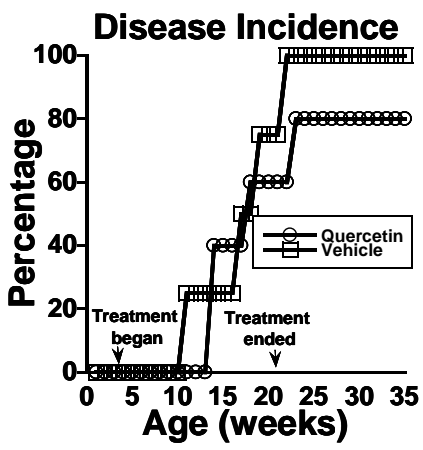

B

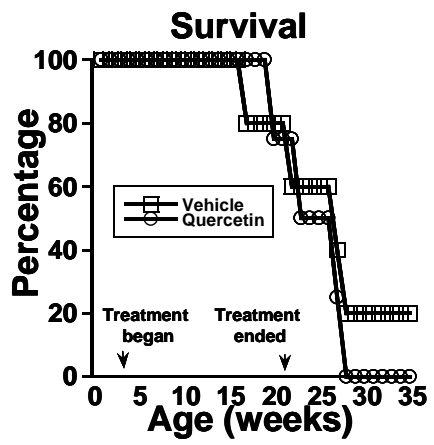

Experiment 2

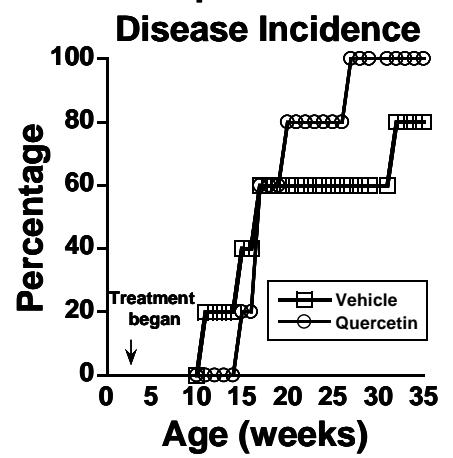

D

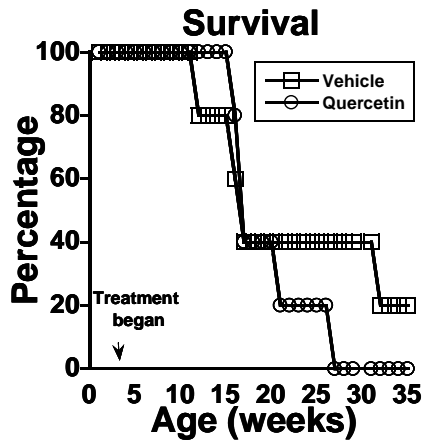

Figure 7. Oral gavage in vivo delivery of quercetin does not delay disease incidence or increase survival in NOD mice. In A) and B) female NOD mice were orally gavaged with a $25 \mathrm{mg} / \mathrm{kg}$ dose of quercetin in oil or vehicle three times a week beginning at three weeks of age and continuing throughout the lifespan of each mouse. Urine glucose was tested beginning at 10 weeks of age. Mice were considered to have diabetes after two consecutive high (>300 mg/dL) blood glucose readings and were sacrificed. Incidence A) and survival B) are shown. In C) and D), mice were orally treated with quercetin or vehicle beginning at three weeks of age and continuing for 18 consecutive weeks. Mice were allowed to die naturally. Testing was performed as in A) and B). Incidence C) and survival D) are shown. $\mathrm{n}=5$ for both experiments. 
Experiment 1

A

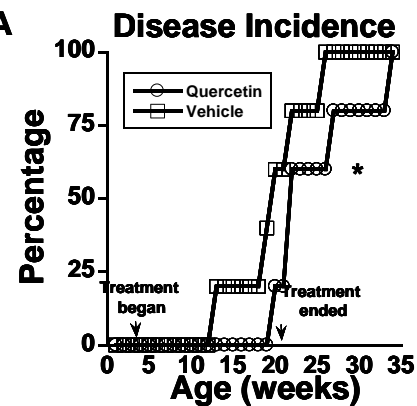

B

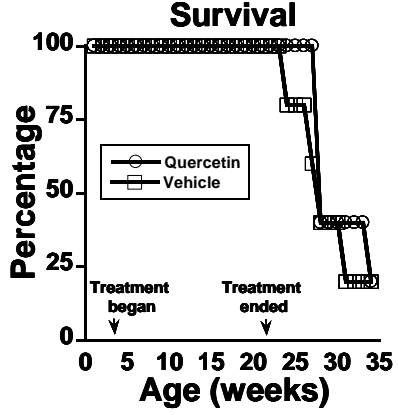

Experiment 2

C ${ }_{100}$ Disease Incidence $E$

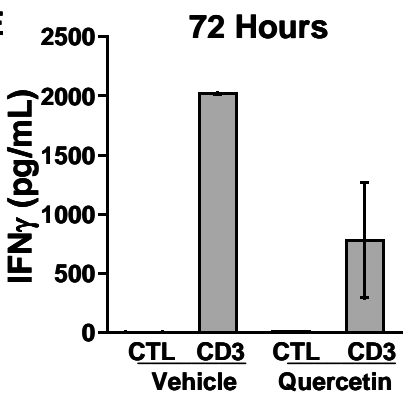

D

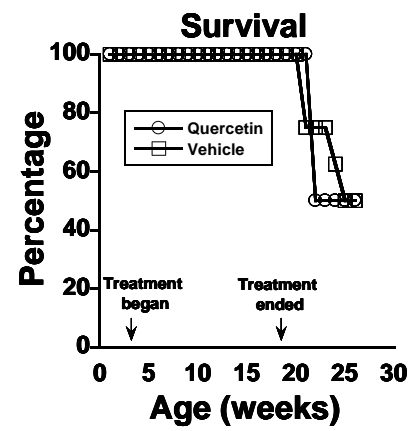

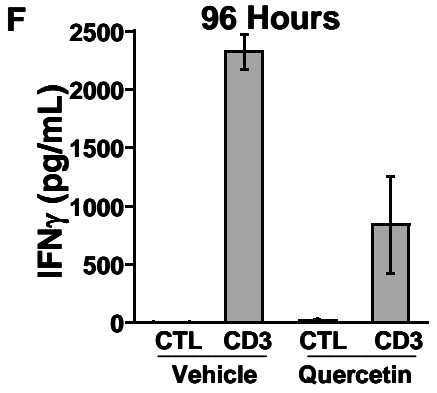

Figure 8. Intraperitoneal injection of quercetin may delay disease incidence and increase survival by reducing the pathogenic inflammatory environment that contributes to Type I diabetes. Female NOD mice $(n=5)$ were injected intraperitoneally with a $5 \mathrm{mg} / \mathrm{kg}$ dose of quercetin or vehicle two times a week beginning at 3 weeks of age and continuing for 18 consecutive weeks. Urine glucose was tested beginning at 10 weeks of age. Mice were considered to have diabetes after two consecutive high $(>300$ $\mathrm{mg} / \mathrm{dL}$ ) blood glucose readings. For the first experiment, incidence is shown in A) and survival in B). For the second experiment, incidence is shown in C) and survival in D). Spleens from a third group of treated mice were harvested after 10 weeks of treatment and cells were stimulated with a $0.5 \mu \mathrm{g} / \mathrm{mL}$ dose of anti-CD3 or no stimulation. Two quercetin-treated and two vehicle-treated mice were used. Supernatants were collected at 72 hours E) and 96 hours F). Supernatants were probed for IFN $\gamma$ through ELISA. 
A

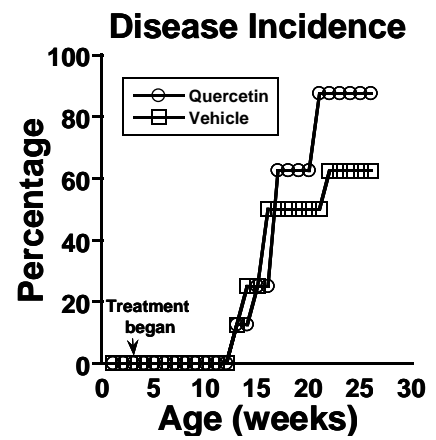

B

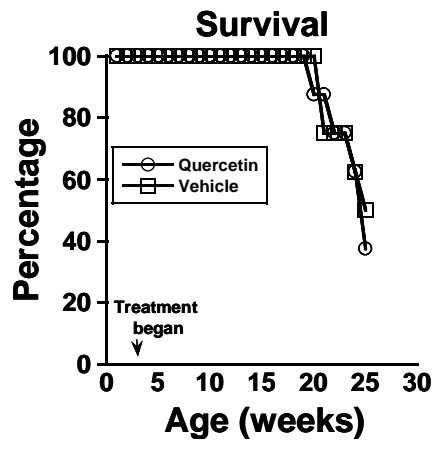

Figure 9. Lifetime intraperitoneal treatment with quercetin does not increase survival or reduce disease incidence as compared to 18 -week treatment. Female NOD mice were injected intraperitoneally with a $5 \mathrm{mg} / \mathrm{kg}$ dose of quercetin or vehicle two times a week beginning at 3 weeks of age and continuing for the duration of the experiment $(n=5)$. Urine glucose was tested beginning at 10 weeks of age. Mice were considered to have diabetes after two consecutive high (>300 mg/dL) blood glucose readings. Incidence is shown in A) and survival in B). 

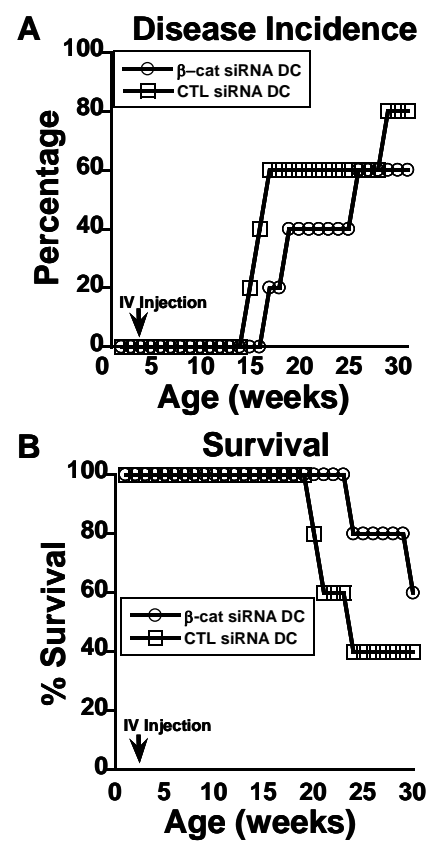

Figure 10. Adoptive transfer of $\beta$-catenin siRNA-treated DC reduces disease incidence and slightly increases survival. A) BMDC were transfected with $\beta$-catenin siRNA or control siRNA and one million cells were then transferred intravenously to female 3 week-old NOD mice $(n=5)$. Urine glucose was tested beginning at 10 weeks of age. Mice were considered to have diabetes after two consecutive high (>300 mg/dL) blood glucose readings. Incidence is shown in A) and survival in B). 


\section{GOAL 3: EXPLORING THE MECHANISMS BY WHICH $\beta$-CATENIN ACCUMULATES AND INFLUENCES PRO-INFLAMMATORY CYTOKINE PRODUCTION}

In Goal 1, we demonstrated that NOD BMDC overexpress $\beta$-catenin and this overexpression correlates with increased pro-inflammatory cytokine production. Therefore, in this study, we aimed to 1) determine the mechanism of accumulation of $\beta$ catenin in NOD BMDC and 2) determine the mechanism by which $\beta$-catenin infuences pro-inflammatory cytokine production. We performed a series of experiments to determine defects that might lead to accumulation including transcription rate, interactions between $\beta$-catenin and E-cadherin, proteasomal degradation and ubiquitination, GSK3 $\beta$ phosphorylation, and stabilizing phosphorylations of $\beta$-catenin. Finally, we examined differences in MAPK pathway activation and NFאB activation as potential mechanisms leading to increased pro-inflammatory cytokine production.

\section{Why does $\beta$-catenin accumulate at high levels in NOD BMDC?}

Due to the complexity of $\beta$-catenin regulation within the cell, there are several possible mechanisms by which $\beta$-catenin may accumulate in the cytoplasm of BMDC from NOD mice. These mechanisms include increased transcription, defective sequestration by E-cadherin, defective proteasomal degradation of $\beta$-catenin, defective ubiquitination of $\beta$-catenin, and defective phosphorylation of $\beta$-catenin. The figure shown on page 26 of the introduction provides an excellent overview of the various 
points at which $\beta$-catenin expression is regulated within the cell [159]. In this study, we examined each of these mechanisms by comparing NOD BMDC to B6.g7 BMDC.

\subsection{Does an elevated level of $\beta$-catenin transcription play a role in $\beta$-catenin accumulation of $\beta$-catenin in NOD BMDC?}

Because transcriptional rates can vary and lead to differences in protein expression, we first examined defects in transcription in NOD BMDC. To identify defects in transcription of $\beta$-catenin mRNA, we compared mRNA levels between NOD BMDC and B6.g7 BMDC by real time RT-PCR. In two independent experiments, there was no difference in $\beta$-catenin mRNA levels observed between the NOD and B6.g7 cells (Figure 11A). This indicates that $\beta$-catenin accumulation is the result of some other mechanism independent of transcriptional rate.

\subsection{Does defective sequestration of $\beta$-catenin by $E$-cadherin play a role in accumulation of $\beta$-catenin in NOD BMDC?}

$\beta$-catenin plays an important role in cell adhesions due to its ability to complex with E-cadherin at the cell membrane. The interaction between these two proteins helps regulate $\beta$-catenin signaling in the cell: several studies suggest that E-cadherin recruits $\beta$ catenin to the cell membrane and keeps it from accumulating in the nucleus where it can induce transcription $[134,135]$. Defects in the interaction between $\beta$-catenin and Ecadherin could therefore result in the accumulation of $\beta$-catenin in NOD BMDC.

We first examined the expression of these two proteins in BMDC by Western blot using anti- $\beta$-catenin and anti-E-cadherin antibodies. We observed that NOD BMDC 
express not only more $\beta$-catenin, but more E-cadherin as well (Figures $11 \mathrm{~B}$ and $\mathrm{C}$ ).

Therefore, we chose to perform a co-immunoprecipitation experiment in which protein from whole cell lysates was pulled down with either a $\beta$-catenin antibody or an Ecadherin antibody. In these coimmunoprecipitation experiments, the ratio of E-cadherin to $\beta$-catenin was not significantly different in the two cell types when using either a $\beta$ catenin or E-cadherin precipitating antibody (Figure 11D-G). This data indicates that there is no difference in the interaction between E-cadherin and $\beta$-catenin in NOD BMDC compared to B6.g7 BMDC. Therefore, excess accumulation of $\beta$-catenin in the NOD BMDC cannot be attributed to defective sequestration at the cell membrane.

\subsection{Does defective proteasomal degradation or ubiquitination play a role in accumulation of $\beta$-catenin in NOD BMDC?}

$\beta$-catenin is a protein that is prone to degradation and for this reason difficult to study in normal primary cells. In the cytoplasm, $\beta$-catenin forms a destruction complex with several other proteins including axin, APC, and GSK3 $\beta$. CK1 phosphorylates $\beta$ catenin at serine $45[120,129]$ which primes the $\beta$-catenin molecule for phosphorylation by GSK $3 \beta$ on Ser33 and 37 and Thr41 [142]. Once $\beta$-catenin is phosphorylated by GSK3 $\beta$, it is ubiquitinated and degraded by the proteasome [130]. Decreases in $\beta$-catenin ubiquitination and proteasomal degradation could therefore explain the accumulation of cytoplasmic $\beta$-catenin in NOD BMDC.

We assessed degradation rate of $\beta$-catenin in NOD and B6.g7 cells BMDC upon overnight pre-treatment with MG-132, a proteasome inhibitor. This treatment, by inhibiting proteasomal degradation, results in accumulation of $\beta$-catenin, allowing for 
easier detection and quantification of this protein in the B6.g7 cells, which as we have shown do not express much $\beta$-catenin. After MG-132 treatment, the cells were washed and cycloheximide, a protein synthesis inhibitor, or the corresponding vehicle control was added for various time-points: 1, 2, 6, or 10 hours. Cells were lysed and the lysates probed with anti- $\beta$-catenin antibodies (Figure $11 \mathrm{H})$. The amount of $\beta$-catenin left at each time point was calculated as a percentage of the original amount for each cell type, plotted on a logarithmic plot, and linear regression performed. The $\mathrm{T}_{1 / 2}$ value was calculated using the equation of the line by solving for time when $50 \%$ of $\beta$-catenin was left (Figure 11I and J). It appears that degradation rate of $\beta$-catenin is much slower in $\mathrm{B} 6 \mathrm{~g} 7 \mathrm{BMDC}$, in which the $\mathrm{T}_{1 / 2}$ value was 6.2 hours with cycloheximide and 6.5 hours with vehicle only, than in NOD, in which the $\mathrm{T}_{1 / 2}$ value was 3.3 hours with cycloheximide and 5.3 hours with vehicle only. The quicker degradation of $\beta$-catenin in NOD BMDC is puzzling, but may be the result of differences in the activity of other degradation pathways, such as the lysosomal pathway. Despite this unexpected result, these data suggest that differences in proteasomal degradation rate do not play a role in the accumulation of $\beta$-catenin in NOD BMDC.

We also determined if there were differences in the amount of ubiquitinated $\beta$ catenin as a proportion of total $\beta$-catenin in NOD and B6.g7 cells. First we quantitatively analyzed the expression of ubiquitinated $\beta$-catenin observed in Figure $1 \mathrm{H}$ in the previous experiment upon MG132 treatment. Ubiquitination will result in bands of heavier molecular weight due to attachment of ubiquitin molecules (approximately $8.5 \mathrm{kDa}$ ). Previous studies have identified this higher molecular weight $\beta$-catenin as monoubiquitinated $\beta$-catenin that accumulated in the presence of the ubiquitin ligase $\beta$ - $\mathrm{TrCP}$ or 
proteasome inhibitors $[192,193]$. Additionally, we only see this higher molecular weight band following MG-132 treatment, suggesting that this band represents ubiquitinated $\beta$ catenin as opposed to phosphorylated $\beta$-catenin or another protein. However, we cannot definitively rule out this heavier band as representing phosphorylated $\beta$-catenin unless we treated the cells with phosphatase in the experimental setup. We found that the amount of mono-ubiquitinated $\beta$-catenin was very similar between B6.g7 and NOD for each time point examined (Figure 11K).

\subsection{Does defective phosphorylation of $\beta$-catenin play a role in accumulation of $\beta$ - catenin in NOD BMDC?}

$\beta$-catenin degradation and stabilization are regulated by its phosphorylation at various residues: phosphorylation at some residues leads to destabilization of $\beta$-catenin, while phosphorylation at other residues leads to its stabilization as illustrated in the figure on page 26 . GSK3 $\beta$ phosphorylation of $\beta$-catenin at Ser33, Ser37, and Thr41 results in its ubiquitination [142] and degradation by the proteasome [130]. In contrast, upon phosphorylation of $\beta$-catenin at Ser552 by PKA [156] or Akt [150] or at Ser675 by PKA [158], $\beta$-catenin degradation is inhibited allowing $\beta$-catenin to accumulate in the cytoplasm and nucleus of cells. In light of these data, we hypothesized that lower destabilizing phosphorylation, or higher stabilizing phosphorylation may be responsible for the accumulation of $\beta$-catenin in NOD BMDC.

Lower levels of GSK3 activity in NOD BMDC could lead to lower $\beta$-catenin degradation and its accumulation. Because GSK3 $\beta$ is known to phosphorylate $\beta$-catenin at residues Ser33, Ser37, and Thr41, which marks $\beta$-catenin for ubiquitination and 
proteasomal degradation $[130,142]$, we hypothesized that downregulation of GSK3 $\beta$ activity may be responsible for $\beta$-catenin accumulation in NOD BMDC. We examined levels of phosphorylation of GSK3 $\beta$ at serine Ser9, an inhibitory phosphorylation [149]. We hypothesized GSK3 $\beta$ may be phosphorylated at higher levels at this residue in NOD BMDC resulting in reduced activity and reduced $\beta$-catenin degradation [149]. It appears that GSK3 $\beta$ from B6.g7 BMDC is phosphorylated at slightly higher levels than in NOD BMDC, although the differences are very small (Figure 12A and B). These data suggests that GSK3 $\beta$ activity is normal in NOD BMDC and thereby does not lead to reduced degradation of $\beta$-catenin in NOD BMDC and does not contribute to $\beta$-catenin accumulation, confirming the previous degradation experiments (Figure 11H). Accumulation of $\beta$-catenin in NOD BMDC must therefore occur through some other mechanism.

Since decreased destabilizing phosphorylation are not responsible for accumulation of $\beta$-catenin, increases in the phosphorylation level of $\beta$-catenin at residues Ser552 and Ser675 may be responsible for the stabilization and accumulation of $\beta$-catenin in NOD BMDC. Western blot analysis of NOD and B6.g7 BMDC using anti-phospho- $\beta$ catenin antibodies for Ser675 (Figure 12C-F) and Ser552 (Figure 12G-J) shows that there is a greater proportion of $\beta$-catenin phosphorylated at these two residues as well as a greater amount of phosphorylated $\beta$-catenin as a proportion of total protein in NOD BMDC as compared to B6.g7 BMDC. This suggests that these stabilizing phosphorylations may be partly or wholly responsible for the accumulation of $\beta$-catenin in NOD BMDC. We therefore examined the impact of inhibiting Akt and PKA on $\beta$ catenin phosphorylation and expression. NOD BMDC cells were treated with a $25 \mu \mathrm{M}$ 
dose of LY294002, a PI3K inhibitor, a $40 \mu \mathrm{M}$ dose of the PKA inhibitor H89 or vehicle for four hours. Cell lysates were prepared and Western blot was performed using anti- $\beta$ catenin and anti- $\beta$-actin antibodies (Figure 12K). Both of these inhibitors resulted in decreased phosphorylation of $\beta$-catenin at Ser552 (Figure 12L) and $\beta$-catenin expression (Figure 12M) suggesting that Akt and PKA may stabilize $\beta$-catenin and lead to its accumulation in NOD BMDC.

Because Akt and PKA appear to mediate accumulation of $\beta$-catenin in NOD BMDC we wondered whether expression and/or activity of Akt and PKA is higher in NOD BMDC. First we examined expression levels of total PKA and total Akt in NOD and B6.g7 BMDC. Western blot analysis using anti-PKA and anti-Akt antibodies showed no difference in expression for either PKA (Figure 13A and B) or Akt (Figure 13C and D) between NOD and B6.g7 BMDC. Next, we assessed the level of activation of PKA and Akt. We measured Akt phosphorylation at Thr308 and Thr473, two known activating residues, after 30 minutes of stimulation with a $1 \mu \mathrm{g} / \mathrm{mL}$ dose of LPS. For Akt Thr308, we found higher levels of phosphorylation in unstimulated NOD BMDC in 2 out of 3 experiments (Figure $13 \mathrm{E}$ and F). Upon LPS stimulation, we found more phosphorylation in B6.g7 BMDC in 3 out of 4 experiments (Figure $13 \mathrm{G}$ and $\mathrm{H}$ ). Therefore it appears that this residue is constitutively phosphorylated at higher levels in NOD BMDC but upon stimulation, it is phosphorylated and activated at higher levels in B6.g7 BMDC. This higher level of phosporylation under non-stimulation conditions may explain the higher levels of phosphorylated $\beta$-catenin in NOD BMDC. In contrast, we found higher levels of phosphorylation of Akt at Thr473 in B6.g7 BMDC (Figure 13I and J) with and without LPS stimulation, in most of the experiments. Therefore, it is unlikely 
that increased activation of Akt through phosphorylation at Thr473 is responsible for the increased phosphorylation of $\beta$-catenin at Ser552 in NOD BMDC. We finally examined levels of phosphorylation of PKA at Thr197, a residue that has been associated with optimal enzymatic activity $[153,154]$. However, it appeared that PKA was phosphorylated at similar levels in B6.g7 and NOD BMDC (Figure $13 \mathrm{~K}$ and L).

\section{Why does $\beta$-catenin accumulate in the nucleus of NOD BMDC but not B6.g7 BMDC?}

There are several possible mechanisms by which $\beta$-catenin may accumulate in the nucleus of the BMDC from NOD mice. These include defects in sumoylation, defects in phosphorylation by Pyk2, or simply defects in degradation that allow excess $\beta$-catenin to accumulate and translocate to the nucleus.

\subsection{Does defective sumoylation play a role in nuclear accumulation of $\beta$-catenin in NOD BMDC?}

Sumoylation of proteins has several biological functions: repression of transcriptional activity, such as in the case of sumoylation of p300, a transcriptional coactivator of $\beta$-catenin; activation of transcriptional activity, such as in the case of Tcf-4, another transcriptional coactivator of $\beta$-catenin; ordering of chromatin structure; DNA repair; nuclear transport and retention; and inhibition of $\mathrm{NF \kappa B}$-mediated inflammatory responses [194].

Because $\beta$-catenin contains candidate sumoylation sites and accumulates at higher levels in the nucleus of NOD BMDC, we hypothesized that differences in sumoylation of 
$\beta$-catenin may contribute to the differences observed in nuclear $\beta$-catenin levels.

Therefore, we performed coimmunoprecipitation experiments to examine the amount of sumoylated $\beta$-catenin in NOD and B6.g7 BMDC. However, we were unable to detect any sumoylated $\beta$-catenin in any of the experiments performed (data not shown). This may be due to several factors: proteins are typically sumoylated at low levels, and desumoylation is usually rapid. Therefore, it is difficult to conclude anything other than sumoylation of $\beta$-catenin may not be occurring and/or there may be undetectable differences in sumoylation of $\beta$-catenin in NOD and B6.g7 BMDC.

\subsection{Does defective expression of Pyk2 or defective phosphorylation of $\beta$-catenin by Pyk2 play a role in nuclear accumulation of $\beta$-catenin in NOD BMDC?}

It has been shown that Pyk, a tyrosine kinase, phosphorylates $\beta$-catenin at tyrosine residues $[195,196]$. This phosphorylation is associated with decreased attachment to Ecadherin and increased stability and nuclear translocation of $\beta$-catenin [197]. Therefore, we examined Pyk2 expression, Pyk2 activity, and the ability of Pyk2 to interact with $\beta$ catenin in NOD and B6.g7 BMDC.

Upon probing the cytoplasmic fraction after cell lysis, we were unable to detect Pyk2 expression in the cytoplasm of either B6.g7 or NOD BMDC (data not shown). Additionally, following coimmunoprecipitation with an anti- $\beta$-catenin antibody, we did not detect any Pyk2 interaction with $\beta$-catenin (data not shown). Finally, we found that treatment with AG17, a Pyk2 inhibitor, did not result in a decrease in $\beta$-catenin nuclear translocation when compared to vehicle-treated cells (data not shown). Although we can not rule out that the experimental conditions were not optimal, these data suggest that 
Pyk2 phosphorylation of $\beta$-catenin may not be an important contributor to $\beta$-catenin nuclear translocation in NOD BMDC.

\section{What are the mechanisms by which $\beta$-catenin induces pro-inflammatory cytokine production?}

It is well-established that NOD dendritic cells produce aberrant levels of proinflammatory cytokines $[119,121,198]$. Additionally, we have established that $\beta$-catenin is overexpressed in NOD BMDC as compared to B6.g7 BMDC. Therefore, we examined several mechanisms by which $\beta$-catenin might directly influence the level of proinflammatory cytokine production in BMDC. The mechanisms explored include an interaction between $\beta$-catenin and the MAPK pathway and an interaction between $\beta$ catenin and the NFkB pathway.

\subsection{Does $\beta$-catenin activate the MAPK pathway to induce pro-inflammatory cytokine production?}

MAP kinases are serine/threonine kinases that phosphorylate transcription factors in order to modulate gene expression. There are three major groups of MAP kinases: JNKs, ERKs, and p38 MAP kinases [199]. There is crosstalk between these pathways and several other signaling pathways. For example, Akt and PI3K can abnormally activate the ERK pathway in cancer [200]. It has also been shown that there is crosstalk between the MAPK pathway and the $\beta$-catenin signaling pathway. In one study ERK was found to be activated by Hepatitis B viral infection. This activation resulted in the inhibitory phosphorylation of GSK3 3 at Ser9 and subsequent accumulation of $\beta$-catenin 
[201].

Interestingly, the MAPK pathways have been shown to be involved in the production of IL-12, although the data is contradictory. Depending on the cell type, stimulation, and experimental system being used, ERK and p38 have a direct relationship with IL-12 production in which stimulation of these pathways increases production or inhibition decreases production [202-204], or an inverse relationship with IL-12 production in which stimulation decreases production and inhibition increases production [205-207]. Yet another set of studies demonstrate that ERK and p38 may have reciprocal functions in which activation of ERK results in suppression of the pro-inflammatory response while activation of $\mathrm{p} 38$ results in increased inflammation [150, 208].

In light of these data, we hypothesized that there may be crosstalk between $\beta$ catenin signaling and the MAPK pathway in BMDC. $\beta$-catenin overexpression may lead to increased ERK or p38 activity in NOD BMDC, resulting in altered pro-inflammatory cytokine production. In order to test this hypothesis, we stimulated NOD and B6.g7 BMDC with a $1 \mu \mathrm{g} / \mathrm{mL}$ dose of LPS for various time points and examined the resulting p38 and ERK1/2 activation. As shown in Figure 14, there was no statistically significant difference in phosphorylation of ERK at p42/p44 and in NOD cells compared to B6g7 cells after LPS stimulation. Additionally, there were no differences in p38 activation. Therefore, the excess pro-inflammatory cytokine production observed in NOD BMDC does not appear to be the result of defects in MAPK activity. 


\subsection{Does $\beta$-catenin interact with the NFאB pathway to induce pro-inflammatory cytokine production?}

It has been well-established that activation of the NFKB pathway induces proinflammatory cytokine production, including the production of IL-12 [209, 210]. The NFkB family includes RelA (p65), RelB, and c-Rel, and NFkB-1 (composed of p105 and p50) and NFkB-2 (composed of p100 and p52). NFkB proteins are usually rendered transcriptionally inactive in the cytoplasm by IкB proteins in the cytoplasm. Upon phosphorylation by IKK proteins, the IאB proteins undergo proteasomal degradation, thereby releasing the NFkB proteins, allowing for them to become transcriptionally active [211]. Additionally, it has been shown that DNA binding by NFkB is higher in NOD BMDC than BMDC from control mice. Moreover, LPS stimulation also resulted in increased NFאB nuclear translocation rates in NOD BMDC than in control cells [121]. Interestingly, $\beta$-catenin can physically interact with NFאB. One study found that upon association of the two proteins, NFKB binding to DNA and target gene expression was reduced in human colon and breast cancer cells [212].

In light of these data, we hypothesized that a defect in the interaction between the $\beta$-catenin and NFאB pathways in NOD BMDC was responsible for the excess IL-12 production by these cells. To test this hypothesis, we treated NOD BMDC with two $\beta$ catenin inhibitors, ICG-001 and quercetin, at 0, 10, 30, and 60 minutes and measured the level of NFkB p50 and p65 activation by ELISA (Figure 15). We found that both inhibitors reduced the amount of activated p50 and p65 as compared to the vehicle treatment for all time points. This suggests that the $\beta$-catenin pathway interacts with the NFkB pathway, and this interaction may influence pro-inflammatory cytokine expression 
in NOD BMDC. 

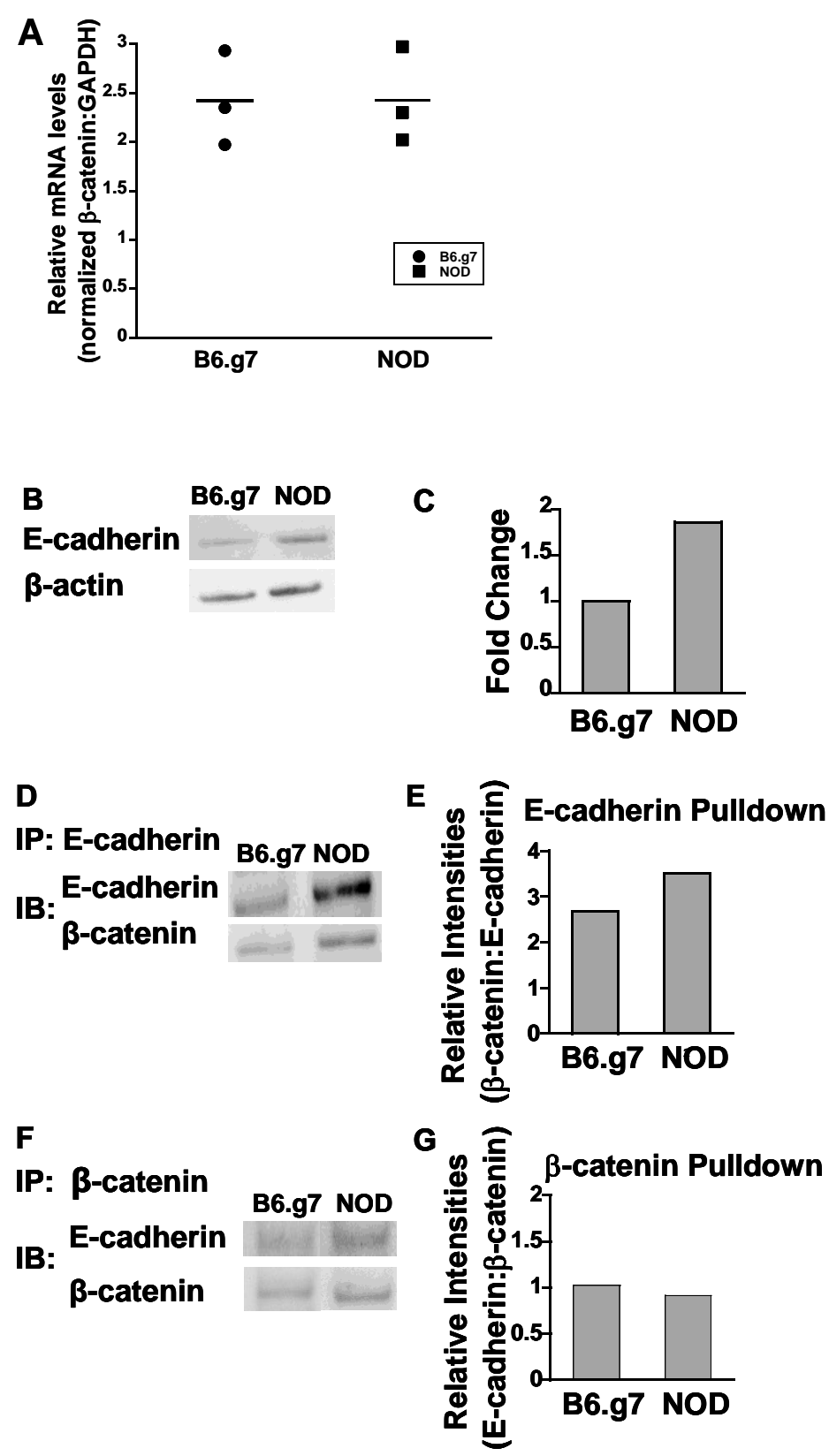


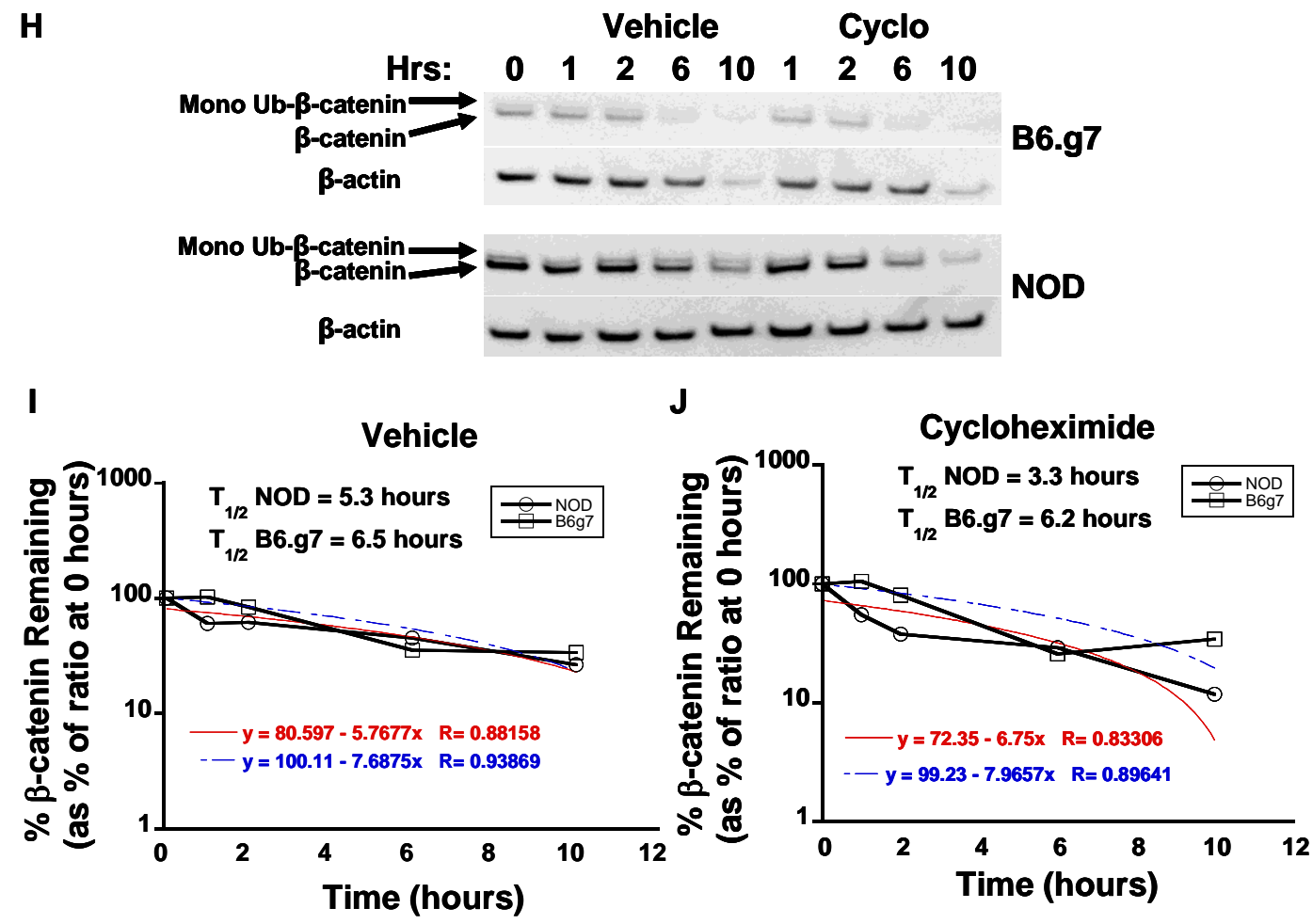

$\mathbf{K}$

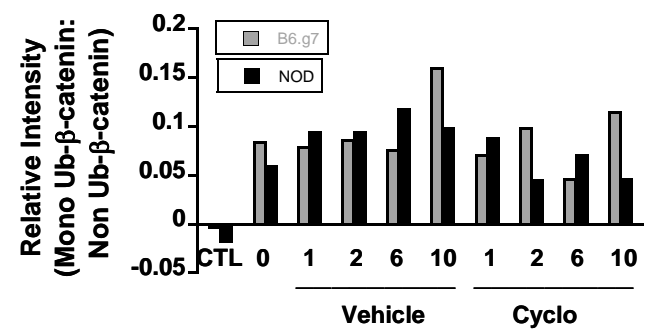

Figure 11. Lack of difference in $\beta$-catenin mRNA levels, in the interaction between $\beta$-catenin and E-cadherin, and in the degradation rate and ubiquitintion of $\beta$ catenin between B6.g7 and NOD BMDC. RNA was isolated from B6.g7 and NOD BMDC and real time rt-PCR was performed to determine the amounts of $\beta$-catenin mRNA relative to the amount of mRNA for the housekeeping gene, GAPDH. The data includes two independent experiments, one of which included two separate samples (A). NOD and B6.g7 BMDC were lysed, and Western blot was performed using anti-Ecadherin and anti- $\beta$-catenin antibodies (B). The fold change of E-cadherin to $\beta$-catenin is shown (C). Coimmunoprecipitation was performed with anti-E-cadherin (D) or anti- $\beta$ catenin (F) antibodies to pull down protein from the cell lysate from NOD or B6.g7 BMDC. Western blot was then performed using anti- $\beta$-catenin and anti-E-cadherin antibodies. The average ratios of $\beta$-catenin to E-cadherin or E-cadherin to $\beta$-catenin for 3 experiments after using an anti-E-cadherin pulldown $(E)$ or anti- $\beta$-catenin $(G)$ pulldown antibody, respectively, are shown. Cells were treated with $50 \mathrm{uM}$ of MG132 for 12 hours, washed and treated with $2 \mathrm{ug} / \mathrm{mL}$ of cycloheximide or vehicle then lysed. Western 
blot was performed on cell lysates with anti- $\beta$-catenin and anti- $\beta$-actin antibodies $(\mathrm{H})$. The percentages of $\beta$-catenin remaining at each time point were plotted on a logarithmic scale and linear regression performed for vehicle (I) and cycloheximide treatments (J). The equations of the lines are shown in blue (B6.g7) and red (NOD). The $T_{1 / 2}$ values are also displayed on the graphs. The fold change for mono-ubiquitinated $\beta$-catenin as a ratio of non-mono-ubiquitinated- $\beta$-catenin is shown $(\mathrm{K})$. Data are representative of two or more independent experiments. 
A
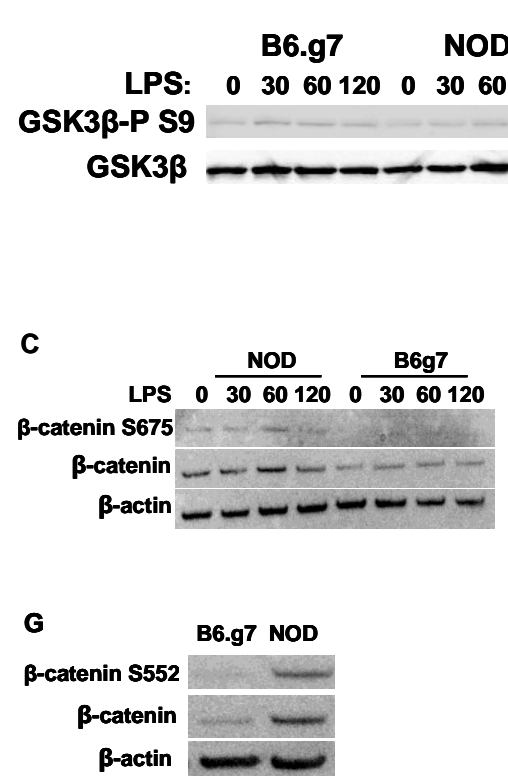

$\mathbf{K}$

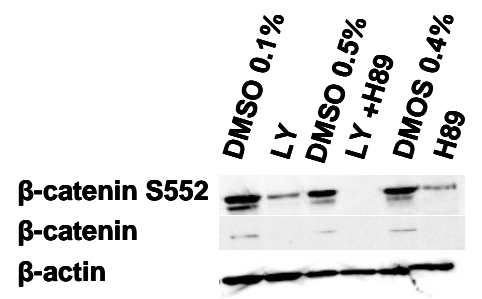

B

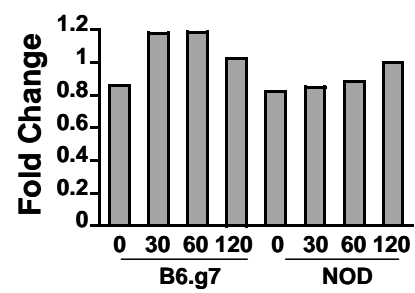

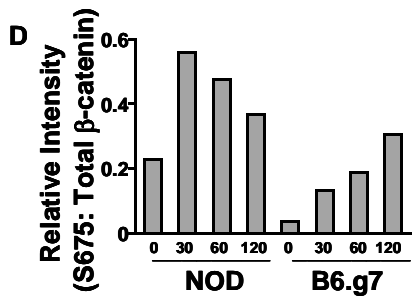

H

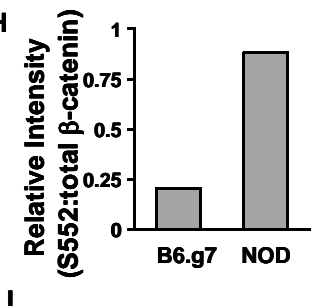

$\mathbf{L}$

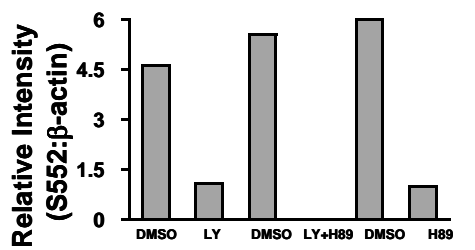

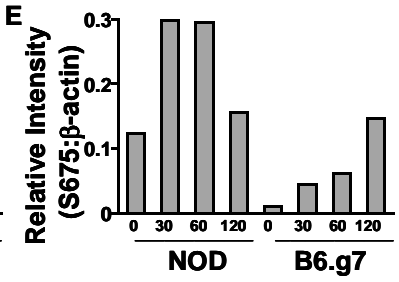
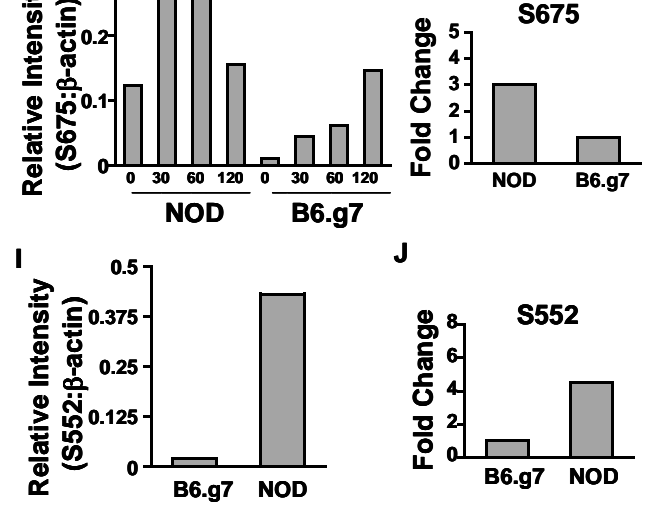

M

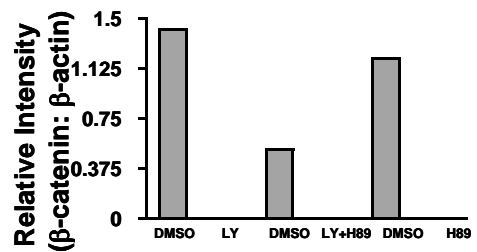

Figure 12: $\beta$-catenin accumulates in NOD BMDC through stabilizing phosphorylations through an Akt and PKA-dependent mechanism. NOD and B6.g7 BMDC were stimulated with $1 \mu \mathrm{g} / \mathrm{mL}$ LPS for $0,30,60$, or 120 minutes. Cells were then lysed and Western blot was performed on cell lysates with anti-phospho-GSK3 $\beta$ and total GSK3 $\beta$ antibodies (A). The fold changes for the ratios of phospho-GSK3 $\beta$ to total GSK $3 \beta$ are shown (B). NOD and B6.g7 BMDC were stimulated with $1 \mu \mathrm{g} / \mathrm{mL}$ LPS for 0 , 30,60 , or 120 minutes. Cells were then lysed and Western blot was performed on cell lysates with anti-phospho- $\beta$-catenin-S675, anti- $\beta$-catenin, and anti- $\beta$-actin antibodies (C) The ratios of phospho- $\beta$-catenin to total $\beta$-catenin (D) and the ratios of phospho- $\beta$ catenin to $\beta$-actin $(\mathrm{E})$ are shown for each time point and for the average of three independent experiments without LPS stimulation (F). NOD and B6.g7 BMDC were lysed and Western blot was performed using anti-phospho- $\beta$-catenin-S552, anti- $\beta$ catenin, and anti- $\beta$-actin antibodies $(\mathrm{G})$. The fold changes for the ratios of phospho- $\beta$ catenin to total $\beta$-catenin $(\mathrm{H})$ and the ratios of phospho- $\beta$-catenin to $\beta$-actin (I) are shown. The average fold change of phosphorylated $\beta$-catenin on residue S552 from three independent experiments from NOD and B6.g7 BMDC is shown (J). NOD and B6.g7 BMDC were treated with LY294002, H89, or a combination of both or DMSO vehicle for 4 hours and then lysed. Western blot was performed using anti-phospho- $\beta$-catenin, 
anti-total- $\beta$-catenin, and anti- $\beta$-actin antibodies $(\mathrm{K})$. The ratios of phospho- $\beta$-catenin to $\beta$-actin (L) and total $\beta$-catenin to $\beta$-actin (M) are shown. Data are representative of two or more independent experiments. 

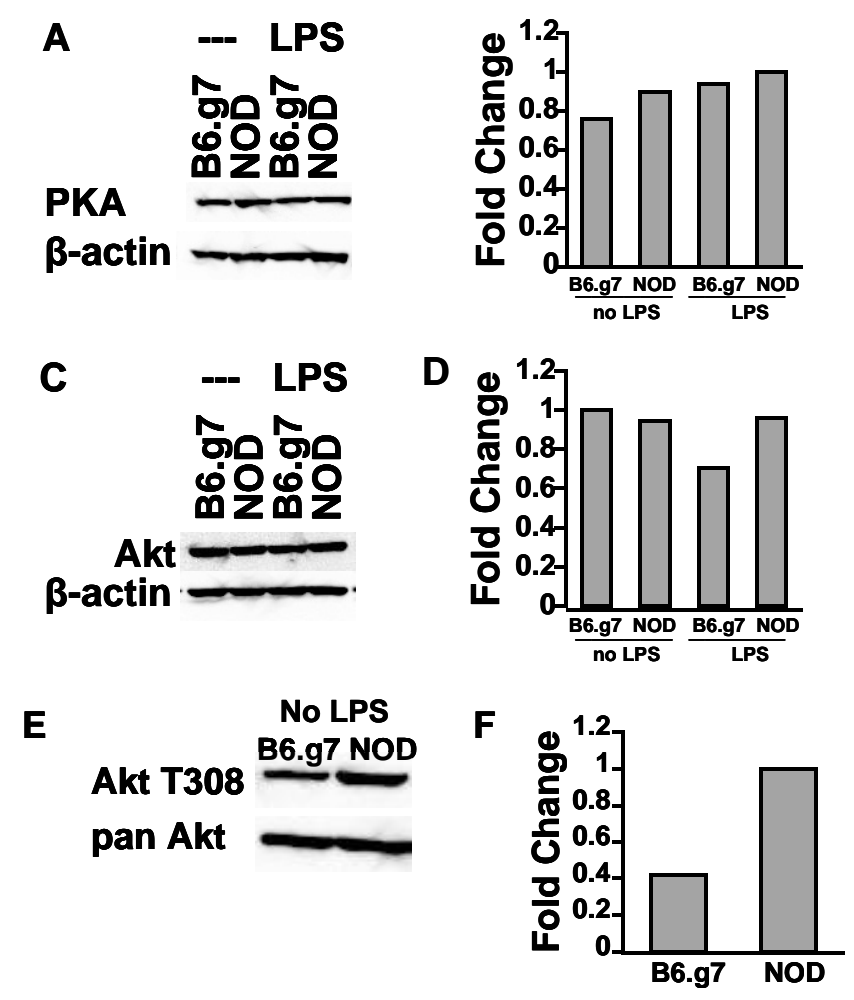

G
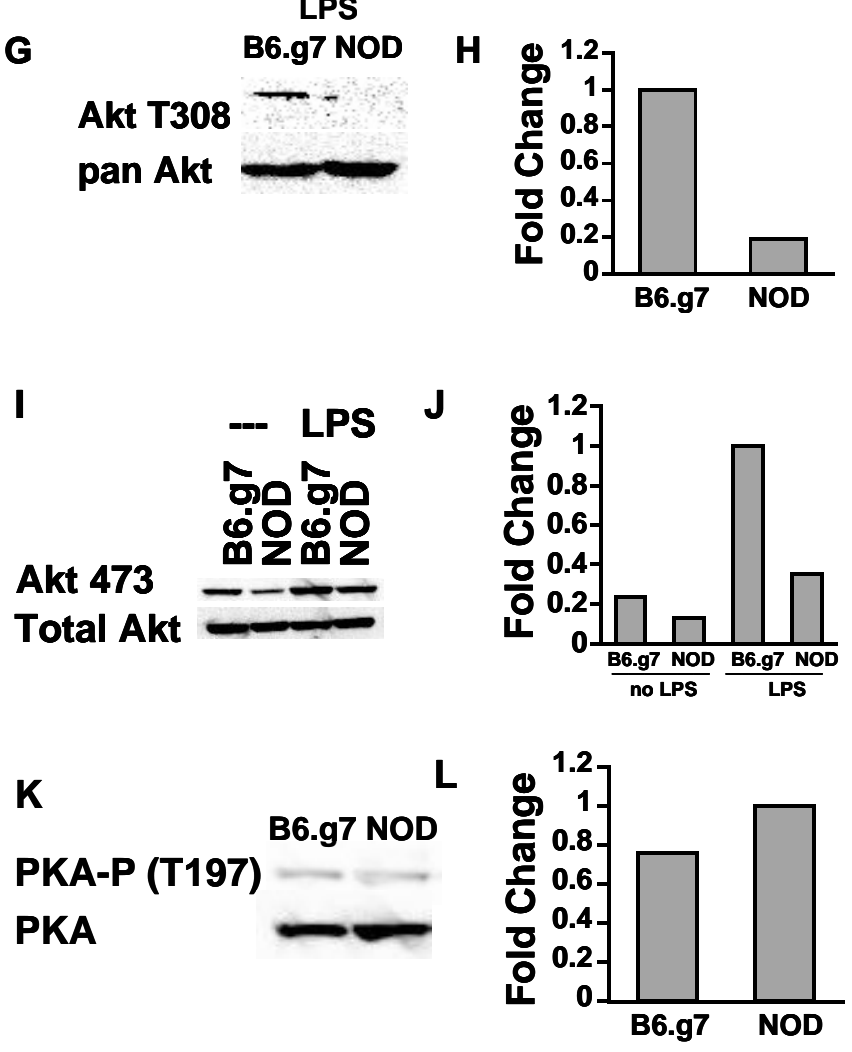
Figure 13. There is no difference in PKA or Akt expression in NOD and B6.g7 BMDC. BMDC were treated with or without LPS for 30 minutes. Western blot was performed on these cell lysates using anti-PKA and anti- $\beta$-actin antibodies (A) or antiAkt and anti- $\beta$-actin antibodies (C). The fold change of PKA expression B) or Akt expression D) is shown. Unstimulated (E) or LPS-stimulated (G) NOD and B6.g7 BMDC were lysed and Western blot was performed using anti-phospho-Akt at Thr308 and anti-pan-Akt antibodies. The fold changes of phospho-Akt to pan-Akt are shown (F) and $(\mathrm{H})$. LPS-stimulated and unstimulated NOD and B6.g7 BMDC were lysed and Western blot was performed using anti-phospho-Akt at Ser473 and anti-pan-Akt antibodies (I) or anti-phospho-PKA and total PKA antibodies (K). The fold changes of phospho-Akt to pan-Akt (J) or phospho-PKA to total PKA (L) are shown. Data are representative of two or more independent experiments. 

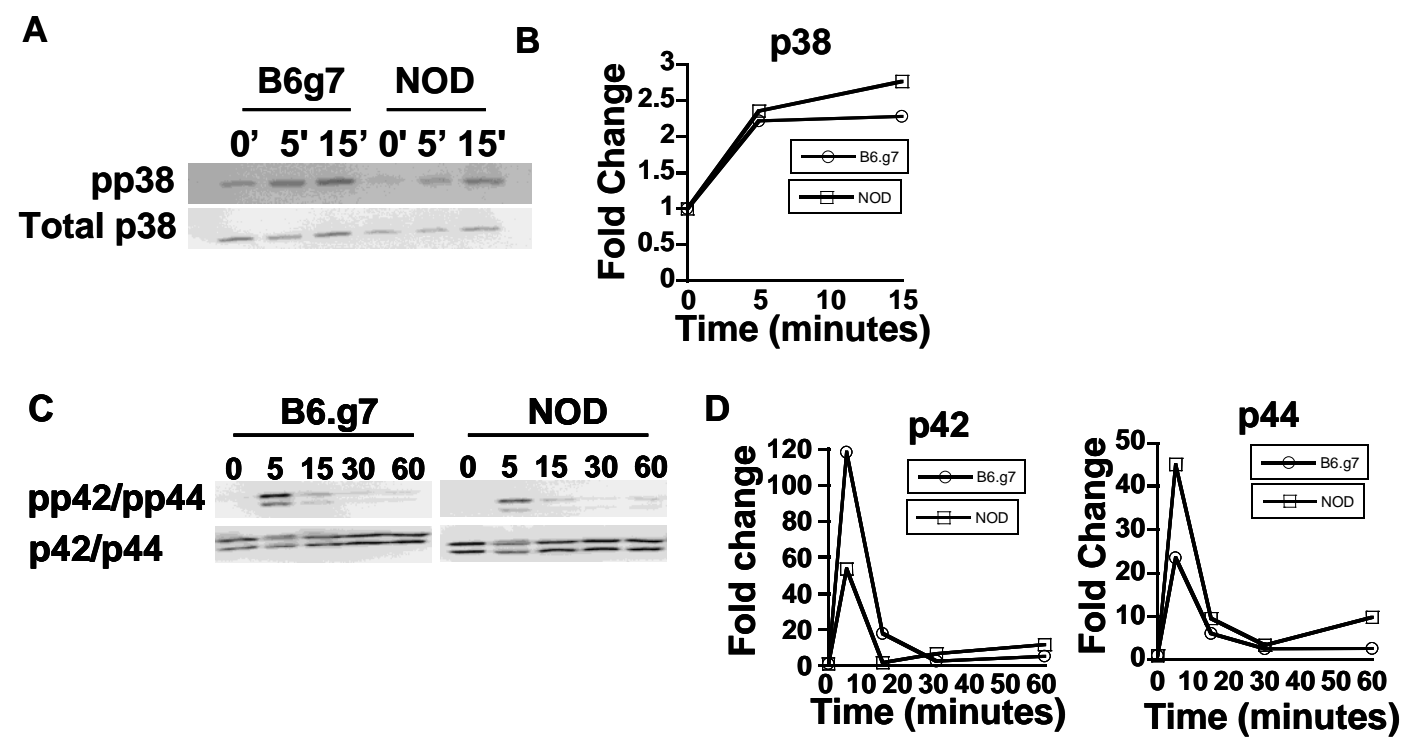

Figure 14: There are no differences in MAPK pathway activation in B6.g7 and NOD BMDC. There are no differences in MAPK pathway activation in B6.g7 and NOD BMDC. B6.g7 and NOD BMDC were stimulated with $1 \mu \mathrm{g} / \mathrm{mL}$ of LPS for 0,5 , or 15 minutes $(\mathrm{A}-\mathrm{B})$ or $0,5,15,30$, or 60 minutes $(\mathrm{C}-\mathrm{F})$ and whole cell lysates extracted. Western blot was then performed using anti-phospho-p38 and anti-p38 antibodies (A-B) or anti-phospho-ERK1/2 and anti-ERK1/2 antibodies (C-D). The fold changes for $\mathrm{p} 38$ (B) or p42 and p44 (D) activation is shown. Data are representative of two or more independent experiments. 
A

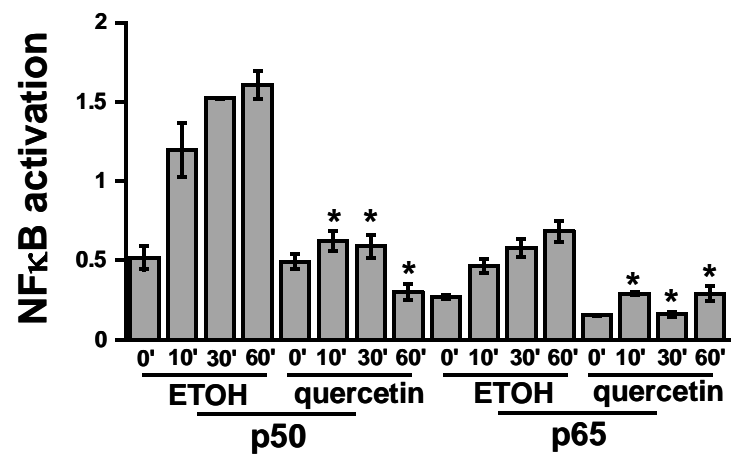

B

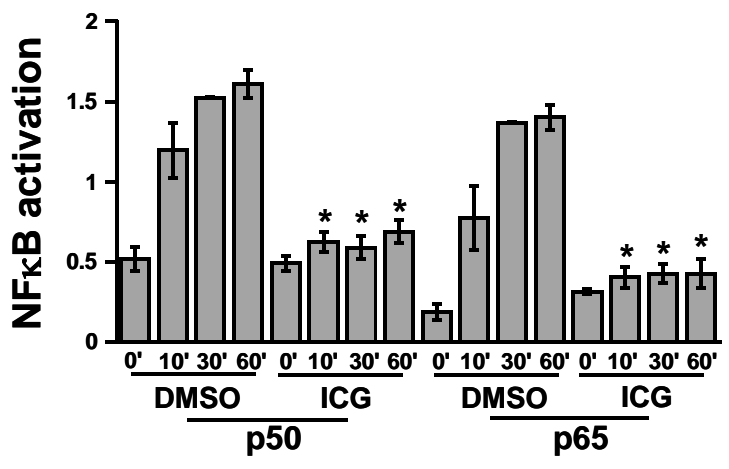

Figure 15: The $\beta$-catenin inhibitors quercetin and ICG-001 reduce NFkB activation in NOD BMDC. NOD BMDC were treated with a $75 \mu \mathrm{M}$ dose of quercetin (A), a 12.5 $\mu \mathrm{M}$ dose of ICG-001 (B) or respective vehicles for $0,10,30$, or 60 minutes. Nuclear lysates were prepared and NFKB activation was measured for both p50 and p65. 


\section{DISCUSSION}

\section{The complex role of $\beta$-catenin in inflammation}

In this study, we have shown that $\beta$-catenin is more highly expressed in NOD BMDC than in BMDC from diabetes-resistant B6.g7 mice and in monocyte-derived DC from diabetic patients as compared to mo-DC from healthy controls. In NOD mice, this defective overexpression occurs in both the cytoplasm and nucleus at various stages of disease including peri-insulitis, insulitis, and full-blown diabetes according to Western blot, confocal microscopy, and FACS analysis, although FACS analysis shows a progressively defective level of $\beta$-catenin expression as the disease progresses suggesting that an increasing number of cells overexpress $\beta$-catenin over the life span of the mice in addition to higher levels of protein being expressed. Overall, these data indicate this novel defect in $\beta$-catenin expression may be a potential prognostic indicator for the development of Type I diabetes.

Additionally, we have shown that inhibition of $\beta$-catenin expression or activity in NOD BMDC results in reduced IL-12 production, while forced expression of $\beta$-catenin or induction of activity in B6.g7 BMDC results in increased IL-12 production. Moreover, in vivo experiments demonstrate that treatment with quercetin, a $\beta$-catenin inhibitor, can reduce diabetes incidence and reduce the inflammatory environment that contributes to disease development. These data demonstrate a potentially important role for $\beta$-catenin 
in the production of a pathogenic cytokine that plays a key role in diabetes development. Therapeutic reductions in the accumulation of $\beta$-catenin or in its transcriptional activity may therefore reduce the pathogenic inflammation important in Type I diabetes.

The role of $\beta$-catenin in inflammation appears to be complex: several studies have pointed to an anti-inflammatory role for $\beta$-catenin $[181,186,213]$ while others have demonstrated a clear pro-inflammatory role for this protein [183-185, 187, 214]. On one hand, $\beta$-catenin has been found to play a role in the production of anti-inflammatory molecules in lamina propria dendritic cells. [181]. Another group of studies have shown that $\beta$-catenin reduces Salmonella-induced inflammation in epithelial cells through an NFkB-dependent mechanism [178] or a mechanism involving inhibition of GSK3 $\beta$-mediated degradation [182]. On the other hand, $\beta$-catenin is also associated with increased inflammatory cytokine production in various cell types. In one study, neutralizing antibody treatment against Wnt5a in mycobacterial products (PPD)-reactive PBMC resulted in reduced IL-12 production by PBMC and reduced IFN $\gamma$ production by T cells [183], suggesting a role for $\beta$-catenin in Th1 cytokine regulation. Other inflammatory cytokines appear to be regulated by $\beta$-catenin signaling as well. $\beta$-catenin modulates IFN $\beta$ production in macrophages in response to VSV infection [184]. Yet another study found that Wnt3A stimulation of microglia, which increases $\beta$-catenin expression, results in the expression of proinflammatory genes and the production of IL6, IL-12, and TNF $\alpha$ [185]. Interestingly, the activation of $\beta$-catenin in APC-/- mice resulted in the induction of a simultaneously pro- and anti-inflammatory environment in the liver [187].

Finally, a group of studies coming from the Halleskog lab have shown that $\beta$ - 
catenin may be pro-inflammatory or anti-inflammatory even in the same cell type. In these studies, Wnt3a signaling leading to $\beta$-catenin stabilization in microglia was found to be associated with Alzheimer's-associated neuroinflammation [185]. However, in another study, the same lab showed that pre-treating mouse microglia with LPS followed by Wnt3a or Wnt5a treatment reduced the inflammatory cytokine response produced by the LPS-treatment, even though Wnt3a or Wnt5a treatment alone induced a proinflammatory response [186]. Therefore, $\beta$-catenin may act as an important master regulator that modulates the pro- versus anti-inflammatory response depending on the cell type, stimulus, and interactions between various stimuli.

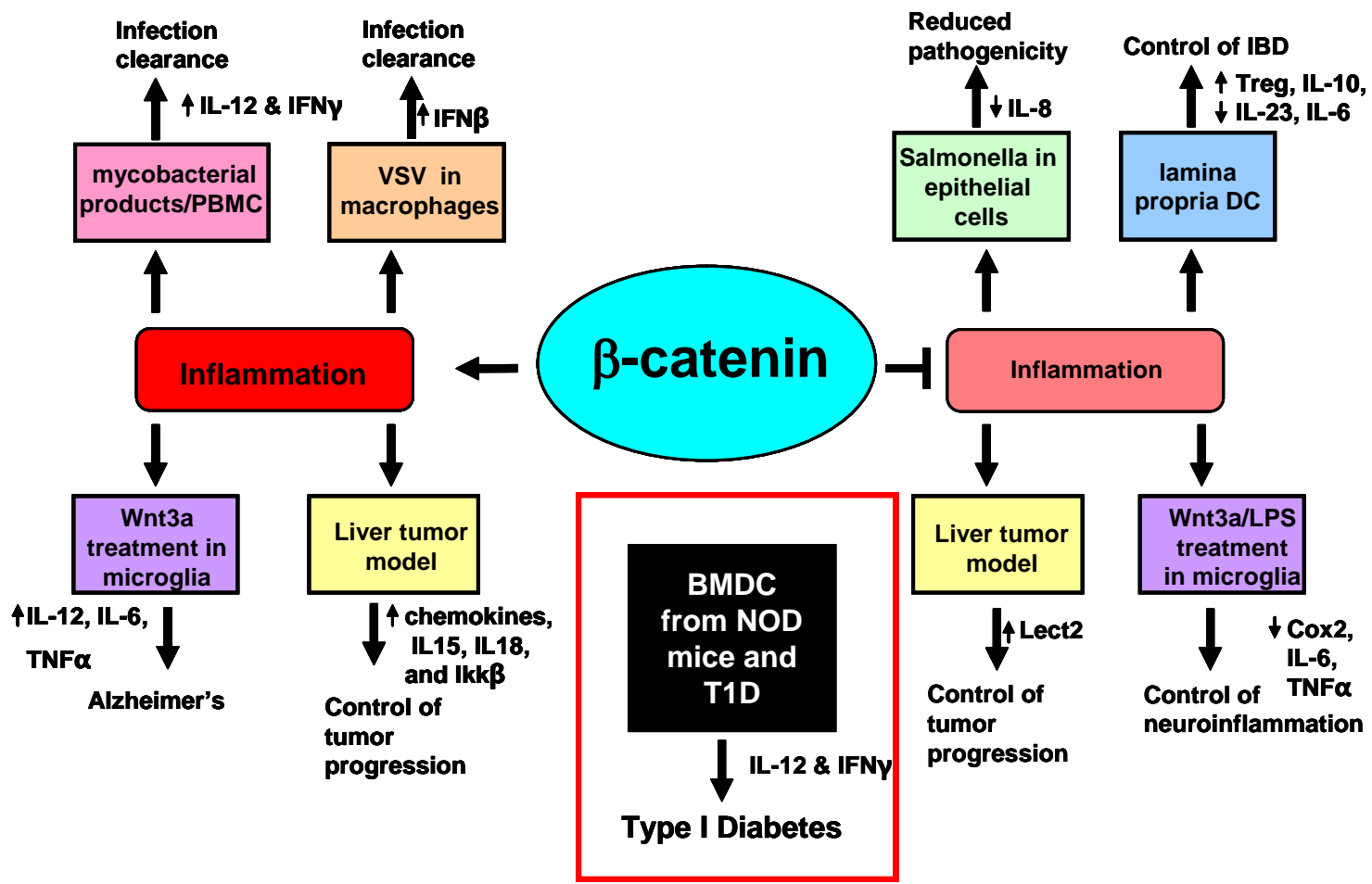

Figure 16. $\beta$-catenin as a master modulator of pro-inflammatory versus antiinflammatory responses. 


\section{Interactions between $\beta$-catenin and other signaling pathways in inflammation and}

\section{Type I diabetes}

The interactions between $\beta$-catenin and other signaling pathways, such as the $\mathrm{NF \kappa B}$ pathway and the MAPK pathways are complex. It has been shown that Wnt3a stimulation of microglia can induce inflammatory responses through the stimulation of both $\beta$-catenin signaling as well as ERK1/2 activation, but through distinct mechanisms [214]. Wnt3a stimulates $\beta$-catenin stabilization through the canonical pathway through the protein Disheveled while also stimulating the MAPK pathway through Phospholipase C. Furthermore, Wnt5a can stimulate ERK activation and inflammation through $\beta$ catenin-independent mechanisms in microglia [215]. Additionally, phosphorylated p38 was observed in infiltrating $\mathrm{CD}^{+} \mathrm{T}$ cells in the pancreas of NOD mice. Treating NOD mice with a p38 inhibitor reduced IFN $\gamma$ production by spleen cells and reduced diabetes incidence without affecting islet infiltration [216]. This study suggests that the p38 pathway may be involved in the pathogenic pro-inflammatory cytokine production that leads to diabetes. However, we found no differences in either p38 or ERK1/2 activation between NOD and B6.g7 BMDC, suggesting that the pro-inflammatory effect of $\beta$ catenin is not mediated through a MAPK-dependent mechanism.

While some studies have shown an inhibitory effect of $\beta$-catenin on NFKB activation [212], others have shown a stimulatory effect [187]. Interestingly, several studies have shown that NFKB signaling is defective in NOD mice leading to increased pro-inflammatory cytokine production $[121,217]$. Our data suggests a new role for $\beta$ catenin in promoting NFאB transcriptional activity in NOD mice. Additionally, our in vivo experiments suggest that inhibiting the activity or expression of $\beta$-catenin can 
downregulate pathogenic pro-inflammatory cytokine production and reduce disease development.

\section{Mechanisms of accumulation of $\beta$-catenin in NOD BMDC}

Determining the mechanisms that result in the accumulation of $\beta$-catenin in NOD BMDC may allow us to identify new targets for the development of therapies for Type I diabetes. We have explored a variety of mechanisms that could lead to $\beta$-catenin overexpression in NOD BMDC. First, we found no differences in mRNA levels, suggesting a lack of transcriptional defect. It has been previously shown that cells in the submandibular glands of NOD mice overexpress E-cadherin, suggesting that defective sequestration of $\beta$-catenin at the cell membrane may be responsible for the accumulation of $\beta$-catenin in NOD BMDC [218]. However, we found no differences in the interaction between these two proteins in NOD BMDC compared to control BMDC. Additionally, when we examined GSK3 $\beta$ phosphorylation at Ser9, which inhibits the ability of the kinase to phosphorylate $\beta$-catenin at the degradation-targeting residues Ser33, Ser37, and Thr41, we found no differences levels of inhibitory phosphorylation between NOD and B6.g7 BMDC. Concordantly, we found no decrease in proteasomal degradation rates in NOD BMDC. In fact it appears that $\beta$-catenin degrades more quickly in NOD BMDC in the presence of a proteasomal inhibitor, suggesting that other degradation pathways, such as the lysosomal pathway, may be involved. Therefore it does not appear that $\beta$-catenin accumulation in NOD BMDC results from a defect in the GSK3 $\beta$-mediated degradation mechanism that regulates $\beta$-catenin expression in the cell.

$\beta$-catenin can be phosphorylated at other residues that lead to stabilization, as 
opposed to degradation. Akt phosphorylates $\beta$-catenin at Ser552 [150] and PKA phosphorylates $\beta$-catenin at Ser552 and Ser675 [156]. Both of these phosphorylations lead to accumulation of $\beta$-catenin and increased transcriptional activity $[150,156]$. We did find that a higher proportion of $\beta$-catenin in NOD BMDC was phosphorylated at the stabilizing residue Ser552 and Ser675 than in B6.g7 BMDC. Interestingly, inhibition of PKA and/or Akt resulted in decreased abundance of phospho- $\beta$-catenin and $\beta$-catenin, indicating that the stabilizing activity of these two kinases are responsible for $\beta$-catenin accumulation in NOD BMDC.

Very few studies on the role of the PI3K/Akt and PKA pathways in Type I diabetes development have been performed. However, one study found that treatment of NOD mice with a PI3K inhibitor, AS605240, led to prevention and reversal of diabetes. Inflammatory cytokine production and IFN $\gamma$-production by splenic cells was decreased while Tregs were expanded with this treatment. Additionally, high levels of phosphorylated total Akt were observed in NOD splenocytes [219]. Interestingly, we found that Akt was phosphorylated at residue Thr308 at higher levels in NOD as compared to B6.g7 BMDC, while Ser473 was phosphorylated at higher levels in B6.g7 cells. The role of phosphorylation of Akt at Thr308 and Ser473 is controversial. It appears that phosphorylation at both Thr308 and Ser473 is necessary for full activity [147, 193]. Phosphorylation at Thr308 may be essential for Akt activity as demonstrated by mutation of this residue leading to low Akt activity [220]. However, another study has shown that phosphorylation at Ser473 may precede and prepare the kinase for phosphorylation at Thr308 [221]. In this study, mutation of Ser473 led to reduced phosphorylation at Thr308. Additionally, phosphorylation at Ser473 may negatively 
regulate phosphorylation at Thr308 as evidence by the fact that knocking out Rictor in the beta cells of mice reduces the level of phosphorylation at Ser473 and greatly increases the level of Thr308 phosphorylation [222]. This high level of phosphorylation at Thr308 and low level at Ser 473 correlated with reduced beta cell mass and insulin secretion. Our data points to a negative regulatory role for Ser473 in which lower levels of phosphorylation of Akt at Ser473 in NOD BMDC may allow for high levels of Thr308 phosphorylation and increased Akt activity. The downstream effect of this increased activity is enhanced stabilization and accumulation of $\beta$-catenin through Ser552 phosphorylation.

Further studies need to be performed to determine the upstream mechanisms leading to these high levels of phosphorylation at Thr308. Possible explanations include defects in expression or activity of PDK1, which is responsible for phosphorylation at Thr308 [147] and/or defects in expression or activity of mTOR, which is responsible for phosphorylation at Ser473 [148]. Additional studies needed to elucidate the mechanisms leading to increased phosphorylation by PKA include examining defects in the levels of cyclic AMP, the molecule responsible for activation of PKA's catalytic subunits. There are also possibly defects in the expression and/or activity of adenylyl cyclase, the protein which converts ATP to cAMP. Finally, in vivo studies using various PKA or Akt inhibitors in NOD mice need to be performed. If Akt and/or PKA activation are responsible for $\beta$-catenin accumulation in NOD BMDC, inhibiting the activity of these molecules in vivo should lead to decreased incidence, increased survival, and a decreased inflammatory environment.

It remains unknown how Akt and/or PKA activity leads to increased phosphorylation of $\beta$-catenin at Ser552 and Ser675 without leading to increased 
phosphorylation of GSK3 $\beta$ at the inhibitory phosphorylation Ser9 in NOD BMDC.

However, it has been proposed that there are two distinct pools of GSK3 $\beta$ in the cell: a pool of free GSK3 $\beta$ that is susceptible to inhibitory phosphorylation by Akt and an axincomplexed pool that is protected from phosphorylation by Akt [223]. It is possible that BMDC contain high levels of Axin-complexed GSK3 $\beta$ that is not available for phosphorylation by Akt and/or PKA. This would allow for phosphorylation and stabilization of $\beta$-catenin by highly active Akt and PKA without affecting the level of phosphorylated GSK3 $\beta$ at Ser9.

\section{Unexplored mechanisms of $\beta$-catenin accumulation in NOD BMDC}

There are other mechanisms that we did not explore that may also contribute to $\beta$ catenin accumulation and enhanced transcriptional activity in NOD BMDC, including $\beta$ catenin acetylation, defective lysosomal degradation of $\beta$-catenin, and defective exosomal export of $\beta$-catenin. Several studies have shown acetylation of $\beta$-catenin at various residues. Acetylation of Lys4 has been linked to negative regulation of transcriptional activity of $\beta$-catenin [224], while acetylation of Lys345 results in increased affinity of $\beta$-catenin for Tcf4, which could contribute to increased transcriptional activity of $\beta$-catenin [225]. A third study showed that high glucose treatment of cells increased $\beta$-catenin acetylation at Lys345 which resulted in increased nuclear accumulation and transcriptional activity [226]. $\beta$-catenin in NOD BMDC may have defects in acetylation at either of these residues leading to increased nuclear translocation and increased transcriptional activity resulting in increased proinflammatory cytokine production. 
Another possible mechanism by which $\beta$-catenin may accumulate includes defects in lysosomal degradation. Several studies have documented the ability of the lysosome to degrade $\beta$-catenin in a GSK-3/proteasome-independent mechanism. In one study, a tea polyphenol induced lysosomal accumulation of excess $\beta$-catenin in a colon cancer model [227]. Another study demonstrated that Notch signaling in stem cells resulted in negative regulation of active $\beta$-catenin (non-phosphorylated at Ser33, 37 and Thr41) through a lysosomal-dependent pathway [228]. Colocalization studies of $\beta$ catenin and the lysosome may reveal decreased lysosomal targeting of $\beta$-catenin in NOD BMDC or reduced ability of the lysosome to degrade excess $\beta$-catenin.

Additionally, it has been shown that CD82 and CD9 induce $\beta$-catenin export from HEK239 cells and dendritic cells through exosomes [229]. Therefore, NOD BMDC may have defects in exosomal export of excess $\beta$-catenin as compared to B6.g7 cells.

\section{$\beta$-catenin in human monocyte-derived DC and human Type I diabetes}

$\beta$-catenin is also overexpressed in human mo-DC from diabetic patients as compared to healthy controls. Similar to the experiments in NOD mice, we found that inhibiting the expression of $\beta$-catenin with siRNA or the activity of $\beta$-catenin with quercetin resulted in decreased pro-inflammatory cytokine production. These data indicate that $\beta$-catenin may play an important role in human patients as well as in mice and suggests that treatments targeting $\beta$-catenin could be effective for human patients. Because we could only delay diabetes in NOD mice treated with quercetin or $\beta$-catenin siRNA-transfected DC, simply reducing the inflammatory environment in Type I diabetes individuals may not be sufficient. Therefore it may be necessary to reduce $\beta$-catenin 
accumulation or activity in combination with other treatments, such as those aimed at increasing tolerance. These possible treatments include administration of Lactobacilli that induce the regulatory cytokine IL-10 [230] or transfer of Tregs [231], or anti-CD3 treatment [21]. However, inhibiting pathways upstream of $\beta$-catenin may achieve both as shown in the study inhibiting PI3K [219]. Inhibiting $\beta$-catenin expression or activity as a therapeutic strategy for preventing or treating Type I diabetes may provide several advantages, including the specific reduction of IL-12, the hallmark pathogenic cytokine involved in Type I diabetes.

\section{Conclusion}
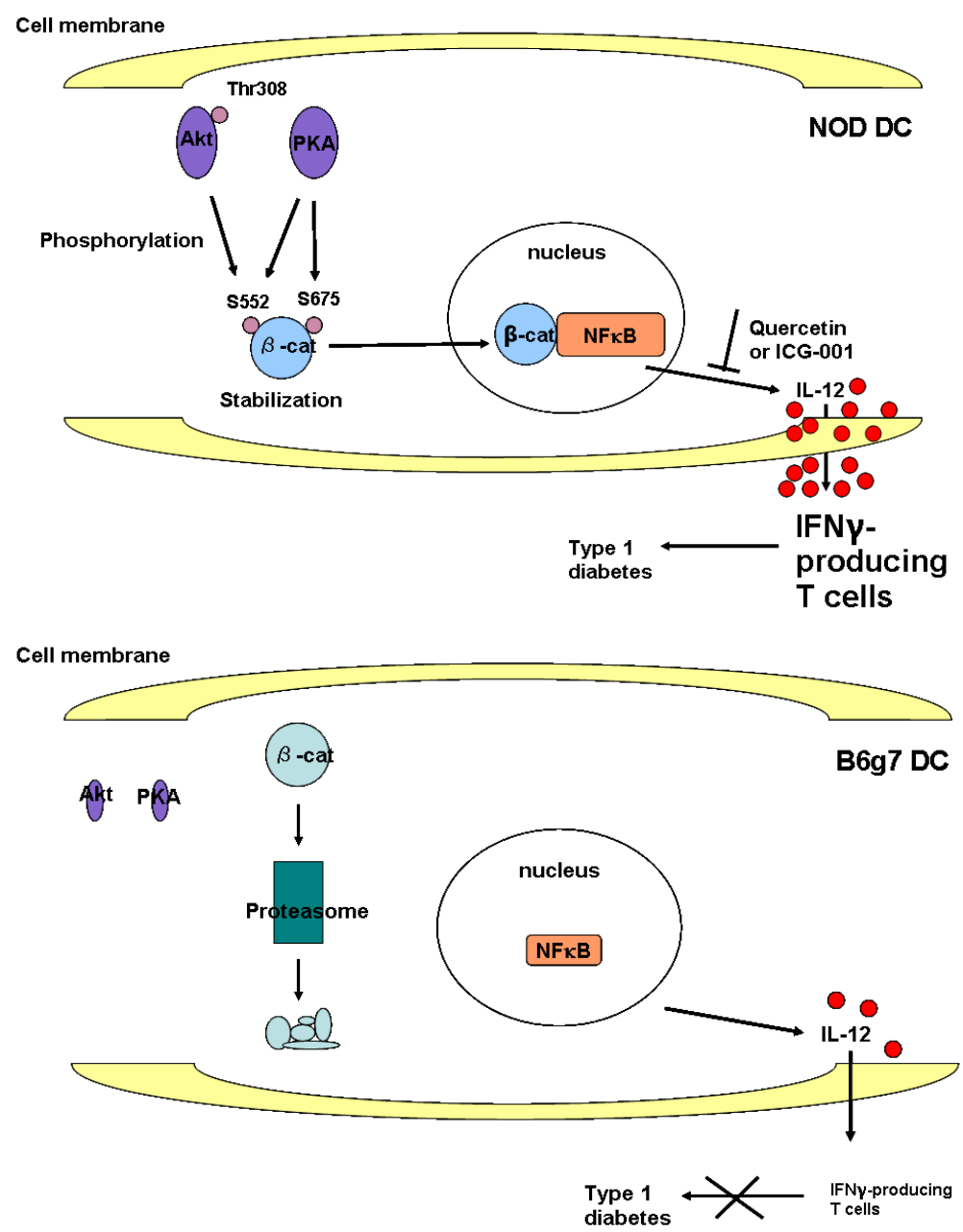
Figure 17. A scenario leading to $\beta$-catenin accumulation and pro-inflammatory cytokine production in NOD BMDC but not B6.g7 BMDC.

Overall, we have found that overexpression of $\beta$-catenin in NOD BMDC leads to increased pathogenic pro-inflammatory cytokine production and inhibiting $\beta$-catenin activity in vivo leads to a decrease in the pro-inflammatory environment. $\beta$-catenin accumulates as a result of increased phosphorylation of Akt at Thr308, which leads to increased phosphorylation of $\beta$-catenin at the stabilizing residue Ser552 and Ser675. Additionally, $\beta$-catenin accumulation leads to increased pro-inflammatory cytokine production through an NFKB-dependent mechanism. 


\section{REFERENCES}

1. Barker, J.M., Type 1 Diabetes-Associated Autoimmunity: Natural History, Genetic Associations, and Screening. Journal of Clinical Endocrinology \& Metabolism, 2006. 91(4): p. 1210-1217 J2 - JCEM LA - en.

2. van Belle, T.L., K.T. Coppieters, and M.G. von Herrath, Type 1 diabetes: etiology, immunology, and therapeutic strategies. Physiological reviews, 2011.91(1): p. 79-118 J2 - Physiol. Rev. LA - eng.

3. Hauer, A.D., et al., Blockade of interleukin-12 function by protein vaccination attenuates atherosclerosis. Circulation, 2005. 112(7): p. 1054-1062 J2 Circulation.

4. Devaraj, S., et al., Evidence of increased inflammation and microcirculatory abnormalities in patients with type 1 diabetes and their role in microvascular complications. Diabetes, 2007. 56(11): p. 2790-2796 J2 - Diabetes.

5. Bettini, M. and D.A.A. Vignali, T cell-driven initiation and propagation of autoimmune diabetes. Current opinion in immunology, 2011. 23(6): p. 754-760 J2 - Curr. Opin. Immunol.

6. Bending, D., P. Zaccone, and A. Cooke, Inflammation and type one diabetes. International Immunology DA - 2012/06/01/, 2012. 24(6): p. 339-346 J2 - Int. Immunol. LA - en.

7. Serreze, D.V., et al., B lymphocytes are essential for the initiation of T cellmediated autoimmune diabetes: analysis of a new "speed congenic" stock of NOD.Ig mu null mice. The Journal of experimental medicine, 1996. 184(5): p. 2049-2053 J2 - J. Exp. Med. LA - eng.

8. Daugherty, R.L. and C.J. Gottardi, Phospho-regulation of Beta-catenin adhesion and signaling functions. Physiology (Bethesda, Md.), 2007. 22: p. 303-309 J2 Physiology (Bethesda).

9. $\quad$ Pinkse, G.G.M., et al., Autoreactive CD8 T cells associated with beta cell destruction in type 1 diabetes. Proceedings of the National Academy of Sciences of the United States of America, 2005. 102(51): p. 18425-18430 J2 - Proc. Natl. Acad. Sci. U.S.A. LA - eng.

10. Hamilton-Williams, E.E., et al., Beta cell MHC class I is a late requirement for diabetes. Proceedings of the National Academy of Sciences of the United States of America, 2003. 100(11): p. 6688-6693 J2 - Proc. Natl. Acad. Sci. U.S.A. LA eng.

11. Christianson, S.W., L.D. Shultz, and E.H. Leiter, Adoptive transfer of diabetes into immunodeficient NOD-scid/scid mice. Relative contributions of CD4+ and CD8+ T-cells from diabetic versus prediabetic NOD.NON-Thy-1a donors. Diabetes, 1993. 42(1): p. 44-55 J2 - Diabetes LA - eng. 
12. Phillips, J.M., et al., Type 1 Diabetes Development Requires Both CD4+ and CD8+ T cells and Can Be Reversed by Non-Depleting Antibodies Targeting Both T Cell Populations. The Review of Diabetic Studies : RDS, 2009. 6(2): p. 97-103 J2 - Rev Diabet Stud.

13. Anderson, M.S. and J.A. Bluestone, THE NOD MOUSE: A Model of Immune Dysregulation. Annual Review of Immunology, 2005. 23(1): p. 447-485 ST THE NOD MOUSE.

14. Xu, P., et al., Prognostic Performance of Metabolic Indexes in Predicting Onset of Type 1 Diabetes. Diabetes Care, 2010. 33(12): p. 2508-2513 J2 - Dia Care LA en.

15. Steck, A.K., et al., Age of Islet Autoantibody Appearance and Mean Levels of Insulin, but Not GAD or IA-2 Autoantibodies, Predict Age of Diagnosis of Type 1 Diabetes Diabetes Autoimmunity Study in the Young. Diabetes Care, 2011. 34(6): p. 1397-1399 J2 - Dia Care LA - en.

16. Ziegler, A.G., Seroconversion to Multiple Islet Autoantibodies and Risk of Progression to Diabetes in Children;Seroconversion and Diabetes Progression in Children. JAMA DA - 2013/06/19/, 2013. 309(23).

17. Hayward, A.R. and M. Shreiber, Neonatal injection of CD3 antibody into nonobese diabetic mice reduces the incidence of insulitis and diabetes. Journal of immunology (Baltimore, Md.: 1950), 1989. 143(5): p. 1555-1559 J2 - J. Immunol. LA - eng.

18. Hayward, A.R. and M. Shriber, Reduced incidence of insulitis in NOD mice following anti-CD3 injection: requirement for neonatal injection. Journal of autoimmunity, 1992. 5(1): p. 59-67 J2 - J. Autoimmun. LA - eng.

19. Chatenoud, L., J. Primo, and J.F. Bach, CD3 antibody-induced dominant self tolerance in overtly diabetic NOD mice. Journal of immunology (Baltimore, Md.: 1950), 1997. 158(6): p. 2947-2954 J2 - J. Immunol. LA - eng.

20. Chatenoud, L., et al., [Remission of established disease in diabetic NOD mice induced by anti-CD3 monoclonal antibody]. Comptes rendus de l'Acadamie des sciences. Sacrie III, Sciences de la vie, 1992. 315(6): p. 225-228 J2 - C. R. Acad. Sci. III, Sci. Vie LA - fre.

21. Chatenoud, L., et al., Anti-CD3 antibody induces long-term remission of overt autoimmunity in nonobese diabetic mice. Proceedings of the National Academy of Sciences of the United States of America, 1994. 91(1): p. 123-127 J2 - Proc. Natl. Acad. Sci. U.S.A. LA - eng.

22. Mottram, P.L., et al., Remission and pancreas isograft survival in recent onset diabetic NOD mice after treatment with low-dose anti-CD3 monoclonal antibodies. Transplant immunology, 2002. 10(1): p. 63-72 J2 - Transpl. Immunol. LA - eng.

23. Shoda, L.K.M., et al., A Comprehensive Review of Interventions in the NOD Mouse and Implications for Translation. Immunity, 2005. 23(2): p. 115-126 J2 Immunity.

24. Ramiya, V.K., et al., Effect of oral and intravenous insulin and glutamic acid decarboxylase in NOD mice. Autoimmunity, 1997. 26(3): p. 139-151 J2 Autoimmunity LA - eng.

25. Herold, K.C., et al., A Single Course of Anti-CD3 Monoclonal Antibody 
hOKT3gammal(Ala-Ala) Results in Improvement in C-Peptide Responses and Clinical Parameters for at Least 2 Years after Onset of Type 1 Diabetes. Diabetes, 2005. 54(6): p. 1763-1769 J2 - Diabetes LA - en.

26. Herold, K.C., et al., Anti-CD3 Monoclonal Antibody in New-Onset Type 1 Diabetes Mellitus. New England Journal of Medicine, 2002. 346(22): p. 16921698.

27. Keymeulen, B., et al., Insulin Needs after CD3-Antibody Therapy in New-Onset Type 1 Diabetes. New England Journal of Medicine, 2005. 352(25): p. 2598-2608.

28. Wilson, C., Diabetes: Anti-CD3 antibody therapy for type 1 diabetes mellitus: outcome 4 years after treatment. Nature Reviews Endocrinology DA 2010/05//print, 2010. 6(5): p. 242-242 J2 - Nat Rev Endocrinol LA - en.

29. Vehik, K., et al., Long-Term Outcome of Individuals Treated With Oral Insulin Diabetes Prevention Trial Type 1 (DPT-1) oral insulin trial. Diabetes Care DA 2011/07/01/, 2011. 34(7): p. 1585-1590 J2 - Dia Care LA - en.

30. Roep, B.O., et al., Plasmid-Encoded Proinsulin Preserves C-Peptide While Specifically Reducing Proinsulin-Specific CD8+ T Cells in Type 1 Diabetes. Science Translational Medicine, 2013. 5(191): p. 191ra82-191ra82 J2 - Sci Trans1 Med LA - en.

31. Ludvigsson, J., et al., GAD65 Antigen Therapy in Recently Diagnosed Type 1 Diabetes Mellitus. New England Journal of Medicine DA - 2012/02/02/, 2012. 366(5): p. 433-442.

32. Mathieu, C., et al., Prevention of autoimmune diabetes in NOD mice by 1,25 dihydroxyvitamin D3. Diabetologia, 1994. 37(6): p. 552-558 J2 - Diabetologia.

33. D'Ambrosio, D., et al., Inhibition of IL-12 production by 1,25-dihydroxyvitamin D3. Involvement of NF-kappaB downregulation in transcriptional repression of the p40 gene. The Journal of clinical investigation, 1998. 101(1): p. 252-262 J2 J. Clin. Invest.

34. Heuberger, J. and W. Birchmeier, Interplay of cadherin-mediated cell adhesion and canonical Wnt signaling. Cold Spring Harbor perspectives in biology, 2010. 2(2 J2 - Cold Spring Harb Perspect Biol).

35. Marjamaki, L., et al., Maternal intake of vitamin D during pregnancy and risk of advanced beta cell autoimmunity and type 1 diabetes in offspring. Diabetologia, 2010. 53(8): p. 1599-1607 J2 - Diabetologia.

36. Tang, Q., et al., In Vitro expanded Antigen-specific Regulatory T Cells Suppress Autoimmune Diabetes. The Journal of Experimental Medicine, 2004. 199(11): p. 1455-1465 J2 - J Exp Med LA - en.

37. Tarbell, K.V., et al., CD25+CD4+ T Cells, Expanded with Dendritic Cells Presenting a Single Autoantigenic Peptide, Suppress Autoimmune Diabetes. The Journal of Experimental Medicine, 2004. 199(11): p. 1467-1477 J2 - J Exp Med LA - en.

38. Marek-Trzonkowska, N., et al., Administration of CD4+CD25highCD127regulatory $T$ cells preserves $\hat{I}^{2}$-cell function in type 1 diabetes in children. Diabetes care, 2012. 35(9): p. 1817-1820 J2 - Diabetes Care LA - eng.

39. Kikutani, H. and S. Makino, The Murine Autoimmune Diabetes Model: NOD and Related Strains, in Advances in Immunology, F.J. Dixon, Editor. 1992, Academic Press. p. 285-322. 
40. Kriegel, M.A., et al., Naturally transmitted segmented filamentous bacteria segregate with diabetes protection in nonobese diabetic mice. Proceedings of the National Academy of Sciences, 2011. 108(28): p. 11548-11553 J2 - PNAS LA en.

41. Boitard, C., Pancreatic islet autoimmunity. La Presse Medicale, 2012. 41(12, Part 2): p. e636-e650 J2 - La Presse Medicale.

42. Xing, Y. and K.A. Hogquist, T-Cell Tolerance: Central and Peripheral. Cold Spring Harbor Perspectives in Biology, 2012. 4(6 J2 - Cold Spring Harb Perspect Biol LA - en).

43. Jaeckel, E., et al., Role of Regulatory T Cells for the Treatment of Type 1 Diabetes Mellitus. Hormone and Metabolic Research DA - 2008/02//, 2008. 40(2): p. 126136.

44. Sharif, S., et al., Activation of natural killer T cells by alpha-galactosylceramide treatment prevents the onset and recurrence of autoimmune Type 1 diabetes. Nature medicine, 2001. 7(9): p. 1057-1062 J2 - Nat. Med.

45. Hong, S., et al., The natural killer T-cell ligand beta-galactosylceramide prevents autoimmune diabetes in non-obese diabetic mice. Nature Medicine DA 2001/09/01/, 2001. 7(9): p. 1052-1056 LA - en.

46. Salomon, B., et al., B7/CD28 costimulation is essential for the homeostasis of the CD4+CD25+ immunoregulatory $T$ cells that control autoimmune diabetes. Immunity, 2000. 12(4): p. 431-440 J2 - Immunity.

47. D'Angeli, M.A., et al., ENVIRONMENTAL FACTORS ASSOCIATED WITH CHILDHOOD-ONSET TYPE I DIABETES: AN EXPLORATION OF THE HYGIENE AND OVERLOAD HYPOTHESES. Archives of pediatrics \& adolescent medicine, 2010. 164(8): p. 732-738 J2 - Arch Pediatr Adolesc Med.

48. Gregori, S., et al., Dynamics of pathogenic and suppressor T cells in autoimmune diabetes development. Journal of immunology (Baltimore, Md.: 1950), 2003. 171(8): p. 4040-4047 J2 - J. Immunol.

49. Tritt, M., et al., Functional Waning of Naturally Occurring CD4+ Regulatory TCells Contributes to the Onset of Autoimmune Diabetes. Diabetes, 2008. 57(1): p. 113-123 J2 - Diabetes LA - en.

50. Berzins, S.P., et al., T-cell compartments of prediabetic NOD mice. Diabetes, 2003. 52(2): p. 327-334 J2 - Diabetes LA - eng.

51. You, S., et al., Autoimmune diabetes onset results from qualitative rather than quantitative age-dependent changes in pathogenic T-cells. Diabetes, 2005. 54(5): p. 1415-1422 J2 - Diabetes LA - eng.

52. Kukreja, A., et al., Multiple immuno-regulatory defects in type-1 diabetes. The Journal of clinical investigation, 2002. 109(1): p. 131-140 J2 - J. Clin. Invest. LA - eng.

53. Brusko, T.M., et al., Functional defects and the influence of age on the frequency of CD4+ CD25+ T-cells in type 1 diabetes. Diabetes, 2005. 54(5): p. 1407-1414 J2 - Diabetes LA - eng.

54. Putnam, A.L., et al., CD4+CD25high regulatory T cells in human autoimmune diabetes. Journal of autoimmunity, 2005. 24(1): p. 55-62 J2 - J. Autoimmun. LA - eng.

55. Lindley, S., et al., Defective suppressor function in CD4(+)CD25(+) T-cells from 
patients with type 1 diabetes. Diabetes, 2005. 54(1): p. 92-99 J2 - Diabetes LA eng.

56. Bacchetta, R., et al., Defective regulatory and effector $T$ cell functions in patients with FOXP3 mutations. The Journal of clinical investigation, 2006. 116(6): p. 1713-1722 J2 - J. Clin. Invest. LA - eng.

57. Wildin, R.S., et al., X-linked neonatal diabetes mellitus, enteropathy and endocrinopathy syndrome is the human equivalent of mouse scurfy. Nature genetics, 2001. 27(1): p. 18-20 J2 - Nat. Genet. LA - eng.

58. Villasenor, J., C. Benoist, and D. Mathis, AIRE and APECED: molecular insights into an autoimmune disease. Immunological reviews, 2005. 204: p. 156-164 J2 Immunol. Rev. LA - eng.

59. Eerligh, P., et al., No extreme genetic risk for type 1 diabetes among DR3/4-DQ8 siblings sharing both extended HLA haplotypes with their diabetic proband. Tissue antigens, 2011. 77(4): p. 338-340 J2 - Tissue Antigens LA - eng.

60. Robles, D.T., et al., Millennium award recipient contribution. Identification of children with early onset and high incidence of anti-islet autoantibodies. Clinical immunology (Orlando, Fla.), 2002. 102(3): p. 217-224 J2 - Clin. Immunol. LA eng.

61. Erlich, H., et al., HLA DR-DQ haplotypes and genotypes and type 1 diabetes risk: analysis of the type 1 diabetes genetics consortium families. Diabetes, 2008. 57(4): p. 1084-1092 J2 - Diabetes LA - eng.

62. Atkinson, M.A., Thirty Years of Investigating the Autoimmune Basis for Type 1 Diabetes Why Can't We Prevent or Reverse This Disease? Diabetes DA 2005/05/01/, 2005. 54(5): p. 1253-1263 J2 - Diabetes LA - en.

63. Bell, G.I., S. Horita, and J.H. Karam, A polymorphic locus near the human insulin gene is associated with insulin-dependent diabetes mellitus. Diabetes, 1984. 33(2): p. 176-183 J2 - Diabetes LA - eng.

64. Wu, J., et al., Identification of substrates of human protein-tyrosine phosphatase PTPN22. The Journal of biological chemistry, 2006. 281(16): p. 11002-11010 J2 - J. Biol. Chem. LA - eng.

65. Waterhouse, P., et al., Lymphoproliferative disorders with early lethality in mice deficient in Ctla-4. Science (New York, N.Y.), 1995. 270(5238): p. 985-988 J2 Science LA - eng.

66. Nistico, L., et al., The CTLA-4 gene region of chromosome $2 q 33$ is linked to, and associated with, type 1 diabetes. Belgian Diabetes Registry. Human molecular genetics, 1996. 5(7): p. 1075-1080 J2 - Hum. Mol. Genet. LA - eng.

67. Ueda, H., et al., Association of the T-cell regulatory gene CTLA4 with susceptibility to autoimmune disease. Nature, 2003. 423(6939): p. 506-511 J2 Nature LA - eng.

68. Lowe, C.E., et al., Large-scale genetic fine mapping and genotype-phenotype associations implicate polymorphism in the IL2RA region in type 1 diabetes. Nature genetics, 2007. 39(9): p. 1074-1082 J2 - Nat. Genet. LA - eng.

69. Vella, A., et al., Localization of a type 1 diabetes locus in the IL2RA/CD25 region by use of tag single-nucleotide polymorphisms. American journal of human genetics, 2005. 76(5): p. 773-779 J2 - Am. J. Hum. Genet. LA - eng.

70. Sykora, K.W., et al., Human interleukin 2 gene is located on chromosome 4. 
Cancer investigation, 1984. 2(4): p. 261-265 J2 - Cancer Invest. LA - eng.

71. Liu, S., et al., IFIH1 polymorphisms are significantly associated with type 1 diabetes and IFIHI gene expression in peripheral blood mononuclear cells. Human molecular genetics, 2009. 18(2): p. 358-365 J2 - Hum. Mol. Genet. LA eng.

72. Nejentsev, S., et al., Rare variants of IFIH1, a gene implicated in antiviral responses, protect against type 1 diabetes. Science (New York, N.Y.), 2009. 324(5925): p. 387-389 J2 - Science LA - eng.

73. Wicker, L.S., et al., Fine mapping, gene content, comparative sequencing, and expression analyses support Ctla4 and Nrampl as candidates for Idd5.1 and Idd5.2 in the nonobese diabetic mouse. Journal of immunology (Baltimore, Md.: 1950), 2004. 173(1): p. 164-173 J2 - J. Immunol. LA - eng.

74. Lyons, P.A., et al., Congenic mapping of the type 1 diabetes locus, Idd3, to a 780$\mathrm{kb}$ region of mouse chromosome 3: identification of a candidate segment of ancestral DNA by haplotype mapping. Genome research, 2000. 10(4): p. 446-453 $\mathrm{J} 2$ - Genome Res. LA - eng.

75. Zheng, P. and S. Kissler, PTPN22 silencing in the NOD model indicates the type 1 diabetes-associated allele is not a loss-of-function variant. Diabetes, 2013. 62(3): p. 896-904 J2 - Diabetes LA - eng.

76. Kyvik, K.O., A. Green, and H. Beck-Nielsen, Concordance rates of insulin dependent diabetes mellitus: a population based study of young Danish twins. BMJ DA - 1995/10/07/, 1995. 311(7010): p. 913-917.

77. Derraik, J.G.B., et al., Increasing Incidence and Age at Diagnosis among Children with Type 1 Diabetes Mellitus over a 20-Year Period in Auckland (New Zealand). PLoS ONE, 2012. 7(2 J2 - PLoS One).

78. Yoon, J.W., et al., Isolation of a virus from the pancreas of a child with diabetic ketoacidosis. The New England journal of medicine, 1979. 300(21): p. 1173-1179 J2 - N. Engl. J. Med.

79. Huber, A.H., et al., The cadherin cytoplasmic domain is unstructured in the absence of beta-catenin. A possible mechanism for regulating cadherin turnover. The Journal of biological chemistry, 2001. 276(15): p. 12301-12309 J2 - J. Biol. Chem.

80. Yeung, W.-C.G., W.D. Rawlinson, and M.E. Craig, Enterovirus infection and type 1 diabetes mellitus: systematic review and meta-analysis of observational molecular studies. BMJ DA - 2011/02/03/, 2011. 342(feb03 1): p. d35.

81. Dahlquist, G., et al., Indications that maternal coxsackie B virus infection during pregnancy is a risk factor for childhood-onset IDDM. Diabetologia, 1995. 38(11): p. 1371-1373 J2 - Diabetologia LA - eng.

82. Hyoty, H., et al., A prospective study of the role of coxsackie B and other enterovirus infections in the pathogenesis of IDDM. Childhood Diabetes in Finland (DiMe) Study Group. Diabetes, 1995. 44(6): p. 652-657 J2 - Diabetes LA - eng.

83. Elfving, M., et al., Maternal enterovirus infection during pregnancy as a risk factor in offspring diagnosed with type 1 diabetes between 15 and 30 years of age. Experimental diabetes research, 2008. 2008 J2 - Exp Diabetes Res LA eng. 
84. Dotta, F., et al., Coxsackie B4 virus infection of beta cells and natural killer cell insulitis in recent-onset type 1 diabetic patients. Proceedings of the National Academy of Sciences, 2007. 104(12): p. 5115-5120 J2 - PNAS LA - en.

85. Tracy, S., et al., Toward testing the hypothesis that group B coxsackieviruses $(C V B)$ trigger insulin-dependent diabetes: inoculating nonobese diabetic mice with CVB markedly lowers diabetes incidence. Journal of virology, 2002. 76(23): p. 12097-12111 J2 - J. Virol. LA - eng.

86. Kaufman, D.L., et al., Autoimmunity to two forms of glutamate decarboxylase in insulin-dependent diabetes mellitus. The Journal of clinical investigation, 1992. 89(1): p. 283-292 J2 - J. Clin. Invest. LA - eng.

87. Tracy, S., K.M. Drescher, and N.M. Chapman, Enteroviruses and type 1 diabetes. Diabetes/Metabolism Research and Reviews, 2011. 27(8): p. 820-823 LA - en.

88. Foulis, A.K., M.A. Farquharson, and A. Meager, Immunoreactive alpha-interferon in insulin-secreting beta cells in type 1 diabetes mellitus. Lancet, 1987. 2(8573): p. 1423-1427 J2 - Lancet LA - eng.

89. Pak, C.Y., et al., Association of cytomegalovirus infection with autoimmune type 1 diabetes. Lancet, 1988. 2(8601): p. 1-4 J2 - Lancet LA - eng.

90. Kasuga, A., R. Harada, and T. Saruta, Insulin-dependent diabetes mellitus associated with parvovirus B19 infection. Annals of internal medicine DA 1996/10/15/, 1996. 125(8): p. 700-701 J2 - Ann. Intern. Med. LA - eng.

91. Craighead, J.E. and M.F. McLane, Diabetes mellitus: induction in mice by encephalomyocarditis virus. Science (New York, N.Y.), 1968. 162(3856): p. 913914 J2 - Science LA - eng.

92. Honeyman, M.C., et al., Association between rotavirus infection and pancreatic islet autoimmunity in children at risk of developing type 1 diabetes. Diabetes, 2000. 49(8): p. 1319-1324 J2 - Diabetes LA - eng.

93. Filippi, C. and M. von Herrath, How viral infections affect the autoimmune process leading to type 1 diabetes. Cellular immunology, 2005. 233(2): p. 125$132 \mathrm{~J} 2$ - Cell. Immunol.

94. Zaccone, P., et al., Parasitic worms and inflammatory diseases. Parasite immunology, 2006. 28(10): p. 515-523 J2 - Parasite Immunol.

95. Goffau, M.C.d., et al., Fecal Microbiota Composition Differs Between Children With beta-Cell Autoimmunity and Those Without. Diabetes, 2013. 62(4): p. 12381244 J2 - Diabetes LA - en.

96. Murri, M., et al., Gut microbiota in children with type 1 diabetes differs from that in healthy children: a case-control study. BMC Medicine, 2013. 11(1 LA - en).

97. Karjalainen, J., et al., A bovine albumin peptide as a possible trigger of insulindependent diabetes mellitus. The New England journal of medicine, 1992. 327(5): p. 302-307 J2 - N. Engl. J. Med. LA - eng.

98. Lempainen, J., et al., Interplay between PTPN22 C1858T polymorphism and cow's milk formula exposure in type 1 diabetes. Journal of autoimmunity, 2009. 33(2): p. 155-164 J2 - J. Autoimmun. LA - eng.

99. Catassi, C., et al., Antigliadin antibodies at onset of diabetes in children. Lancet DA - 1987/07/18/, 1987. 2(8551 J2 - Lancet LA - eng).

100. MacFarlane, A.J., et al., A type 1 diabetes-related protein from wheat (Triticum aestivum). cDNA clone of a wheat storage globulin, Glbl, linked to islet damage. 
The Journal of biological chemistry, 2003. 278(1): p. 54-63 J2 - J. Biol. Chem. LA - eng.

101. Oldstone, M.B., Prevention of type I diabetes in nonobese diabetic mice by virus infection. Science (New York, N.Y.), 1988. 239(4839): p. 500-502 J2 - Science.

102. Cooke, A., et al., Infection with Schistosoma mansoni prevents insulin dependent diabetes mellitus in non-obese diabetic mice. Parasite immunology, 1999. 21(4): p. 169-176 J2 - Parasite Immunol.

103. Saunders, K.A., et al., Inhibition of Autoimmune Type 1 Diabetes by Gastrointestinal Helminth Infection. Infection and Immunity, 2007. 75(1): p. $397-$ $407 \mathrm{~J} 2$ - Infect. Immun. LA - en.

104. Wen, L., et al., Innate immunity and intestinal microbiota in the development of Type 1 diabetes. Nature, 2008. 455(7216): p. 1109-1113 J2 - Nature LA - eng.

105. Jansen, A., M. van Hagen, and H.A. Drexhage, Defective maturation and function of antigen-presenting cells in type 1 diabetes. Lancet, 1995. 345(8948): p. 491492 J2 - Lancet.

106. Takahashi, K., M.C. Honeyman, and L.C. Harrison, Impaired Yield, Phenotype, and Function of Monocyte-Derived Dendritic Cells in Humans at Risk for InsulinDependent Diabetes. The Journal of Immunology, 1998. 161(5): p. 2629-2635 J2 - J Immunol LA - en.

107. Fujino, T., et al., Low-density lipoprotein receptor-related protein 5 (LRP5) is essential for normal cholesterol metabolism and glucose-induced insulin secretion. Proceedings of the National Academy of Sciences, 2003. 100(1): p. 229-234 J2 - PNAS LA - en.

108. Lee, M., A.Y. Kim, and Y. Kang, Defects in the differentiation and function of bone marrow-derived dendritic cells in non-obese diabetic mice. Journal of Korean medical science, 2000. 15(2): p. 217-223 J2 - J. Korean Med. Sci.

109. Piganelli, J.D., T. Martin, and K. Haskins, Splenic macrophages from the NOD mouse are defective in the ability to present antigen. Diabetes, 1998. 47(8): p. 1212-1218 J2 - Diabetes.

110. Serreze, D.V., H.R. Gaskins, and E.H. Leiter, Defects in the differentiation and function of antigen presenting cells in NOD/Lt mice. The Journal of Immunology DA - 1993/03/15/, 1993. 150(6): p. 2534-2543 J2 - J Immunol LA - en.

111. Trinchieri, G., Interleukin-12 and the regulation of innate resistance and adaptive immunity. Nature Reviews Immunology, 2003. 3(2): p. 133-146 J2 - Nat Rev Immunol LA - en.

112. Adorini, L., et al., The Role of IL-12 in the Pathogenesis of Thl Cell-Mediated Autoimmune Diseases. Annals of the New York Academy of Sciences DA 1996///, 1996. 795(1): p. 208-215 LA - en.

113. Bode, K.A., et al., Kinetic of RelA Activation Controls Magnitude of TLRMediated IL-12p40 Induction. The Journal of Immunology, 2009. 182(4): p. 2176-2184 J2 - J Immunol LA - en.

114. Koblansky, A.A., et al., Recognition of Profilin by Toll-like Receptor 12 Is Critical for Host Resistance to Toxoplasma gondii. Immunity, 2013. 38(1): p. 119-130 J2 - Immunity.

115. Krummen, M., et al., Release of IL-12 by dendritic cells activated by TLR ligation is dependent on MyD88 signaling, whereas TRIF signaling is indispensable for 
TLR synergy. Journal of Leukocyte Biology, 2010. 88(1): p. 189-199 J2 - J Leukoc Biol LA - en.

116. Morahan, G., et al., Association of IL12B promoter polymorphism with severity of atopic and non-atopic asthma in children. The Lancet, 2002. 360(9331): p. 455$459 \mathrm{~J} 2$ - The Lancet.

117. Morahan, G., et al., Linkage disequilibrium of a type 1 diabetes susceptibility locus with a regulatory IL12B allele. Nature genetics, 2001. 27(2): p. 218-221 J2 - Nat. Genet.

118. Trembleau, S., et al., Interleukin 12 administration induces Thelper type 1 cells and accelerates autoimmune diabetes in NOD mice. The Journal of Experimental Medicine DA - 1995/02/01/, 1995. 181(2): p. 817-821 J2 - J Exp Med LA - en.

119. Alleva, D.G., et al., Aberrant macrophage cytokine production is a conserved feature among autoimmune-prone mouse strains: elevated interleukin (IL)-12 and an imbalance in tumor necrosis factor-alpha and IL-10 define a unique cytokine profile in macrophages from young nonobese diabetic mice. Diabetes, 2000. 49(7): p. 1106-1115 J2 - Diabetes.

120. Liu, C., et al., Control of beta-catenin phosphorylation/degradation by a dualkinase mechanism. Cell, 2002. 108(6): p. 837-847 J2 - Cell.

121. Weaver, D.J., Jr, et al., Dendritic cells from nonobese diabetic mice exhibit a defect in NF-kappa B regulation due to a hyperactive I kappa B kinase. Journal of immunology (Baltimore, Md.: 1950), 2001. 167(3): p. 1461-1468 J2 - J. Immunol.

122. Macatonia, S.E., et al., Dendritic cells produce IL-12 and direct the development of Th1 cells from naive CD4+ T cells. Journal of immunology (Baltimore, Md.: 1950), 1995. 154(10): p. 5071-5079 J2 - J. Immunol.

123. O'hara, R.M., S.L. Henderson, and A. Nagelin, Prevention of a Thl Disease by a Thl, Cytokine: IL-12 and Diabetes in, NOD Mice. Annals of the New York Academy of Sciences DA - 1996///, 1996. 795(1): p. 241-249 LA - en.

124. Graba, Y., et al., Wnt/Wingless Signaling in Drosophila. 2000.

125. Gough, N.R., Focus issue: Wnt and beta-catenin signaling in development and disease. Science signaling, 2012. 5(206 J2 - Sci Signal).

126. Anastas, J.N. and R.T. Moon, WNT signalling pathways as therapeutic targets in cancer. Nature Reviews Cancer, 2013. 13(1): p. 11-26 J2 - Nat Rev Cancer LA en.

127. Howe, L.R. and A.M.C. Brown, Wnt signaling and breast cancer. Cancer biology \& therapy, 2004. 3(1): p. 36-41 J2 - Cancer Biol. Ther. LA - eng.

128. Huelsken, J. and J. Behrens, The Wnt signalling pathway. Journal of cell science DA - 2002/11/01/, 2002. 115(Pt 21): p. 3977-3978 J2 - J. Cell. Sci.

129. Amit, S., et al., Axin-mediated CKI phosphorylation of beta-catenin at Ser 45: a molecular switch for the Wnt pathway. Genes \& development, 2002. 16(9): p. 1066-1076 J2 - Genes Dev.

130. Hart, M., et al., The F-box protein beta-TrCP associates with phosphorylated beta-catenin and regulates its activity in the cell. Current biology: CB, 1999. 9(4): p. 207-210 J2 - Curr. Biol.

131. Thomas, G.M., et al., A GSK3-binding peptide from FRAT1 selectively inhibits the GSK3-catalysed phosphorylation of axin and beta-catenin. FEBS letters, 1999. 
458(2): p. 247-251 J2 - FEBS Lett. LA - eng.

132. Korinek, V., et al., Constitutive transcriptional activation by a beta-catenin-Tcf complex in APC-/- colon carcinoma. Science (New York, N.Y.), 1997. 275(5307): p. 1784-1787 J2 - Science LA - eng.

133. Jin, T., The WNT signalling pathway and diabetes mellitus. Diabetologia, 2008. 51(10): p. 1771-1780 J2 - Diabetologia LA - en.

134. Fagotto, F., et al., Binding to cadherins antagonizes the signaling activity of betacatenin during axis formation in Xenopus. The Journal of cell biology, 1996. 132(6): p. 1105-1114 J2 - J. Cell Biol.

135. Orsulic, S., et al., E-cadherin binding prevents beta-catenin nuclear localization and beta-catenin/LEF-1-mediated transactivation. Journal of cell science, 1999. 112 ( Pt 8): p. 1237-1245 J2 - J. Cell. Sci.

136. Dupre-Crochet, S., et al., Casein kinase 1 is a novel negative regulator of $E$ cadherin-based cell-cell contacts. Molecular and cellular biology, 2007. 27(10): p. 3804-3816 J2 - Mol. Cell. Biol.

137. Rao, T.P. and M. Kahl, An Updated Overview on Wnt Signaling Pathways A Prelude for More. Circulation Research, 2010. 106(12): p. 1798-1806 J2 Circulation Research LA - en.

138. Roura, S., et al., Regulation of E-cadherin/Catenin association by tyrosine phosphorylation. The Journal of biological chemistry, 1999. 274(51): p. 3673436740 J2 - J. Biol. Chem.

139. Piedra, J., et al., p120 Catenin-associated Fer and Fyn tyrosine kinases regulate beta-catenin Tyr-142 phosphorylation and beta-catenin-alpha-catenin Interaction. Molecular and cellular biology, 2003. 23(7): p. 2287-2297 J2 - Mol. Cell. Biol.

140. Brembeck, F.H., et al., Essential role of BCL9-2 in the switch between betacatenin's adhesive and transcriptional functions. Genes \& development, 2004. 18(18): p. 2225-2230 J2 - Genes Dev.

141. Rhee, J., et al., Cables links Robo-bound Abl kinase to N-cadherin-bound betacatenin to mediate Slit-induced modulation of adhesion and transcription. Nature Cell Biology, 2007. 9(8): p. 883-892 J2 - Nat Cell Biol LA - en.

142. Yost, C., et al., The axis-inducing activity, stability, and subcellular distribution of beta-catenin is regulated in Xenopus embryos by glycogen synthase kinase 3. Genes \& development, 1996. 10(12): p. 1443-1454 J2 - Genes Dev.

143. Aberle, H., et al., beta-catenin is a target for the ubiquitin-proteasome pathway. The EMBO journal, 1997. 16(13): p. 3797-3804 J2 - EMBO J.

144. Gwak, J., et al., Small molecule-based promotion of PKCalpha-mediated betacatenin degradation suppresses the proliferation of CRT-positive cancer cells. PloS one, 2012. 7(10 J2 - PLoS ONE).

145. Hajduch, E., G.J. Litherland, and H.S. Hundal, Protein kinase B (PKB/Akt)--a key regulator of glucose transport? FEBS letters, 2001. 492(3): p. 199-203 J2 FEBS Lett. LA - eng.

146. Jacinto, E., et al., SIN1/MIP1 maintains rictor-mTOR complex integrity and regulates Akt phosphorylation and substrate specificity. Cell, 2006. 127(1): p. 125-137 J2 - Cell LA - eng.

147. Alessi, D.R., et al., Mechanism of activation of protein kinase B by insulin and IGF-1. The EMBO journal, 1996. 15(23): p. 6541-6551 J2 - EMBO J. LA - eng. 
148. Sarbassov, D.D., et al., Phosphorylation and regulation of Akt/PKB by the rictormTOR complex. Science (New York, N.Y.), 2005. 307(5712): p. 1098-1101 J2 Science LA - eng.

149. Cross, D.A.E., et al., Inhibition of glycogen synthase kinase-3 by insulin mediated by protein kinase B. Nature DA - 1995/12/28/print, 1995. 378(6559): p. 785-789 J2 - Nature LA - en.

150. Fang, D., et al., Phosphorylation of beta-catenin by AKT promotes beta-catenin transcriptional activity. The Journal of biological chemistry, 2007. 282(15): p. 11221-11229 J2 - J. Biol. Chem.

151. Castellone, M.D., et al., Prostaglandin E2 Promotes Colon Cancer Cell Growth Through a Gs-Axin-beta-Catenin Signaling Axis. Science, 2005. 310(5753): p. 1504-1510 J2 - Science LA - en.

152. Monick, M.M., et al., Lipopolysaccharide activates Akt in human alveolar macrophages resulting in nuclear accumulation and transcriptional activity of beta-catenin. Journal of immunology (Baltimore, Md.: 1950), 2001. 166(7): p. 4713-4720 J2 - J. Immunol.

153. Cauthron, R.D., et al., Physiological phosphorylation of protein kinase A at Thr197 is by a protein kinase A kinase. Molecular and cellular biology, 1998. 18(3): p. 1416-1423 J2 - Mol. Cell. Biol. LA - eng.

154. Cheng, X., et al., Phosphorylation and activation of cAMP-dependent protein kinase by phosphoinositide-dependent protein kinase. Proceedings of the National Academy of Sciences of the United States of America, 1998. 95(17): p. 98499854 J2 - Proc. Natl. Acad. Sci. U.S.A.

155. Fang, X., et al., Phosphorylation and inactivation of glycogen synthase kinase 3 by protein kinase A. Proceedings of the National Academy of Sciences, 2000. 97(22): p. 11960-11965 J2 - PNAS LA - en.

156. Taurin, S., et al., Phosphorylation of beta-catenin by cyclic AMP-dependent protein kinase. The Journal of biological chemistry, 2006. 281(15): p. 9971-9976 J2 - J. Biol. Chem.

157. van Veelen, W., et al., beta-catenin tyrosine 654 phosphorylation increases Wnt signalling and intestinal tumorigenesis. Gut, 2011. 60(9): p. 1204-1212 J2 - Gut.

158. Hino, S.-i., et al., Phosphorylation of beta-catenin by cyclic AMP-dependent protein kinase stabilizes beta-catenin through inhibition of its ubiquitination. Molecular and cellular biology, 2005. 25(20): p. 9063-9072 J2 - Mol. Cell. Biol.

159. Brudvik, K.W., et al., Protein kinase A antagonist inhibits beta-catenin nuclear translocation, $c-M y c$ and $C O X-2$ expression and tumor promotion in ApcMin/+ mice. Molecular Cancer, 2011. 10(1 LA - en).

160. Wu, X., et al., Rac1 Activation Controls Nuclear Localization of beta-catenin during Canonical Wnt Signaling. Cell, 2008. 133(2): p. 340-353 J2 - Cell.

161. Krieghoff, E., J.r. Behrens, and B. Mayr, Nucleo-cytoplasmic distribution of betacatenin is regulated by retention. Journal of cell science, 2006. 119(Pt 7): p. 14531463 J2 - J. Cell. Sci.

162. Cong, F. and H. Varmus, Nuclear-cytoplasmic shuttling of Axin regulates subcellular localization of beta-catenin. Proceedings of the National Academy of Sciences of the United States of America, 2004. 101(9): p. 2882-2887 J2 - Proc. Natl. Acad. Sci. U.S.A. 
163. Hendriksen, J., et al., RanBP3 enhances nuclear export of active (beta)-catenin independently of CRM1. The Journal of cell biology, 2005. 171(5): p. 785-797 J2 - J. Cell Biol.

164. Takemaru, K.I. and R.T. Moon, The transcriptional coactivator CBP interacts with beta-catenin to activate gene expression. The Journal of cell biology, 2000. 149(2): p. 249-254 J2 - J. Cell Biol.

165. Hecht, A., et al., The p300/CBP acetyltransferases function as transcriptional coactivators of beta-catenin in vertebrates. The EMBO journal, 2000. 19(8): p. 1839-1850 J2 - EMBO J.

166. ten Berge, D., et al., Wnt Signaling Mediates Self-Organization and Axis Formation in Embryoid Bodies. Cell Stem Cell, 2008. 3(5): p. 508-518 J2 - Cell Stem Cell.

167. Jamora, C., et al., Links between signal transduction, transcription and adhesion in epithelial bud development. Nature, 2003. 422(6929): p. 317-322 J2 - Nature.

168. Shah, K.V., et al., CTLA-4 is a direct target of Wnt/beta-catenin signaling and is expressed in human melanoma tumors. The Journal of investigative dermatology, 2008. 128(12): p. 2870-2879 J2 - J. Invest. Dermatol.

169. Tetsu, O. and F. McCormick, Beta-catenin regulates expression of cyclin D1 in colon carcinoma cells. Nature, 1999. 398(6726): p. 422-426 J2 - Nature.

170. Shtutman, M., et al., The cyclin D1 gene is a target of the beta-catenin/LEF-1 pathway. Proceedings of the National Academy of Sciences of the United States of America, 1999. 96(10): p. 5522-5527 J2 - Proc. Natl. Acad. Sci. U.S.A.

171. Roose, J., et al., Synergy between tumor suppressor APC and the beta-cateninTcf4 target Tcfl. Science (New York, N.Y.), 1999. 285(5435): p. 1923-1926 J2 Science.

172. Hovanes, K., et al., Beta-catenin-sensitive isoforms of lymphoid enhancer factor-1 are selectively expressed in colon cancer. Nature genetics, 2001. 28(1): p. 53-57 J2 - Nat. Genet.

173. Filali, M., et al., Wnt-3A/beta-catenin signaling induces transcription from the LEF-1 promoter. The Journal of biological chemistry, 2002. 277(36): p. 3339833410 J2 - J. Biol. Chem.

174. Yan, D., et al., Elevated expression of axin 2 and hnkd $m R N A$ provides evidence that Wnt/beta -catenin signaling is activated in human colon tumors. Proceedings of the National Academy of Sciences of the United States of America, 2001. 98(26): p. 14973-14978 J2 - Proc. Natl. Acad. Sci. U.S.A.

175. Lustig, B., et al., Negative feedback loop of Wnt signaling through upregulation of conductin/axin2 in colorectal and liver tumors. Molecular and cellular biology, 2002. 22(4): p. 1184-1193 J2 - Mol. Cell. Biol.

176. Jho, E.-h., et al., Wnt/beta-catenin/Tcf signaling induces the transcription of Axin2, a negative regulator of the signaling pathway. Molecular and cellular biology, 2002. 22(4): p. 1172-1183 J2 - Mol. Cell. Biol.

177. Emami, K.H., et al., A small molecule inhibitor of beta-catenin/cyclic AMP response element-binding protein transcription. Proceedings of the National Academy of Sciences of the United States of America DA - 2004/08/24/, 2004. 101(34): p. 12682-12687 J2 - PNAS LA - en.

178. Eguchi, M., et al., ICG-001, a novel small molecule regulator of TCF/beta- 
catenin transcription. Medicinal chemistry (Shariqah (United Arab Emirates)), 2005. 1(5): p. 467-472 J2 - Med Chem.

179. Park, C.H., et al., Quercetin, a potent inhibitor against beta-catenin/Tcf signaling in SW480 colon cancer cells. Biochemical and biophysical research communications, 2005. 328(1): p. 227-234 J2 - Biochem. Biophys. Res. Commun.

180. Shan, B.-E., M.-X. Wang, and R.-q. Li, Quercetin inhibit human SW480 colon cancer growth in association with inhibition of cyclin D1 and survivin expression through Wnt/beta-catenin signaling pathway. Cancer investigation, 2009. 27(6): p. 604-612 J2 - Cancer Invest. LA - eng.

181. Manicassamy, S., et al., Activation of beta-catenin in dendritic cells regulates immunity versus tolerance in the intestine. Science (New York, N.Y.), 2010. 329(5993): p. 849-853 J2 - Science.

182. Duan, Y., et al., beta-Catenin activity negatively regulates bacteria-induced inflammation. Laboratory Investigation, 2007. 87(6): p. 613-624 J2 - Lab Invest LA - en.

183. Blumenthal, A., et al., The Wingless homolog WNT5A and its receptor Frizzled-5 regulate inflammatory responses of human mononuclear cells induced by microbial stimulation. Blood, 2006. 108(3): p. 965-973 J2 - Blood.

184. Yang, P., et al., The cytosolic nucleic acid sensor LRRFIP1 mediates the production of type I interferon via a beta-catenin-dependent pathway. Nature immunology, 2010. 11(6): p. 487-494 J2 - Nat. Immunol.

185. Halleskog, C., et al., WNT signaling in activated microglia is proinflammatory. Glia, 2011. 59(1): p. 119-131 J2 - Glia.

186. Halleskog, C. and G. Schulte, WNT-3A and WNT-5A counteract lipopolysaccharide-induced pro-inflammatory changes in mouse primary microglia. Journal of neurochemistry, 2013. 125(6): p. 803-808 J2 - J. Neurochem. LA - eng.

187. Anson, M., et al., Oncogenic beta-catenin triggers an inflammatory response that determines the aggressiveness of hepatocellular carcinoma in mice. The Journal of clinical investigation, 2012. 122(2): p. 586-599 J2 - J. Clin. Invest.

188. Grattan, M., et al., Congenic mapping of the diabetogenic locus Idd4 to a 5.2-cM region of chromosome 11 in NOD mice: identification of two potential candidate subloci. Diabetes, 2002. 51(1): p. 215-223 J2 - Diabetes LA - eng.

189. Greve, B., et al., The diabetes susceptibility locus Idd5.1 on mouse chromosome 1 regulates ICOS expression and modulates murine experimental autoimmune encephalomyelitis. Journal of immunology (Baltimore, Md.: 1950), 2004. 173(1): p. 157-163 J2 - J. Immunol. LA - eng.

190. Katz, J.D., et al., Following a diabetogenic T cell from genesis through pathogenesis. Cell, 1993. 74(6): p. 1089-1100 J2 - Cell LA - eng.

191. Schlachterman, A., et al., Combined resveratrol, quercetin, and catechin treatment reduces breast tumor growth in a nude mouse model. Translational oncology, 2008. 1(1): p. 19-27 J2 - Transl Oncol LA - eng.

192. Kitagawa, M., et al., An F-box protein, FWD1, mediates ubiquitin-dependent proteolysis of $\hat{I}^{2}$-catenin. The EMBO Journal, 1999. 18(9): p. 2401-2410 J2 EMBO J LA - en. 
193. Yang, W.-L., et al., Regulation of Akt signaling activation by ubiquitination. Cell cycle (Georgetown, Tex.), 2010. 9(3): p. 487-497 J2 - Cell Cycle LA - eng.

194. Johnson, E.S., Protein Modification by Sumo. Annual Review of Biochemistry, 2004. 73(1): p. 355-382.

195. Otero, K., et al., Macrophage colony-stimulating factor induces the proliferation and survival of macrophages via a pathway involving DAP12 and beta-catenin. Nature immunology, 2009. 10(7): p. 734-743 J2 - Nat. Immunol.

196. Buul, J.D.v., et al., Proline-rich Tyrosine Kinase 2 (Pyk2) Mediates Vascular Endothelial-Cadherin-based Cell-Cell Adhesion by Regulating beta-Catenin Tyrosine Phosphorylation. Journal of Biological Chemistry DA - 2005/06/03/, 2005. 280(22): p. 21129-21136 J2 - J. Biol. Chem. LA - en.

197. Lilien, J. and J. Balsamo, The regulation of cadherin-mediated adhesion by tyrosine phosphorylation/dephosphorylation of beta-catenin. Current Opinion in Cell Biology, 2005. 17(5): p. 459-465 J2 - Current Opinion in Cell Biology.

198. Liu, J. and D. Beller, Aberrant production of IL-12 by macrophages from several autoimmune-prone mouse strains is characterized by intrinsic and unique patterns of NF-kappa B expression and binding to the IL-12 p40 promoter. Journal of immunology (Baltimore, Md.: 1950), 2002. 169(1): p. 581-586 J2 - J. Immunol.

199. Feng, G.-J., et al., Extracellular Signal-Related Kinase (ERK) and p38 MitogenActivated Protein (MAP) Kinases Differentially Regulate the LipopolysaccharideMediated Induction of Inducible Nitric Oxide Synthase and IL-12 in Macrophages: Leishmania Phosphoglycans Subvert Macrophage IL-12 Production by Targeting ERK MAP Kinase. The Journal of Immunology, 1999. 163(12): p. 6403-6412 J2 - J Immunol LA - en.

200. McCubrey, J.A., et al., Roles of the Raf/MEK/ERK pathway in cell growth, malignant transformation and drug resistance. Biochimica et Biophysica Acta (BBA) - Molecular Cell Research, 2007. 1773(8): p. 1263-1284 J2 - Biochimica et Biophysica Acta (BBA) - Molecular Cell Research.

201. Ding, Q., et al., Erk associates with and primes GSK-3beta for its inactivation resulting in upregulation of beta-catenin. Molecular cell, 2005. 19(2): p. 159-170 J2 - Mol. Cell.

202. Dong, B., et al., TLR4 regulates cardiac lipid accumulation and diabetic heart disease in the Non Obese Diabetic mouse model of type 1 diabetes. American journal of physiology. Heart and circulatory physiology, 2012.

203. Jeong, Y.-J., et al., Vitamin C-treated murine bone marrow-derived dendritic cells preferentially drive naive T cells into Th1 cells by increased IL-12 secretions. Cellular immunology, 2011. 266(2): p. 192-199 J2 - Cell. Immunol.

204. Lu, H.T., et al., Defective IL-12 production in mitogen-activated protein (MAP) kinase kinase 3 (Mkk3)-deficient mice. The EMBO journal, 1999. 18(7): p. 1845$1857 \mathrm{~J} 2$ - EMBO J.

205. Kroening, P.R., et al., Cigarette smoke-induced oxidative stress suppresses generation of dendritic cell IL-12 and IL-23 through ERK-dependent pathways. Journal of immunology (Baltimore, Md.: 1950), 2008. 181(2): p. 1536-1547 J2 J. Immunol.

206. Agrawal, A., et al., ERK1-/- mice exhibit Th1 cell polarization and increased 
susceptibility to experimental autoimmune encephalomyelitis. Journal of immunology (Baltimore, Md.: 1950), 2006. 176(10): p. 5788-5796 J2 - J. Immunol.

207. Yang, Z., et al., The regulation of Th1 responses by the p38 MAPK. Journal of immunology (Baltimore, Md.: 1950), 2010. 185(10): p. 6205-6213 J2 - J. Immunol.

208. Mathur, R.K., et al., Reciprocal CD40 signals through p38MAPK and ERK-1/2 induce counteracting immune responses. Nature medicine, 2004. 10(5): p. 540$544 \mathrm{~J} 2$ - Nat. Med.

209. Plevy, S.E., et al., Multiple control elements mediate activation of the murine and human interleukin 12 p 40 promoters: evidence of functional synergy between $C / E B P$ and Rel proteins. Molecular and cellular biology, 1997. 17(8): p. 45724588 J2 - Mol. Cell. Biol.

210. Murphy, T.L., et al., Regulation of interleukin 12 p40 expression through an NFkappa B half-site. Molecular and cellular biology, 1995. 15(10): p. 5258-5267 J2 - Mol. Cell. Biol.

211. Dolcet, X., et al., NF-kB in development and progression of human cancer. Virchows Archiv: an international journal of pathology, 2005. 446(5): p. 475-482 J2 - Virchows Arch.

212. Deng, J., et al., beta-catenin interacts with and inhibits NF-kappa B in human colon and breast cancer. Cancer cell, 2002. 2(4): p. 323-334 J2 - Cancer Cell.

213. Lee, W.-J., Bacterial-modulated signaling pathways in gut homeostasis. Science signaling, 2008. 1(21 J2 - Sci Signal LA - eng).

214. Halleskog, C. and G. Schulte, Pertussis toxin-sensitive heterotrimeric G(alphai/o) proteins mediate WNT/beta-catenin and WNT/ERK1/2 signaling in mouse primary microglia stimulated with purified WNT-3A. Cellular signalling, 2013. 25(4): p. 822-828 J2 - Cell. Signal. LA - eng.

215. Halleskog, C., et al., Heterotrimeric G protein-dependent WNT-5A signaling to ERK1/2 mediates distinct aspects of microglia proinflammatory transformation. Journal of neuroinflammation, 2012.9 J2 - J Neuroinflammation LA - eng.

216. Ando, H., S. Kurita, and T. Takamura, The specific p38 mitogen-activated protein kinase pathway inhibitor FR167653 keeps insulitis benign in nonobese diabetic mice. Life sciences, 2004. 74(14): p. 1817-1827 J2 - Life Sci. LA - eng.

217. Wheat, W., et al., Increased NF-kappa B activity in B cells and bone marrowderived dendritic cells from NOD mice. European journal of immunology, 2004. 34(5): p. 1395-1404 J2 - Eur. J. Immunol.

218. Esch, T.R., et al., Leukocytes infiltrating the submandibular glands of NOD mice express E-cadherin. Journal of autoimmunity, 2000. 15(4): p. 387-393 J2 - J. Autoimmun. LA - eng.

219. Azzi, J., et al., The novel therapeutic effect of phosphoinositide 3-kinase- $\hat{I}^{3}$ inhibitor AS605240 in autoimmune diabetes. Diabetes, 2012. 61(6): p. 1509-1518 J2 - Diabetes LA - eng.

220. Hart, J.R. and P.K. Vogt, Phosphorylation of AKT: a mutational analysis. Oncotarget, 2011. 2(6): p. 467-476 J2 - Oncotarget LA - eng.

221. Scheid, M.P., P.A. Marignani, and J.R. Woodgett, Multiple phosphoinositide 3kinase-dependent steps in activation of protein kinase B. Molecular and cellular 
biology, 2002. 22(17): p. 6247-6260 J2 - Mol. Cell. Biol. LA - eng.

222. Gu, Y., et al., Rictor/mTORC2 is essential for maintaining a balance between beta-cell proliferation and cell size. Diabetes, 2011. 60(3): p. 827-837 J2 Diabetes LA - eng.

223. Ng, S.S., et al., Phosphatidylinositol 3-Kinase Signaling Does Not Activate the Wnt Cascade. Journal of Biological Chemistry, 2009. 284(51): p. 35308-35313 J2 - J. Biol. Chem. LA - en.

224. Wolf, D., et al., Acetylation of beta-Catenin by CREB-binding Protein (CBP). Journal of Biological Chemistry, 2002. 277(28): p. 25562-25567 J2 - J. Biol. Chem. LA - en.

225. LÃ@vy, L., et al., Acetylation of beta-Catenin by p300 Regulates betaa-CateninTcf4 Interaction. Molecular and Cellular Biology, 2004. 24(8): p. 3404-3414 J2 Mol Cell Biol.

226. Chocarro-Calvo, A., et al., Glucose-Induced beta-Catenin Acetylation Enhances Wnt Signaling in Cancer. Molecular Cell, 2013. 49(3): p. 474-486.

227. Dashwood, W.-M., et al., Lysosomal trafficking of beta-catenin induced by the tea polyphenol epigallocatechin-3-gallate. Mutation research, 2005. 591(1-2): p. 161172 J2 - Mutat. Res. LA - eng.

228. Kwon, C., et al., Notch Post-Translationally Regulates beta-Catenin Protein in Stem and Progenitor Cells. Nature Cell Biology, 2011. 13(10): p. 1244-1251 J2 Nat Cell Biol.

229. Chairoungdua, A., et al., Exosome release of beta-catenin: a novel mechanism that antagonizes Wnt signaling. The Journal of Cell Biology, 2010. 190(6): p. 1079-1091 J2 - J Cell Biol LA - en.

230. Manirarora, J.N., et al., NOD Dendritic Cells Stimulated with Lactobacilli Preferentially Produce IL-10 versus IL-12 and Decrease Diabetes Incidence. Clinical and Developmental Immunology, 2011. 2011 LA - en.

231. Battaglia, M., et al., Induction of tolerance in type 1 diabetes via both CD4+CD25+ T regulatory cells and T regulatory type 1 cells. Diabetes, 2006. 55(6): p. 1571-1580 J2 - Diabetes LA - eng. 


\section{CURRICULUM VITAE}

Arin Zirnheld, MAT, M.S.

Graduate Student, Department of Microbiology and Immunology

University of Louisville School of Medicine

502-852-5349

alzirn02@louisville.edu

Education/Training

\begin{tabular}{|l|l|l|l|l|}
\hline \multicolumn{1}{|c|}{$\begin{array}{c}\text { Institution \& } \\
\text { Location }\end{array}$} & \multicolumn{1}{|c|}{ Dates Attended } & \multicolumn{1}{|c|}{ Degree } & \multicolumn{1}{c|}{$\begin{array}{c}\text { Conferred } \\
(\mathrm{mm} / \mathrm{yy})\end{array}$} & \multicolumn{1}{|c|}{ Field of Study } \\
\hline $\begin{array}{l}\text { University of } \\
\text { Louisville, } \\
\text { Louisville KY }\end{array}$ & $\begin{array}{l}08 / 2002- \\
12 / 2006\end{array}$ & $\begin{array}{l}\text { B.S., Magna Cum } \\
\text { Laude }\end{array}$ & $12 / 12$ & Biology \\
\hline $\begin{array}{l}\text { University of } \\
\text { Louisville, } \\
\text { Louisville KY }\end{array}$ & $01 / 2007-05 / 2008$ & MAT & $05 / 12$ & $\begin{array}{l}\text { Secondary } \\
\text { Education - } \\
\text { Biology }\end{array}$ \\
\hline $\begin{array}{l}\text { University of } \\
\text { Louisville, } \\
\text { Louisville KY }\end{array}$ & $08 / 2009-07 / 2011$ & M.S. & $08 / 12$ & $\begin{array}{l}\text { Microbiology and } \\
\text { Immunology }\end{array}$ \\
\hline $\begin{array}{l}\text { University of } \\
\text { Louisville, } \\
\text { Louisville KY }\end{array}$ & $8 / 2012-$ current & PhD & Expected 7/13 & $\begin{array}{l}\text { Microbiology and } \\
\text { Immunology }\end{array}$ \\
\hline
\end{tabular}

\section{Positions:}

Middle School Science Teacher, St. Michael Life-long Learning Center, 08/2008 05/2009

Courses Taught: $8^{\text {th }}$ Grade Physical Science, $7^{\text {th }}$ Grade Life Science

Science Teacher, Our Lady of Providence Jr.-Sr. High School, 08/2011-05/2012

Courses Taught: $8^{\text {th }}$ Grade General Science, $9^{\text {th }}$ Grade Honors Biology, AP Biology 
Graduate Research Assistant, University of Louisville, Department of Microbiology and Immunology, 08/2009 - 07/2011 and current

Research project: The Involvement of $\beta$-catenin in the Inflammatory Response Leading to Autoimmune Diabetes Development

Techniques: primary cell culture, Western blot, flow cytometry and FACS analysis, ELISA, coimmunoprecipitation, confocal microscopy, mouse techniques, RT-PCR

Mentor: Dr. Pascale Alard

\section{Peer Reviewed Publications:}

Kosiewicz, MM, Zirnheld, AL, Alard, P (2011). Gut microbiota, immunity, and disease: a complex relationship. Frontiers in Microbiology, 2: 1-11.

Kosiewicz, MM, Chhabra, AY, Zirnheld, AL, Alard, P (2011). CD8+ suppressor cells resurrected and vindicated. Immunotherapy, 3: 316-317.

Kosiewicz, MM, Chhabra, AY, Zirnheld, AL, Alard, P (2011). $\square$-catenin: does it have a role in tolerance? Immunotherapy, 3: 314-316.

Kosiewicz, MM, Chhabra, AY, Zirnheld, AL, Alard, P (2011). Commensal flora: Friends or foes? Immunotherapy, 3: 313-314.

Kosiewicz, MM, Zirnheld, AL, Alard, P (2013). Tuning of skin immunity by skin commensal bacteria. Immunotherapy, 5: 23-5.

Zirnheld, AL, Fan, C, Holmberg, A, Kahn, M, Kosiewicz, MM, Alard, P (2013). $\beta$ catenin regulates IL-12 production by DC and subsequent induction of IFN $\gamma$-producing $\mathrm{T}$ cells in T1D (submitted to Journal of Immunology).

\section{Posters:}

Arin Zirnheld, Michele Kosiewicz, Sarah Parnell, and Pascale Alard. (2010). $\beta$-catenin as a diagnostic marker and therapeutic target for the treatment of Type I diabetes.

Research!Louisville 2010.

Arin Zirnheld, Michele Kosiewicz, Sarah Parnell, and Pascale Alard. (2011). $\beta$-catenin as a diagnostic marker and therapeutic target for the treatment of Type I diabetes. AAI Annual Conference, San Francisco 2011.

Pascale Alard, Arin Zirnheld, Sarah Parnell, and Michele Kosiewicz (2012).

Overexpression of $\beta$-catenin in dendritic cells from type 1 diabetes patients and NOD mice may drive induction of $\mathrm{T}$ cells involved in $\beta$-cell destruction.

AAI Annual Conference, Boston 2012. 
Arin Zirnheld, Michele Kosiewicz, and Pascale Alard. (2012). $\beta$-catenin as a prognostic marker and therapeutic target for the treatment of Type I diabetes. Research!Louisville 2012.

Arin Zirnheld, Michele Kosiewicz, and Pascale Alard (2013). $\beta$-catenin Modulates Inflammatory Cytokine Production and Disease development in NOD mice. AAI Annual Conference, Honolulu 2013.

\author{
Awards: \\ IPIBS Fellowship, Fall 2009- Spring 2011 \\ Sponsored Research Tuition Award, Fall 2012 - Spring 2013 \\ Research!Louisville Poster Presentation 2012, ${ }^{\text {rd }}$ place in the Basic Science Graduate \\ Student - Doctoral division
}

2013 AAI Trainee Poster Award for AAI 2013 Conference

\title{
Professional Memberships:
}

American Association of Immunologists 